Christel NeusüB, Bernhard Blanke, Elmar Altvater

KAPITALISTISCHER WELTMARKT UND WELTWAHRUNGSKRISE

\title{
Einientug
}

Die Bankrotterklärung des Dollar durch die Aufhebung der Eintauschbarkeit des Dollar in Gold am 15. August 1971 - was ja dem offiziellen Eingeständnis der Zahiungsuniähigkeit der USA gegenüber allen Gläubigern gleichkommt - hat das seit dem zweiten Weltkrieg mehr schlecht als recht, aber immerhin funktionierende Weltwährungssystem ins Chaos gestürzt. In den Wochen nach dieser Entscheidung jagt eine Konferenz die andere, um das für die kapitalistische Weltwirtschaft Schlimmste abzuwenden. Aber dennoch zeigt sich allenthalben, daß die Konkurrenz auf dem Weltmarkt schärfer wird - so scharf, daß die Nationalstaaten in der Wahrnehmung der nationalen Kapitalinteressen anfangen, die Gesamtinteressen an einem funktionsfähigen Weltmarkt hintanzustellen: Japan versucht alle günstigen Faktoren seiner jahrelangen Exportoffensive zu erhalten; die USA schneiden den US-Marki tür ausländische Konkurrenten durch die Einfuhrbesteuerung rigoros ab und die EWG-Staaten halten sich zur Vermeidung eines Handelskriegs noch zurück. Wie lange noch?

Waren von den Währungskrisen der vergangenen Jahre so vergleichsweise urwichtige Wärungen wie das englische Pfund, der französische Franc, die doutsche Mark hnd dis Jewells attachierten kleineren Währungen wie Gulden, Krone, Schilng, Schweizer Franken usw. betroffen, und hatien da her die Krisen jeweis nur vorubergehenden und lokalen Charakter, so hat sich seit derm August 1971 die Bituation grundlegend gewandelt. Mis dem Dollar ist namlich nich irgendane Warhrung aines Nationalstagtes in den Krisenstrudel geraten, sondern das Waltgeld in Paplergeldiorm. das als WenmaB, zirkulationsmitte' und Geikkoplal auf dem kapitalistischen Well mark stugierte.

Dar Dollar ist sozusagen dar Drah und Angeipunkt des gesamten Weitwährungssysteme: Der Dollar wird von allen Zentrabanken der kapitalistischen Länder als Wahrungsreserve gehalten, mit der intemationale Trans aktionen durchgefüht werden (Reservewährung); die Wechsekurse der don inemationalen Währungstonds (WF) angeschiossenen länder sind am Dollar fixiert - jodentals solange sig die Wehrung nicht "fhaten" lieben - whe 
erst über den Dollar an die entsprechende Goldmenge (Leitwährung); die Zentralbanken der wichtigsten kapitalistischen industrieländer sind aufgrund des europäischen Währungsabkommens (EWA) verpflichtet, Interventionen an den Devisenmärkten durch Ankäufe und Verkäufe ausschließlich von USDollars zu unterstützen ') (Interventionswährung). Der US-Dollar ragt aiso gegenüber allen anderen Währungen wegen seiner besonderen Funktionen im Weitwährungssystem hervor. Er ist zugleich Reservewährung, Leitwährung, Interventionswährung und damit das Treibrad des ganzen komplizierten künstlichen Währungsmechanismus. Funktioniert das Treibrad nicht mehr, dann kann der Mechanismus nicht laufen, und versuchen die einzelnen kleineren Währungen den Antrieb zu ersetzen, dann kann nur die gänzliche Zerstörung des Systems die Folge sein.

Dies ist die oberflächlich konstatierte Situation, wie sie auch in der bürgerlichen Presse festgestellt werden mußte - allerdings zugleich mit der Hoffnung verknüpft, daß man nun endlich zu einer "rationalen" Lösung der Schwierigkeiten der letzten Jahre, wie sie im Dollarkrach lediglich kulminierten, gelangen werde; so etwa nach dem Motto: die Krise macht vernünftig, genau wie Prügel ein Kind zur Einsicht brigen sollen. Aber das eine stimmt genauso wenig wie das andere, und um die Konsequenzen der Währungskrise abschätzen zu können, wird es notwendig sein, ihre Ursachen zu anaIysieren. Diese können sicherlich nicht im Währungssystem selbst gefunden werden, sondern müssen in den dem Währungssystem zugrundeliegenden Weltmarktprozessen gesucht werden. Denn das Weltwährungssystem stellt sich vor allem als Zirkulationsmechanismus dar, weshalb die Frage lauten muß: Was wird auf dem Weltmarkt zirkuliert? Aber auch mit dieser Frage sind wir noch nicht am Kern der Sache. Denn die Zirkulation ist kein Selbstzweck, sondern sie findet statt, um Waren auszutauschen und vor allem, Kapital aus der Geldform in die Warenform, aus der Warenform in die Form des produktiven Kapitals und daraus wieder in die Warenform und erneut in die Geldform zu verwandeln. Dies ist wichtig insofern, als nun deutlich wird, daß die Zirkulation nur vonstatten gehen kann, wenn die Zirkulierenden, die Geld- und Warenbesitzer, die aber allesamt Kapitalisten sind, die jeweiligen Zirkulationsakte reibungslos vollziehen. Ein reibungsloser Vollzug der Zirkulationsakte findet aber nur unter der Bedingung statt, daß die Kapitalisten in der Lage sind, bei ihren Handelsgeschäften einen Profit zu realisieren.

Diese Überlegung führt zu der Konsequenz, daß Währungskrisen gar nicht unabhängig von den Zirkulationsprozessen des Kapitals und seinem Produktionsprozeß untersucht werden können. In vermittelter, also nicht unmittelbar bedingter Weise, sind sie Ausdruck von Zirkulationsstörungen, die selbst wiederum auf Probleme im Produktions- als VerwertungsprozeB von Kapital zurückführbar sind. Oberflächlicher Ausdruck dieses Zusammenhangs ist die Tatsache, daß die Dollarkrise in dem gegenwärtigen Ausmaß akut wurde, als die US-Wirtschaft in die Krise geriet- Wir gehen nicht davon aus, daß beide Krisen unabhängig voneinander sind und wir suchen nach einer

1) Vgl. Helmut Lipfert, Internationaler Devisen- und Geldhandel, Frankfurt 1967, S. 167. 
Erklärung, deren Grundstrukturen wir in diesem Aufsatz, der notgedrungen unter Zeitdruck geschrieben wurde, vorlegen, nicht zuletzt, um die Diskussion zu diesem Problem anzuregen.

In unseren Darlegungen gehen wir also erstens davon aus, daß Währungskrisen nur oberflächlicher Ausdruck von in den Produktions- und Wertverhältnissen angeległen Prozessen ungleichmäßiger Entwicklung auf dem Weltmarkt sind, daß sich in ihnen also nicht nur Währungsprobleme, sondern für den Weltkapitalismus strukturelle Probleme spiegeln. Zweitens gehen wir davon aus, daß keine Krise ewig dauert und daß die derzeitige Währungskrise sicherlich nicht der Anfang vom Ende des Imperialismus ist. Man kann die Krise und also auch die Währungskrise nur in ihrer doppelten Funktion richtig begreifen, die Widersprüche der kapitalistischen Produktonsweise auf die Spitze zu treiben und damit auch die gegeneinander verselbständigten Momente der kapitalistischen Widersprüche wieder zusammenzuführen, um eine neue Phase kapitalistischer Akkumulation zu ermöglichen. Die Krise ist daher immer auch "Reinigungs- und Stabilisierungskrise", wie die bürgerliche OKkonomie diese Funktion vom Standpunkt des Kapitalismus aus benennit.

Ist die Währungskrise, die sich nun schon seit Jahren hinschleppt und im August dieses Jahres ihren bisherigen Höhepunkt erreicht hat, selbst nur Ausdruck der Widersprüche der Kapitalproduktion und -zirkulation auf dem Weltmarkt, so können auch diese Widersprüche nur über Krisen der Kapitalproduktion auf Weltmarktebene eine zeitweilige Lösung finden. Da die bürgerliche Klasse und mit ihr ihre politischen Organisationen, die nationalen Regierungen im Schein der Zirkulation des Kapitals und ihrer Formen, dem Geld, verhaftet sind, so werden sie solange den Versuch machen, Linderungsmaßnahmen technischer Art auf der Ebene der Weltgeldzirkulation, also auf der Ebene der Währungssysteme zu finden und zu konstruieren, wie die Widersprüche in der Produktion den Konkurrenzkampf der Kapitale noch nicht auf die Spitze getrieben haben. Mit der Verschärfung der Krise müssen auch die Versuche der Kapitalistenklasse, als vereinte Klasse auf Weltmarktebene zu handeln, scheitern. Vereinigen kann sie sich dann nicht mehr zum Zwecke des gemeinsamen Geschäfts, sondern nur noch zur Niederhaltung der Arbeiterklasse.

Selbstverständlich sind wir nicht in der Lage, das Eintreffen der Weltmarktkrise genau zu prognostizieren. Was wir können, ist lediglich, die Bedingungen aufzuzeigen, unter denen die Krise auftreten muß. Die Gliederung des Aufsatzes ergab sich somit aus der Uberlegung, daß die Währungskrise zurückgeführt werden muß auf die Widersprüche der Kapitalentwicklung auf Weltmarktebene.

Die Entwicklung des Kapitals auf dem Weltmarkt vollzieht sich in den gleichen Formen, wie die Entwicklung des Kapitals im national-staatich umgrenzten Raum. Auf dem Weltmarkt sind die einzelnen Formen des Kapitals - angefangen mit den einfachen Formen der Ware und des Geldes sowie der einfachen Zirkulation - noch einmal in ihrem Entstehungsproze $B$ 
nachzuvollziehen. Die genetische Darstellung der Entwicklung des Kapitals und seiner Formen, wie sie in der Darstellung des allgemeinen Kapitalbegriffs von Marx im "Kapital" logisch nachvollzogen wurde, ist einer Analyse der Entwicklung des Weltmarkts in den letzten Jahrzehnten zugrundezulegen und historisch nachyollziehbar.

Denn erst als Weltkapital entspricht das Kapital voll seinem Begriff, welcher ais historische Tencienz des Kapitals zu begreifen ist. Unser Versuch einer Analyse der Weitmarktentwicklung weicht insofern stark von den meisten bisherigen Versuchen, das Phänomen des "Imperialismus" zu begreifen, ab. Der Imperialismus wurde weitgehend nur als Konkurrenz der nationalstaatlich begrenzten Kapitale analysiert, der Zusammenhang der Kapitalentwicklung, wie er sich auf dem Weltmarkt herstellt, wurde indessen nur als äußerlicher dargestell ${ }^{2}$ ). Wenn die Konkurrenz im allgemeinen aber nichis anderes ist als die innere Natur des Kapitals, äußerlich erscheinend als Zwangsgesetz, und sich gerade vermittels der Konkurrenz der Zusammenhang der vereinzelten "Privatproduzenten“ (der einzelnen, in besonderen Produktionszweigen angelegten Kapitale) herstellt, dann muß dies auch auf dem Weltmarkt gelten. Der Weltmarkt ist demnach unter den gleichen Aspekten zu untersuchen, wie die nationale Akkumulation des Kapitals. Die Modifikationen der Durchsetzung der Gesetze der kapitalistischen Entwicklung auf dem Weltmarkt stellen eben nur vorübergehende Erscheinungen dar, welche gerade der noch nicht voll hergestellten Weltmarktexistenz des Kapitals geschuldet sind.

Es war bei der Analyse des kapitalistischen Weltmarktes und der Währungskrise also beim Wert der Waren auf dem Weltmarkt anzufangen und von da aus zu den Formen der Preise, des Geldes als Weltgeld, der internationalen Zirkulation und den Möglichkeiten der Krise fortzuschreiten. Daß wir in diesem Aufsatz weitgehend bei der Analyse der Formen der internationalen Zirkulation verblieben, ist dem Rohzustand unserer Forschung geschuldet. Eine ganze Reihe von wesentlichen Fragen, die sich gerade auf die Herstellung der Weltmarktexistenz des Kapitals beziehen, konnten noch nicht beantwortet werden. Wir meinen dennoch, daß unser Ansatz der einzig mögliche ist, will man die Darstellung des allgemeinen Begriffs des Kapital von Marx ernst nehmen. Die bislang vorliegenden Analysen des Weltmarktes verfallen unseres Erachtens gerade deswegen in unhaltbare Konstruktionen, weil sie nicht menr versuchen, auf der Ebene der Werttheorie die Probleme des Weitmarktes zu entwickeln.

Aus diesen Uberlegungen leitet sich folgende Disposition des Aufsatzes ab: 1. Das Werigeselz aut don Welmarkt

1.1. Funktion und Omronselzung des Werigesetzes

\footnotetext{
"Benin stell iri seine Auseinandersezung um cie Entwicklung des Kapitalismus in RuBland die ruhmiche Ausreme von dieser Behauptung dar: ${ }_{n}$ Die Frage der Realisation ist eine abstrake Frage, die zur Theorie des Kapitalismus überhaupt gehört. Ob wir ein Land oder die ganze Welt nehmen, die von Marx entdeckten grundlegenden Gesezze der Realisalion bleiben ein und dieselben", in Lenin, Werke, Bd. 4, S. 77. Lenin hat allerdings dieses methodische Postulat in seiner Imperialismustheorie kaum ausgefuhrt.
} 
1.2. Die Modifikation der Durchsetzung des Wertgesetzes auf dem Weltmarkt

1. 3. Ungleichmäßigkeit der Entwicklung innerhalb der nationalen Kapitale

1. 4. Empirie der Ungleichmäßigkeit

2. Wertgesetz und Wert der Währungen

2. 1. Wechselkurs als "Preis" der Währungen

2. 2. Modifikation des Wertgesetzes und fixe Wechselkurse

3. Nationale und internationale Zirkulation - Formen des Weltgeldes

3. 1. Möglichkeit und Ausbreitung von Krisen in der internationalen Zirkulation

3. 2. Dollar als Weltpapiergeld

3. 3. Das Weltwährungssystem

4. Die konkreten Gründe für Währungskrisen in den Reproduktionsbedingungen der wichtigsten Weltmarktländer. 


\section{express international}

erscheint seit 8 Jahren in Frankfurt

\section{express international}

bringt ständig kritische Beiträge zur Gewerkschaftspolitik

\section{express international}

beschäftigt sich mit den aktuellen politischen Fragen

\section{express international}

berichtet über die internationalen Auseinandersetzungen

\section{express international}

druckt wichtige Aufsätze zur theoretischen Diskussion

\section{express international}

erscheint vierzehntägig zum Preis von 0,50 DM

\section{express international}

ist zu beziehen über die Redaktion: 6 Frankfurt, Fichardstraße 15, Hof 


\section{Das Wertgesetz auf dem Weltmarkt}

Die gegenwärtigen Auseinandersetzungen der kapitalistischen Staaten um die Auf- bzw. Abwertung nationaler Währungen führen uns zu der Frage, welche Veränderungen in der Produktion von Wert und Mehrwert zu der Krise des Weltwährungssystems geführt haben. Wie sieht das Verhältnis von nationaler Wertproduktion und internationalem Währungssystem überhaupt aus? Auf welche Weise werden vermittelt über die Austauschverhältnisse der nationalen Währungen die Warenwerte auf internationaler Ebene verglichen? Was bedeutet die Festsetzung der Währungsparitäten, d. h. der relativen Werte der nationalen Währungen, wie sie im System von Bretton Woods vorgenommen wurde, wenn sich die Bedingungen der Wertproduktion bei den unterschiedlichen nationalen Kapitalen verändern? Welche Wirkungen entstehen auf Grund solcher Festsetzungen für die internationalen Warenkapital- und Geldkapitalbewegungen? ${ }^{3}$ )

Um diese Fragen zu lösen, ist es notwendig, sich zunächst das Wirken des Wertgesetzes auf dem Weltmarkt zu verdeutlichen, um von da aus schrittweise die konkrete Vermittlung des Wirkens des Wertgesetzes im Medium der Währungsparitäten bzw. Währungsdisparitäten zu entwickeln.

Marx geht davon aus, daß auf dem Weltmarkt eine Modifikation der Durchsetzung des Wertgesetzes stattfindet. Dies bedeutet nicht, daß das Wertgesetz auf dem Weltmarkt nicht seine Wirkung entfaltet, sondern daß die Bestimmung des Werts der Waren durch die in ihnen enthaltene gesellschaftlich notwendige Arbeitszeit, sowie - in Bezug auf die Kapitalbewegung die Durchsetzung einer Durchschnittsprofitrate modifiziert wird. Zur Klärung dieser Modifikation ist es notwendig, sich zu vergegenwärtigen, was Wertbestimmung der Ware durch gesellschaftlich notwendige Arbeitszeit heißt, und unter welchen Bedingungen sie stattfindet. Daher gehen wir sehr kurz auf die wesentlichen Momente der Wertbestimmung der Waren ein ${ }^{4}$ ).

\section{1. Funktion und Durchsetzung des Wertgesetzes}

In der Wertbestimmung der Ware entwickelt sich in einer Waren produzierenden Gesellschaft hinter dem Rücken der Privatproduzenten die bestimmte Form, in welcher die Privatarbeiten zueinander in Beziehung gesetzt werden, in welcher also der gesellschaftliche Zusammenhang des arbeitsteilig und ohne gesellschaftlichen Plan stattfindenden Produktionsprozesses sich herstellt. Die Arbeit der Privatproduzenten erstellt Gebrauchsgegenstände, Ge-

$\left.{ }^{3}\right)$ In der Statistik spricht man von Waren. und Kapitalbewegungen. Gemeint sind damit Warenkapital- und Geldkapitalbewegungen, da ja auch die Waren Kapitalform haben. Wenn wir im Folgenden die Begriffe der Statistik verwenden, dann immer in dem hier erläuterten Sinn.

4) Das Folgende basiert auf den ersten drei Kapiteln des ersten und dem zehnten Kapitel des dritten Bandes des, Kapital'. Zitert wird nach der MEW (Marx Engels Werke) Ausgabe: Kapital Bd. I = MEW 23, Kapital. Bd. II = MEW 24, Kapital Bd. III $=$ MEW 25, Theorien über den Mehwert Bd. 1, 2, $3=$ MEW 26, 1, 2, 3. 
brauchswerte, und als solche hat sie konkret nützlichen Charakter, sie erstelit aber die Gebrauchswerte als Gebrauchswerte für andere. Zu solchen werden sie im Austauschprozeß, in dem die besonderen Arbeiten der Privatproduzenten miteinander verglichen werden müssen. Der Vergleichungsprozeß erfordert, daß sich die Arbeit des Privatindividuums als ihr Gegenteil, als gesellschaftliche darstellt. Sie ist es als abstrakt allgemeine Arbeit, die sich nur noch in der Zeitdauer ihrer Verrichtung unterscheidet, aber sonst gleiche, gesellschaftlich notwendige Arbeit ist. Als solche bildet sie die Substanz des Tauschwerts der Ware, welcher im Austauschprozeß erscheint und seine Darstellung im Geld als allgemeinem Aquivalent findet. „Die Verselbständigung des Tauschwerts der Ware in Geld ist selbst Produkt des Austauschprozesses, der Entwicklung der in der Ware enthaltenen Widersprüche von Gebrauchswert und Tauschwert, und des nicht minder in ihr enthaltenen Widerspruchs, daß die bestimmte besondere Arbeit des Frivatindividuums sich als ihr Gegenteil, gleiche, notwendige, allgemeine und in dieser Form gesellschaftliche Arbeit darstelien muß." (MEW 26. 3., S. 128). Sehen wir von der Notwendigkeit der Darstellung gleicher abstrakter Arbeit im Geld nun zunächst $a b$, und fragen wir nach der Grundlage dieser Tauschabstraktion im ProduktionsprozeB. Gleiche menschliche Arbeit ist nicht nur eine Abstraktion vom konkret nützlichen Charakter der Arbeit, gesetzt aus den Notwendigkeiten des Zirkulationsprozesses, sondern Realabstraktion insofern, als jede individuelle Arbeitskraft nur soweit gleiche menschliche Arbeit verrichtet, ,als sie den Charakter einer gesellschaftlichen Durchschnittsarbeitskraft besitzt und als solche gesellschaftliche Durchschnittsarbeitskraft wirkt, also in der Produktion einer Ware auch nur die im Durchschnitt notwendige oder gesellschaftlich notwendige Arbeitszeit braucht." (MEW, 23, S. 53) Gleiche menschliche Arbeit meint also immer die Durchschnittsarbeit, wobei der jeweils historisch erreichte Stand in der Entwicklung der Produktionsbedingungen, der Intensität und der Qualifikation in Ihrem Durchschnittsgrad als Kriterien für gesellschaftlich notwendige Arbeitszeit sind. Diese Durchschnittsbedingungen als gesellschaftlich wirkende Produktionsbedingungen werden in zweifacher Weise vom Kapital in seinem Bewegungsprozeß erzeugt. Zum einen bewirkt die Herrschaft des Kapitalisten über den Arbeiter im Produktionsprozeß, daß die Arbeitskraft „,mit dem gesellschaftlich üblichen Grad an Intensität" und dem "gewöhnlichen DurchschnittsmaB an Anstrengung" vom Arbeiter verausgabt wird. (MEW 23, S. 210).

Der Zwang, welchen der Kaptalist über den Arbelter ausübt, indem er dafür sorgt, daB dieser seine Arbeitskraft mindestens in gesell. schaftich durchschnititichem AusmaB verausgabt s), ist vermiftelt über die Konkurrenz der Enzelkapitale. Da jede einzelne Ware nur als Exemplar inrei Gattung gilt, als aliquoter Tell der auf einem Markt vorhandenen Warenmasse, erzwingt dieser über den Zirkulatongerozeb her Waren wemitielte Zusammenhang der Privatproduzenten, erscheinend als Konkurrenz, daß

5) Verlangh der Kapitalis? weit darüber hinausgehende Anstrengungen, denn werden Gie arbolier zu anderen Kapitalisten gehen, um ihre Arbeitskraft zu verkauten, sofern dies thre Mobilitäl und die Konjunktur erlauben. 
jeder einzelne Kapitalist den Produktionsprozeß seiner Waren gemäß den jeweiligen historischen Durchschnittsbedingungen organisiert. Als Produkt gleicher menschlicher Arbeit ist die Ware Tauschwert. Als Produkt konkret nützlicher Arbeit ist sie Gebrauchswert. Vergegenwärtigen wir uns noch die Momente der Bestimmung gesellschaftlich notwendiger Arbeitszeit, welche der Ware von ihrer Gebrauchswertseite zukommen. Als gesellschaftlich notwendige wertbildende Arbeitszeit, als Tauschwert dargestellt im Geld, realisiert sich der Warenwert im AustauschprozeB. Eine Ware kann aber nur getauscht werden, wenn ein gesellschaftliches Bedürfnis, sprich in Geld ausgedrücktes zahlungsfähiges Bedürfnis, nach inr besteht, d. h., wenn das Quantum der gesellschaftlichen Bedürfnisse, bestimmt durch die Kapitalakkumulation auf der Basis antagonistischer Verteilungsverhältnisse, der zur Produktion einer bestimmten Warenmasse aufgewandten gesellschaftlich notwendigen Arbeitszeit entspricit. (MEW 25, S. $191 \mathrm{ff}$ ) Ist das Quentum des gesellschaftlichen Bedürfnisses, ausgedrückt im Geld, welches die Käufer bereit sind zu zahlen, geringer als das Quantum der zur Produktion der Warenmasse unter durchschnittlichen gesellschaftlichen Bedingungen aufgewandten Arbeitszeit, so findet Entwertung der Warenmasse statt. Die von den Produktionsbedingungen her gesetzte gesellschaftlich notwendige Arbeitszeit erweist sich dann als gesellschaftlich nutzlose, sie realisiert sich nicht als wertbildende Arbeit. „Diese quantitave Schranke der auf die verschiedenen besonderen Produktionssphären verwendbaren Quoten der gesellschaftlichen Arbeitszeit ist nur weiterentwickelter Ausdruck des Wertgesetzes überhaupt; obgleich die notwendige Arbeitszeit hier einen anderen Sinn erhält. Es ist nur soundsoviel davon notwendig zur Befriedigung des gesellschaftlichen Bedürfnisses. Die Beschränkung tritt hier ein durch den Gebrauchswert". (MEW 23, S. 649) Der EntwertungsprozeB selbst macht sich geltend als Widerspruch zwischen dem gesellschaftlichen Wert der Ware, der wie gezeigt, doppelt bestimmt ist, und der von jedem Kapitalisten zur Produktion in Bewegung gesetzten Arbeit, sowohl der vergegenständlichten, als auch der lebendigen, als Widerspruch zwischen gesellschaftlichem und individuellem Warenwert. ${ }^{6}$ )

Der von der quantitativen Grenze des gesellschaflichen Bedürfnissses bestimmte Entwertungsproze $\beta$ bewirkt Veränderungen innerhalb des Produktionsprozesses selbst, sei es, daß die Produktion eingeschränkt wird, sei es, daß durch "Rationalisierungsinvestitionen“ oder durch Kapitalvernichtung die zur Produktion der Warenmasse aufgewandte Arbeitszeit sich vermindert und das gesellschaftliche Bedürfnis nach dieser Warenmasse infolge ihres gesunkenen Werts, ausgedrückt in einem gesunkenen Preis der Einzelware, steigt.

Als blind wirkender innerer Regulator der kapitalistischen Produktion hat das Wertgesetz demnach zweierlei Funktionen: Es bewirkt, daß in den jeweiligen Produktionssphären Durchschnittsbedingungen für die Produktion

Gie hier enthaltenen Probleme bezüglich der Marktwertbestimmung der Warenmasse können hier nicht behandelt werden. 
der Warenmasse innerhalb des Produktionsprozesses selbst hergestellt werden, wobei jeweils die fortgeschrittensten Produktionsbedingungen sich als durchschnittliche etablieren müssen. Zum anderen bewirkt es die Verteilung des gesellschaftlichen Arbeitsfonds, der lebendigen und der im Kapital vergegenständlichten Arbeit, in die verschiedenen Produktionssphären gemäß den Bedürfnissen des Akkumulationsprozesses innerhalb einer Produktionssphäre und zwischen den Produktionssphären. Dieser Wirkungsmechanismus läßt sich am einfachsten anhand der Darstellung der Kategorie des Extramehrwertes im ersten Band des „Kapital" nachvollziehen (MEW 23, S. 355 ff): Führt ein Kapitalist aufgrund technischer Erfindungen Maschinerie ein, welche es ihm ermöglicht, die Waren unter der gesellschaftlich durchschnittlich notwendigen Arbeitszeit zu produzieren, so verwendet er Arbeit von höherem spezifischem Gewicht und produziert einen Extramehrwert. Die bel diesem Einzelkapital zur Produktion einer Ware aufgewandte Arbeitszeit liegt unter dem gesellschaftlichen Durchschnitt, der individuelle Wert seiner Waren unter dem gesellschaftlichen. Die Arbeitsstunde der vom produktiveren Kapital angewandten Arbeitskraft ist nicht identisch mit einer Arbeitsstunde bei dem Kapitalisten, welcher gemäß durchschnittlichen Bedingungen produziert, ihr gesellschaftlicher Wert liegt höher, da ja in einer Arbeitsstunde jetzt z. B. zwei Produkte hergestellt werden und nicht mehr nur eines, wie es dem Durchschnitt entspräche. Daher zählt eine Arbeitsstunde beim produktiveren Kapital wie zwei Arbeitsstunden beim Durchschnittskapital.

Wie verläuft nun der ProzeB, welcher die fortgeschrittensten Produktionsbedingungen wieder zu den durchschnittlichen macht? Der „zwölfstündige Arbeitstag“' des produktiveren Kapitalisten stellt sich „jetzt für inn in 24 Stück Ware' dar statt früher in 12. Um also das Produkt eines Arbeitstages zu verkaufen, bedarf er doppelten Absatzes oder eines zweifach größeren Marktes. Unter den sonst gleichbleibenden Umständen erobern seine Waren nur größeren Marktraum durch Kontraktion inrer Preise. Er wird sie daher über ihrem individuellen, aber unter ihrem gesellschaftlichen Wert verkaufen “. (MEW, 23, S. 336) Dies zwingt nun die anderen Kapitalisten dieser Produktionssphäre, die fortgeschrittensten Produktionsmethoden einzuführen, so daß diese sich verallgemeinern und wieder zu den durchschnittlichen werden. $D a B$ der produktivere Kapitalist gezwungen ist, seine Waren unter ihrem gesellschaftlichen Wert zu verkaufen, ist Folge der Beschränkung des zahlungsfähigen gesellschaftlichen Bedürfnisses nach einer bestimmten Warenmasse, welche dem Einzelkapital als Konkurrenz der Waren seiner Branche mit den Waren anderer Branchen erscheint. So bewirkt die durch die Konkurrenz zwischen den Produktionssphären beeinflußte Konkurrenz Innerhalb der Produktionssphären, daß die fortgeschrittensten Bedingungen immer wieder zu den durchschnittlichen Bedingungen der Produktion werden. Dieser ProzeB setzt sich im Kapitalismus in der Form zyklischer Krisen durch. In der Phase des Aufschwungs des Akkumulationsprozesses bis hin zur Schwindelblüte der Konjunktur scheint die Nachfrage unbegrenzt, so daß auch die produktiveren Kapitalisten nicht zu Preissenkungen, also zur Senkung der Warenpreise unter ihren gesellschaftlichen Wert gezwungen sind, 
im Gegenteil, es finden in dieser Phase sogar Aufblähungen des Geldausdrucks der Warenwerte, Preissteigerungen statt. ${ }^{7}$ ) Die Möglichkeit der Aufblähung des Geldausdrucks der Warenwerte ist vermittelt über das Kreditwesen. „Die Seite der Konkurrenz, die momentan die schwächere ist, ist zugleich die, worin der einzelne unabhängig von der Masse seiner Konkurrenten und oft direkt gegen sie wirkt und gerade dadurch die Abhängigkeit des einen vom anderen fühlbar macht, während die stärkere Seite stets mehr רder minder als geschlossene Einheit dem Widerpart gegenübertritt. Ist für diese bestimmte Sorte Waren die Nachfrage größer als die Zufuhr, so überbietet - innerhalb gewisser Grenzen - ein Käufer den anderen und verteuert so die Ware für alle über den Marktwert, während auf der anderen Seite die Verkäufer gemeinsam zu einem hohen Marktpreis zu verkaufen suchen. Ist umgekehrt die Zufuhr größer als die Nachfrage, so fängt einer an, wohlfeiler loszuschlagen, und die anderen müssen folgen, während die Käufer gemeinsam darauf hinarbeiten, den Marktpreis möglichst tief unter den Marktwert herabzudrücken. Die gemeinsame Seite interessiert jeden nur, solange er mehr mit ihr gewinnt, als gegen sie. Und die Gemeinsamkeit hört auf, sobald die Seite als solche die schwächere wird, wo dann jeder einzelne auf eigene Hand sich möglichst gut herauszuwinden sucht. $\cdot$. Hat eine Seite die Oberhand, so gewinnt jeder, der ihr angehört; es ist, als hätten sle eln gemeinschaftliches Monopol geltend zu machen." (MEW, 25, S. 206) (Unterstreichungen - A. B. N.) Erst wenn zuviel Produktionsmittel produziert worden sind, die als Kapital bei einem gegebenen Exploitationsgrad fungieren könnten, also erst im Zustand der Öberakkumulation von Kapital, sei es in einem Produktionszweig, sei es innerhalb des Gesamtkapitals, setzen sich die fortgeschrittensten Produktionsbedingungen als durchschnittliche durch. Vermittelt ist dieser Prozeß über die Vernichtung der weniger produktiven Kapitale in Form von Zentralisationsprozessen und Konkursen, durch Preisverfall der Waren oder - im Prozeß der "säkulären Inflation“ - durch unterdurchschnittliche Preissteigerungen bei überdurchschnittlich steigenden Kosten. Er kann als "Strukturkrise" eines Produktionszweiges stattfinden, er findet für das Gesamtkapital als zyklische Krise statt. Der Verlust wird dann unvermeidlich für die Klasse. "Wieviel aber jeder einzelne davon zu tragen, wieweit er überhaupt daran teilzunehmen hat, wird dann Frage der Macht und der List, und die Konkurrenz verwandelt sich dann in einen Kampf der feindlichen Brüder." (MEW, 25, S. 263) Die gesellschaftliche Form der Durchsetzung des Wertgesetzes ist die Krise.

\section{2. Die Modifikation der Durchsetzung des Wertgesetzes auf dem Weltmarkt} Die volle Ausbilaung der Konkurrenz schließt die Einzelkapitale zum Gesamtkapital zusammen, welches als solches seinen Ausdruck in der tendenziellen Bildung einer Durchschnittsprofitrate für die Einzelkapitale findet. Die politische Form des Gesamtkapitals ist der bürgerliche Staat, welcher die ökonomischen Beziehungen der konkurrierenden Einzelkapitale als Rechtsverhältnisse sanktioniert. Die nationalen Gesamtkapitale bilden sich

7) Vgl. dazu Kapital Bd. 2, MEW 24, 16. Kapitel, insbesondere, S. 316 ff; zum Kreditwesen: Kapital Bd. 3, MEW 25, 30. - 32. Kapitel. 
auf dem Weltmarkt unter unterschiedlichen historischen Bedingungen und zu unterschiedlichen historischen Zeiträumen heraus.

In den Beziehungen der nationalen Kapitale auf dem Weltmarkt zeigen sich nun Erscheinungen, welche sich innerhalb eines nationalen Kapitals tendenziell ausschließen, bzw. nur vorübergehenden Charakter haben. Während sich innerhalb des nationalen Kapitals das Wertgesetz in der Form der Vernichtung der kleineren und der zurückgebliebenen Kapitale durchsetzt, seine Durchsetzung also mit dem Sieg der entwickelsten Kapitale und dem Untergang der zurückgebliebenen Kapitale verknüpft ist, ist dies auf dem Weltmarkt nicht ohne weiteres der Fall. Der Aufstieg des deutschen Kapitals gegen das englische Weltmarktmonopol im 19. Jahrhundert zeigt ebenso ${ }^{8}$ ), wie der Wiederaufstieg des europäischen Kapitals und die Akkumulation des japanischen Kapitals nach dem zweiten Weltkrieg, daß es auf dem Weltmarkt den zurückgebliebenen Kapitalien gelingen kann, die entwickelteren Kapitale einzuholen. Das Wertgesetz kann sich also auf dem Weltmarkt nur in modifizierter Form durchsetzen. Die Grundiage dieser Modifikation ist die Möglichkeit der Brechung der Konkurrenz der Kapitale auf dem Weltmarkt durch den bürgerlichen Staat $a_{1}$ politische Form, welche die bürgerliche Gesellschaft aus sich entwickelt. Er setzt der freien Beweglichkeit des Kapitals Grenzen. Empirischer Ausdruck dieser Beschränkung der freien Beweglichkeit des Kapitals auf dem Weltmarkt sind Zollgesetzgebung, Einfuhrbeschränkungen, gesetzliche Beschränkungen von Kapitalexport und Kapitalimport (Devisenbewirtschaftung). Ausdruck dafür, daß sich auf dem Weltmarkt nicht einfach konkurrierende Einzelkapitale, sondern nationale Kapitale gegenübertreten, sind die nationalen Währungen, das nationale Geld als Darstellungsform der nationalen Durchischnittsarbeit ${ }^{9}$ ). Wesentliche ökonomische Grundlage der Modifikation der Durchsetzung des Wertgesetzes auf dem Weltmarkt ist die Tatsache, daß die Mobilität der Arbeiterklasse sich zunächst nur auf nationaler Ebene herstellt, auf internationaler nur, so-

8) Aus diesen Zusammenhängen formulierten die Anti-Freihändler ihre Argumente. Vgl. z. B. Friedrich List, Das natürliche System der politischen Okonomie, Berlin 1961, Kapitel XXI, "Über den Zollschutz im Allgemeinen“, wo es heiBt: "Nationen, deren Markt seit Jahrhunderten der ausländischen Konkurrenz offenstand und deren Theoretiker fast ausnahmslos glühende Anhänger und Verteidiger der kosmopolitischen Prinzipien sind - wie beispielsweise die deutsche Nation -, haben ebenfalls begriffen, daß sie ohne ein Zollsystem keinen Schritt vorankommen können ... Unter den heutigen politischen Bedingungen der Nationen soll der Zollschutz entgegen allen anderen Behauptungen - dazu dienen, die allseitige Handeisfreiheit herbeizuführen. So völlig pradox dies auch klingen mag, so ist es dennoch nicht weniger wahr!... Schließlich hat die Erfahrung bewiesen, daß die mächtigsten und forgeschritiensten Nationen immer - oder doch zumindest sehr oft - ihr Ubergewicht und ihre Uberlegenheit gegenüber den weniger fortgeschrittenen Nationen mißbrauchen - und wäre es auch nur, um überhaupt von ihrer Macht Gebrauch zu machen ..." (S, $137 \mathrm{f}$ )

9) Vgl. dazu Tell 2 des Aufsatzes.

10) Selbstverständlich ist der Begriff der, geographischen Schranken' relativ zu verstehen. Diese vermindern sich mit der Entwicklung des Verkehrswesens, und können inzwischen, was die Mobilität der Arbeitskräfte innerhalb der EWG-Länder angeht, als aufgehoben gelten; was tendenziell Rückwirkungen für die Ausgleichung der Ausbeutungsraten innerhalb der europäischen nationalen Kapitale haben muß. 
fern keine gesetzlichen, aber was hier wichtiger ist, keine geographischen und sprachlichen Schranken bestehen. ${ }^{10}$ ) Hinzu kommt die primär nationale politische und gewerkschaftliche Organisation der Arbeiterklasse, welches zusammengenommen national unterschiedliche Lebensbedingungen der Arbeiterklasse setzt, und damit relativ unabhängig vom Stand der Entwicklung der Produktivkraft, unterschiedliche Ausbeutungsraten.

Was ist nun der Inhalt der modifizierten Durchsetzung des Wertgesetzes auf dem Weltmarkt? Auf dem Weltmarkt werden die Waren der unterschied.lich entwickelten nationalen Kapitale ausgetauscht; im Vergleichungsprozeß muß also abstrakte menschliche Arbeit als Substanz der Warenwerte, dargestellt im Geld, die Grundlage des Austauschprozesses bilden. Aufgrund der unterschiedlich entwickelten Produktivkraft und Intensität in den verschiedenen Ländern hat gleiche menschliche Arbeit jedoch zunächst keine materielle Basis im Produktionsprozeß, wie auf nationaler Ebene, sondern ist in der Tat eine Tauschabstraktion, welche sich aus den Notwendigkeiten der Warenzirkulation bildet. „In jedem Lande gilt eine gewisse mittlere Intensität der Arbeit, unter welcher die Arbeit bei der Produktion einer Ware mehr als die geselischaftlich notwendige Zeit verbraucht und daher nicht als Arbeit normaler Qualität zählt. Nur ein über den nationalen Durchschnitt sich erhebender Intensitätsgrad ändert in einem gegebenen Lande das $\mathrm{Ma} \beta$ des Wertes durch die bloße Dauer der Arbeitszeit. Anders auf dem Weltmarkt, dessen integrierende Teile die einzelnen Länder sind. Die mittlere Intensität der Arbeit wechselt von Land zu Land; sie ist hier größer, dort kleiner. Diese nationalen Durchschnitte bilden eine Stufenleiter, deren Maßeinheit die Durchschnittseinhelt der universellen Arbelt ist. Verglichen mit der weniger intensiven produziert also die intensivere Arbeit in gleicher Zeit mehr Wert, der sich in mehr Geld ausdrückt. Noch mehr aber wird das Wertgesetz in seiner internationalen Anwendung dadurch modifiziert, daß auf dem Weltmarkt die produktivere nationale Arbeit ebenfalls als die intensivere zählt, so oft die produktivere Nation nicht durch die Konkurrenz gezwungen wird, den Verkaufspreis ihrer Ware auf ihren Wert zu senken. " ") Die produktivere Nation realisiert demnach im AustauschprozeB auf dem Weltmarkt einen Extramehrwert, verglichen mit der weniger produktiven. An die Stelle der durchschnittlich gesellschaftlich notwendigen Arbeitszeit als Kategorie der Warenproduktion und Zirkulation beim nationalen Gesamtkapital tritt auf internationaler Ebene die Kategorie der universellen

11) Kapital Bd. 1, MEW 23, S. 583-84, vgl, auch Kapital Bd. 3, MCiv 25, S. 247: „Kapitale, im auswărtigen Handel angelegt, können eine höhere Profitrate abwerfen, weil hier erstens mit Waren konkurriert wird, die von anderen Ländern mit minderen Produktionleichtigkeiten hergestellt werden, so daß das fortgeschrittenere Land seine Waren über ihrem Wert verkauft, obgleich wohlfeiler, als die Konkurrenzländer. Sofern dile Arbeit des fortgeschrittenen Landes hier als Arbeit von höherem spezifischem Gewicht verwertet wird, steigt die Profitrate, indem die Arbeit, die nicht als qualitativ höhere bezahlt, als solche verkauft wird. . . Ganz wie der Fabrikant, der eine neve Erfindung vor ihrer Verallgemeinerung benutzt, wohlfeiler verkauft, als seine Konkurrenten und dennoch über dem individuellen Wert seiner Ware verkauft, $d . h$. die spezifisch höhere Produktivkraft der von ihm angewandten Arbeit als Mehrarbeit verwertet." 
Arbeit als gewogener Durchschnitt der Stufenfolge der Produktivitätsgrade und Intensitätsgrade der Arbeit der nationalen Kapitale, und zwar für die Waren, welche auf dem Weltmarkt getauscht werden. ${ }^{12}$ ) National notwendige gesellschaftliche Arbeitszeit stellt auf dem Weltmarkt sich nicht unbedingt als gesellschaftich notwendige, sondern als individuelle Arbeitszeit dar. Der nationale gesellschaftliche Wert wird zum individuellen, dessen Realisierungsgrad sich richtet nach seinem Verhältnis zur universellen, als auf dem Weltmarkt gesellschaftlich notwendigen Arbeit. (Dabei ist davon auszugehen, daß bei einem Teil der auf dem Weltmarkt getauschten Waren nationaler und Weltmarktwert zusammenfallen, ein Teil der Nationen zu den durchschnittlichen Produktionsbedingungen produziert, welche in der Kategorie der universelien Arbeit, dargestellt im Weltmarktpreis der Waren, als WertmaB gelten. Aber universelle Arbeit muB nicht den massenhaften Produktionsbedingungen der auf dem Weltmarkt getauschten Waren entsprechen. "Ole verschiedenen Waren quanta derselben Art, die in verschiedenen Ländern in gleicher Arbeitszeit produziert werden, haben also ungleiche internationale Werte, die sich in verschiedenen Preisen ausdrücken, $d . h$. je nach den internationalen Werten verschiedenen Geldsummen." (MEW, 23, S. 584) Vereinfacht ausgedrückt̃: Auf dem Weltmarkt kann folgendes Verhältnis zwischen den Nationen $X, Y$ und $Z$ bestehen (wir setzen hier Dollar als Weltgeld):

1 Arbeitstag der Nation $Y=1,2$ universelle Arbeitstage $=12$ Ware $X=$ 12 Dollar. 1 Arbeitstag der Nation $Y=1$ universeller Arbeitstag $=10$ Ware $x=10$ Dollar. 1 Arbeitstag der Nation $Z=0,8$ universelle Arbeitstage $=$ 8 Ware $X=8$ Dollar.

Die Produktivkraft der Arbeit ist unterschiedlich in den Nationen $X, Y$ und $Z$, wobel $X$ die Nation (gemeint natürlich immer das nationale Kapital) mit der höchsten und $Z$ diejenige mit der niedrigsten Produktivität der Arbeit ist. Der Arbeitstag der Nation $Y$ repräsentiert die Durchschnittsbedingungen, wenn auch nicht die massenhaften Produktionsbedingungen auf dem Weltmarkt. Die einzelne Ware hat den gleichen Welmarktwert (Wert hier gleich Preis), obwoh unterschiedliche Quanta nationaler Arbeitszeit in ihr vergegenständlicht sind. Dies findet seinen Geldausdruck darin, daß der relative Wert des Geldes kleiner ist - bezogen auf den jeweiligen nationalen Arbeisstag - bei der Nation mit entwickelter kapitalistischer Produktions-

Yal. Gunther Konmey, Karl Marx Theorie von den internationalen Werten, in: problame der Polnischen bkonome, Jahrbuch des Instituts für Wirtschaftswissenschafen, 8a. 5. Berlin 1962, 5. 44. Kohimeys Aufsatz ist die einzige ernsthafte Ausarisandersetzung mit der Theorie der Modifikalion des Wertgesetzes auf dem Weltmryerkt bei hark. Kritik, die uns an der Analyse notwendig erscheint, könen wir hler Thuth bringen, da sie den Rahmen des Aufsatzes sprengen würde. Ebenso können wir his: nicht die Probleme, welche in unserer einfachen Zusammenfassung von, Inten-

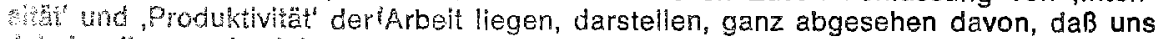
sats seiger noch eniges unklar ist. Deshalb behandeln wir auch im folgenden Teil mat das Problem unterschiedlicher Produktivitäts entwicklung innerhalb der Thionalen Kaplate. Die Frage der Herausbildung einer durchschnittlichen Arbeits.

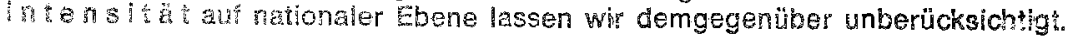


weise. ${ }^{13}$ ) Nur bei der Ware, die vom Land $Y$ geliefert wird, entsprechen sich nationaler und internationaler Wert. Die Kapitalisten von Land $X$ realisieren einen Extramehrwert auf dem Weltmarkt, die des Landes $Z$, verkaufen die Waren unter ihrem individuellen, sprich hier nationalen gesellschaftichen Wert. Bedingung dafür, daß die Kapitale des zurückgebliebenen Landes trotzdem akkumulieren können, ist eine höhere Ausbeutungsrate der Arbeiterklasse des zurückgebliebenen Landes. Aurghund niedrigerer Löhne und längerer Arbeitszeilen können die zurückgebliebenen Kapilale trotz des Entwertungsprozesses ihrer Waren auf dem Weltmarkt eine Profitrate erzielen, die ihnen die Konkurrenz mit den fortgeschrittenen Kapitalen erlaubt. ${ }^{14}$ )

Im nächsten Kapitel wird zu zeigen sein, wie sich die unterschiedliche Gewichtung der nationalen Arbeitstage im Medium des Verhältnisses der verschiedenen nationalen Währungen zueinander durchsetzt. Für die Probleme der Weltwährungskrise kann hier schon angedeutet werden, daß $\mathrm{B}$ auf der einen Seite die Relation der nationalen Durchschnittsarbeiten in Form fixierter Währungsparitäten festgelegt sind, aber im Verlauf der Entwicklung die Produktivitäts- und Intensitätsänderungen der unterschiedlichen nationalen Arbeiten nicht im Gleichschritt, sondern ungleichmäßig erfolgen. Daraus resultiert aber eine veränderte Struktur der Beziehungen der nationalen Arbeitstage zur universellen Arbeit, was in den Formen der. Beziehungen der nationalen Währungen zueinander seinen Ausdruck finden muß.

Es muß davon ausgegangen werden, daß auch auf dem Weltmarkt die Funktion des Wertgesetzes, nämlich die jeweils fortgeschrittensten Produktionsbedingungen $\mathrm{zu}$ den massenhaft durchschnittlichen $\mathrm{zu}$ machen, nicht auf die Dauer außer Kraft gesetzt werden kann, insbesondere dann nicht, wenn, wie seit den 50er Jahren die freie Beweglichkeit des Kapitals auf dem Weltmarkt tendenziell hergestellt wird. Die jeweilige Einheit universeller Arbeit als Tauschabstraktion kann nur ein vorübergehender Zustand sein. Die Pro-

$\left.{ }^{13}\right) \mathrm{Vgl}$. MEW 23, S. 584. Die genauere Entwicklung der Darstellung der verschieden gewichteten nationalen Arbeiten in den nationalen Geldausdrücken, den Währungen und ihrem differierenden Verhältnis zum Weltgeid wird im Teil 2 der Arbeit erfolgen.

$\left.{ }^{14}\right)$ „Finden wir hohe Profitrate da, wo die Arbeit noch sehr unproduktiv, keine Maschinerie, Teilung der Arbeit etc. angewandt wird, so nur, entweder wie in Indien teilweise, weil die Bedürfnsse des Arbeiters absolut klein sind und er selbst noch unter diese geringe Bedürftigkeit herabgedrückt wird, teilweise aber weil Unproduktivität der Arbeit identisch ist mit kleinem Verhältnis des capital fixe zu dem in Arbeitslohn ausgelegten Teil des Kapitals ... odor endlich weil die Arbeitszeit auBerordentlich verlängert wird. Letzteres der Fall in den Ländern, wo schon kapitalistischo Produktionsweise existiert, diese Länder aber zu konkurrieren haben-mit viel weiter entwickelten Ländern." Marx, Theorien über den Mehrwert, Bd. 2, MEW 26, 2, S. 8.

Für Lenins Theorie der Arbeiteraristokratie der entwickelten kapitalistischen Länder, korrumpiert aus den Extraprofiten der Monopole, ergäbe sich von hier aus der Einwand: Der Unterschied in der Lebenslage der Arbeiterklasse zwischen fortgeschrittenen und zurückgebliebenen kapitalistischen Ländern deutet nicht notwendig auf eine Korruption der Árbeiterklasse der entwickelten Länder aus den Weltmarktextraprofiten, sondern auf eine Bezahlung der Arbeitskraft unter Wert in den zurückgebliebenen Länciern hin. (Vgl. auch Marx, Zitat: Anmerkung 17). 
duktionsbedingungen der Waren müssen sich angleichen in den verschiedenen Weltmarkt!ändern. Aber für die Durchsetzung des Wertgesetzes als Kateaorie der Warenzirkulation und -produktion müssen weitaus läncere Zeiträume angesetzt werden, als auf nationaler Ebene, wo sich gegenwärtig im Zeitraum eines 4-5jährigen Zyklus die jeweils fortgeschrittensten als durchschnittlicine Produktionsbedingungen durchsetzen.

In der Krise macht sich der gesellschaftliche Zusammenhang der unabhängig voneinander agierenden Privatoroduzenten gewaltsam geltend. Der industrielle Zyklus ist die Form, in welcher sich die GesetzmäBigkeiten des Akkumulationsprozesses des Kapitals durchsetzen. Für die Konstitution des Kapitals als wirkliches Gesamtkapital kann aber auf Weltmarktebene nichts anderes gelten, als auf nationaler Ebene. Aus dem allgemeinen Begriff des Kapitals ergibt sich die zyklische Form der Durchsetzung seiner immanenten Beweaunasqesetze. Nun besagt die Modifikation des Wertgesetzes auf dem Weltmark? nichts anderes, als daB die historisch wirkliche Form, in welcher das Kapital seinem Beqriff adäauat wird, in doppelter Weise erfolgt, nämlich einme! im historisch aesetzten Rahmen des nationalen Gesamtkapitals, daneben aber auf dem Weltmarkt. Die Entwickluna des Kapitals zum historisch wirkiichen Weltkapital überlagert seinen Konstitutionsprozeß zum Gesamtkanital auf nationaler Ebene. Letztere ist selbst als historische Besonderung der allaemeinen Entwickluna des Kapitals zu verstehen. Seinem Beariff, nämlich alle historischen Besonderungen proaressiv zu zerstören, wird das Kapital erst als restes Gesamtkapital auf dem Weltmarkt adăouat. Dies imbliziert jedor daß die Formen der Durchsetzuna des Wertaesetzes auf Weltmarkteberia keine anderen sein können, als auf nationaler Ebene. Der Unterschied besteht in der länceren Zeitdauer, die es das Kaoital kostet, seine GesetzmäBiakeiten auf internationaler Ebene durchzusetzen, und in der Form der Krise. Beweaen sich nun jeweils relevante Teile des nationalen Gesamtkapitals auf dem Weltmarkt, so eraibt sich daraus, daß die nationalen Zykien von Weltmarktzvklen überlacert werden müssen, welche selbst sich modifizierend auf die zyklische Bewequna der nationalen Kapitale auswirken müssen. Solanee sich das Weltkapital in der aufsteidenden Phase seines Zyklus beweat. bilden Krisen der nationalen Kapitale nur bearenzie Prozesse. welche von der Weltmarktbeweauna des Kanitals wieder aufqefanden werden können. Die Eklats der nationalen Gesamtkapitale werden weniqer scharf und daher leichter zu überwinden sein. Auf der anderen Seite werden sich die Krisen der nationalen Kabitale verschärfen, wenn der Weltmarktzukius sich seinem Ende zuneiat, wenn die Krise als aewaltsame Form der Durchsetzuna des Wertaesetzes für das zum Weltmarktkapital sich entwickelnde Kapital herangereift ist.

Eine solche Annahme würde die historischen Entwicklunasohasen des Kapitals auf dem Weltmarkt erklären können. Während im 19. Jahrhundert das englisine Kanital wirkliches Weltmarktmonovol hatte. ist die monopolistische Benarrschuna des Weltmarktes durch ein Land seit Ende des 19. JahrhunHert olon Jem Zeinounkt; wo das USA- und das deutsche Kavital das Weltmarktmonopol Engiands endgütig brachen, nicht mehr vorgekommen. Die 
zyklischen, in ca. zehnjährigen Abständen erfolgenden Weltmarktkrisen im 19. Jahrhundert ließen sich aus der monopolistischen Position des englischen Kapitals erklären, dessen zyklische Krisen notwendig sich zu Weltmarktkrisen ausweiten mußten, solange die anderen nationalen Kapitale noch keine Position auf dem Weltmarkt errungen hatten. Die Schwäche ihrer Entwicklung wäre die Grundiage dafür, daß sie noch keine eigenständige Bewegung entfalten konnten. Die letzte große Weltmarktkrise im 19. Jahrhundert fand im Jahre 1873 statt. Die nächste erst im Jahre 1929 folgende. Dazwischen liegt der Vorstoß des US- und deutschen Kapitals auf dem Weltmarkt und der erste Weltkrieg. Die nationalen Konjunkturabschwünge, welche sich auch in ihrer Schärfe abmilderten, vertiefen nicht mehr synchron. ${ }^{15}$ ) Nicht die Ablösung des Konkurrenz- durch den Monopolkapitalismus wäre demnach die Erklärung für die neuen Erscheinungsformen der Kapitalbewegung auf Weltmarktebene seit dem letzten Viertel des 19. Jahrhunderts, sondern die Brechung des englischen Weltmarktmonopols und die Entfaltung der Konkurrenz der großen nationalen Kapitale auf dem Weltmarkt. Nicht daß sich das Kapital yon seinem Begriff entfernt und ais Monopolkapital eine neue Qualität annimmt, würde die Entwicklung kennzeichnen, sondern daß es historisch den Weltmarkt, welcher in seinem Begriff enthalten ist, wirklich hervorbringt und daß die Kapitalkonkurrenz sich von der bornierten nationalen auf die Ebene des Weltmarkts verlagert, da $\beta$ also das Kapital in seiner realen Bewegung seinem Begriff, Kapital auf dem Weltmarkt zu sein, tendenziell adäquat wird. Nach der großen Krise der 30 er Jahre entfaltete sich das Kapital als Weltmarktkapital erst wieder seit den fünfziger Jahren. Träfe unsere These zu, so müßte die volle Entfaltung des Weltmarktes seit den fünfziger Jahren früher oder später in einer Weltmarktkrise enden, in welcher sich gewaltsam die Durchsetzung des Wertgesetzes auf Weltmarktebene volizieht. Der asynchrone Verlauf der nationalen Zyklen, welcher die bisherige Entwicklung kennzeichnete, sowie die vergleichsweise geringe Schärfe der zyklischen Abschwünge in den einzelnen Ländern müßte in den Zusammenhang der Modifikation des Wertgesetzes auf dem Weltmarkt, d. h. einen die nationalen Zyklen überlagernden Weltmarktzyklus gestellt werden. Für die Währungskrisen der letzten Jahre, sowie für die gegenwärtige wäre die Frage zu stellen, ob sie erste Anzeichen des Niedergehens der Weltmarktkonjunktur sind. Wir können diese These noch nicht stringent ableiten, sie bedürften viel genauerer theoretischer aber vor allem auch empirischer Untersuchungen, die wir jetzt noch nicht leisten können. ${ }^{16}$ )

15) Vgl. dazu auch Fred OelBner, Die Wirtschaftskrisen (Raubdruck), S. 263 ff. Im Zusammenhang unserer These ist wichtig, zu sehen, daß Marx den auswärtigen Handel im 14. Kapitel des 13. Bandes des Kapital, Entgegenwirkende Ursachen (gegen den tendenziellen Fall der Profitrate) behandelt; zu fragen ist, ob er hier nicht gerade die Momente aufführt, welche modifizierend auf die zyklische Durchsetzung der Gesetzo der Akkumulation wirken.

i6) Vgl. aber noch die empirischen Teile des Aufsatzes. Zu bemerken ist hier allerdings noch, daB wir auf dir Annahme, es müsse einen Weltmarktzyklus geben, erst am Ende unserer Arbeit an dem Aufsatz gekommen sind, und daß demgemäB die folgenden Toile nicht unter dem Gesichtspunkt dieser These geschrieben worden sind. 
Wir formulieren sie zunächst als mögliche Erklärung historischer Entwicklungen des Kapitals und ais Ansatz für weitere Untersuchungen.

\subsection{Ungleichmäßigkeif der}

Die Entwicklung des Kapitais zum historisch wirklichen Weltkapital, die die nationale Akkumulation iendenzieli jDerlagert, muß sich auch in Form einer Veränderung der Konkurrenz der Kaoltale innerhalb des natic kntlichen Rahmens ausdrücken. Denn das nationale Gesamtkapital gliec.. wieder in verschiedene Produktionszweige mit unterschiedlichen Produktionsbedingungen.

Wir sind bis jetzt davon ausgegangen, daB die national gerellsche lich notwendigen Arbeitszeiten nur auf dem Weltmarkt eine Stufenisw, pilden, wobei, was noch genauer zu entwickeln ist, das Verhältnis der nationalen Währungen zueinander die Darstellungsform der unterschiedenen nationalen Durchschnittsarbeit im Geld ist. Nun stellt sich aber die Frage, ob es überhaupt eine nationale Durchschnittsproduktivität und Intensität der Arbeit gibt, oder ob sich der Durchschnitt jeweils nur auf bestimmte Produktionszweige bezieht. Anders gefragt: Stehen ein "westdeutscher Arbeitstag“ und ein "US-amerikanischer Arbeitstag" in allen Produktionszweigen in einem gleichen Abstufungsverhältnis zueinander, oder unterscheidet sich dieses je nach den verschiedenen Branchen? Gibt es solche Unterscheidungen, so stellt sich die Frage, was das für die Kategorie der nationalen Durchschnittsarbeit, welche im Verhältnis der Währungen zueinander immerhin eine Realität hat, bedeutet. Wir können diese Frage noch nicht befriedigend lösen, wollen aber doch noch unsere vorläufigen Überlegungen dazu kurz entwickeln.

Marx selbst behandelte das Problem im Zusammenhang der Auseinandersetzung um die Kornzölle in England. Die Argumentation der Freihändlerfraktion im Parlament lautete nach Marx folgendermaßen: „Würden wir aber, anstatt unser Kapital, unsere Arbeit auf einen durchaus unfruchtbaren Boden zu verschwenden, den Ackerbau aufgeben und uns ausschließlich der Industrie widmen, dann würde ganz Europa seine Fabriken aufgeben und England eine einzige große Fabrikstadt bilden, mit dem ganzen übrigen Europa als Ackerbauprovinz... Einmal der Getreidezoll abgeschafft, werden wir vom Ausland billigeres Getreide bekommen. Dann werden wir den Lohn herabsetzen". . mit den niedrigen Löhnen "werden wir den Kontinent schon zwinger. von uns zu kaufen." ${ }^{17}$ ) Die Argumentation bezieht sich also darauf, daB in Kontinentaleuropa und England die Produktivkraft der Arbeit in jeweils verschiedenen Branchen - hier in der Landwirtschaft, dort in der

auch nicht sämtlich darauthin noch umgearbeitet werden konnten. Da uns jedoch die Gesamtheit der im Aufsatz angestellten theoretischen Uberlegungen und empirischen Untersuchungen zu dieser These geführt haben, gehen wir davon aus, daß auch für den Leser Zusammenhänge sichtbar werden.

17) Rede über den Freihandel, MEW Bd.. 4, S. 445-46, vgl. auch: Theorien über den Mehrwert, MEW 26,2, $\$$, 474 ff. 
Industrie - relativ höher ist und daher der Austausch auf dem Weltmarkt zwischen den Ländern und Gebieten am günstigsten nach Freihändieraufw fassung, wenn jeweils die Waren für den Weltmarkt produziert werden, die komparativ "kostengünstiger" - infolge der relativ höheren Produktivität der Arbeit - produziert werden können. Die unterschiedliche Entwicklung der Arbeitsproduktivität ist hier allerdings nicht durch unterschiedliche Entwicklung des Kapitals in verschiedenen Industriezweigen, sondern durch Naturunterschiede gesetzt, welche vom Kapital selbst nicht übersprungen werden können. Während in der industriellen Produktion die Produktivkraft der Arbeit vom Produktionsprozeß des Kapitals selbst hergestellt wird, bilden natürliche Unterschiede in der landwirtschaftlichen Produktion Schranken für die Entwicklung seiner Produktivkrait. ${ }^{18}$ ) Eine weitere mögliche Schranke für die gleichmäßige Entwicklung der Produktivkraft innerhabb eines Landes besteht dann, wenn bestimmte Produktionszweige oder mögm liche Kapitalanlagesphären (Landwirtschaft, Handel, Dienstleislungssektor) noch nicht kapitalistisch betrieben werden.

Da die kleinbürgerlichen Schichten nicht zum Zweck der Kapitalverwertung, sondern zum Zweck der Bedürfnisbefriedigung produzieren oder zumindest sich noch in einer Zwischenstellung befinden, gilt für sie nicht, was Gesetz für das Kapital, daß nämlich tendenziell auf gleich große eingesetzte Kapitale gleiche Profitraten erzielt werden müssen. Als Gebrauchswertproduzenten (Warenproduzenten, welche ihre Waren produzieren und tauschen, um ihre Bedürfnisse zu befriedigen) unterliegen sie nicht den Gesetzmäßigkeiten der Kapitalakkumulation und fallen damit außerhalb der Tendenz zur Bildung einer Durchschnittsprofitrate. Da sich über diese Tendenz jedoch die Entwicklung der Produktivkraft in den verschiedenen Produktionszweigen gemäß dem jeweils historisch erreichten Stand der technischen Entwicklung durchsetzt, bleiben solche vorkapitalistisch betriebenen Produktionszweige in der Entwicklung der Produktivkraft der Arbeit zurück.

Lenin beschreibt in der "Entwicklung des Kapitalismus in Rußland" den Prozeß, wie, vermittelt über die Weltmarktbewegung des nationalen Kapitals, ungleichmäßige Entwicklungen innerhalb des Landes - der nichikapitalistischen Organisation einzelner Produktionszweige geschuldet - sogar var schärft werden:

"Die Fabrikanten brauchen den Markt sofort, und wenn die Rückständigkeit anderer Seiten der Volkswirtschaft den Markt im alten Geblet verengt", dann werden sie einen äußeren Markt suchen. „Der Prozeß der Bildung des Marktes im Kapitalismus hat also zwei Seiten: die Eniwicklung des Kapitaw lismus in der Tiefe, d. h. weiteres Wachstum der kapitalistischen Landwirtschaft und der Industrie auf einem gegebenen, bestimmten, in sich geschlossenen Territorium, und die Entwicklung des Kapizalismus in die Breite, d. h. Ausdehnung der Herrschaftssphäre des Kapitalismus auf neue Territorien ... Die Lösung der dem Kapitalismus eigenen und von ihm erzeugten Widersprüche wird dadurch zeitweilig hinausgeschoben, daß sich der Kam

18) Vgl. Kapital Bd, 3, MEW 25, S. 653 捧. 
pitalismus leicht in die Breite entwickeln kann. Das gleichzeitige Bestehen fortgeschrittenster Formen der Industrie und halbmittelalterlicher Formen der Landwirtschaft z. B. stellt zweifellos einen Widerspruch dar. Hätte sich der russische Kapitalismus nirgends über die Grenzen des Territoriums ausdehnen können ... dann hätte dieser Widerspruch zwischen der kapitalistischen Großindustrie und den archaischen Institutionen im Dorf ... rasch zur völligen Beseitigung dieser Institutionen, zur völligen Freilegung des Weges für den landwirtschaftlichen Kapitalismus in Rußland führen müsse." ${ }^{19}$ ) Die Zerstörung vorkapitalistischer Produktionsweisen in bestimmten Produktionszweigen findet also deshalb nicht statt, weil das Kapital durch die Möglichkeit,' auf dem Weltmarkt zu expandieren, nicht gezwungen wird, in den zurückgebliebenen Zweigen zu akkumulieren. Dies gilt nach Lenin allerdings auch für das Verhältnis verschiedener vom Kapital selbst betriebener Produktionszweige zueinander: "Die verschiedenen Industriezweige, die einander als ,Markt' dienen, entwickeln sich nicht gleichmäßig, sondern überflügeln einander, und die entwickelte Industrie sucht sich einen äußeren Markt. Es zeigt nur die Disproportionalität in der Entwicklung der einzelnen Produktionszweige. Bei einer anderen Verteilung des nationalen Kapitals könnte die gleiche Produktenmenge im Land realisiert werden. Damit jedoch das Kapital einen Industriezweig verläßt und sich einem anderen zuwendet, ist eine Krise in diesem Zweig notwendig, und welche Gründe könnten wohl die Kapitalisten, denen eine solche Krise droht, davon abhalten, einen ăuBeren Markt zu suchen. “ ${ }^{20}$ )

Lenins These von der über den Weltmarkt vermittelten Verschärfung der Ungleichmäßigkeit der Entwicklung der nationalen Kapitale kann hier deshalb nicht weiter verfolgt werden, weil sie genaue Uberlegungen zum Verhältnis der Bildung einer nationalen und einer internationalen Durchschnittsprofitrate erfordert. Dieses Problem haben wir bis jetzt aus der Analyse ausgeklammert, weil wir hier noch nicht zu schlüssigen Ergebnissen gekommen sind. Seine genaue Untersuchung wäre schon deshalb notwendig, weil nur über die Lösung dieser Frage geklärt werden könnte, wie sich die Modifikation der Durchsetzung des Wertgesetzes auf dem Weltmarkt nun wieder modifizierend auf die Durchsetzung des Wertgesetzes für das nationale Gesamtkapital auswirkt. Daß eine solche Modifikation stattfinden muß, ergibt sich daraus, daß Teile der nationalen Gesamtkapitale als Weltmarktkapital sich bewegen, andere Teile nur auf beschränkt nationaler Ebene agieren. Dabei ergeben sich für uns $z$. $B$. folgende Probleme:

1. die zurückgebliebenen nationalen Kapitale können nur unter der Bedingung mit den fortgeschrittenen Kapitalen auf die Dauer konkurrieren, daß sie höhere Profitraten und eine vergleichsweise größere (verglichen zum eingesetzten Kapital) Profitmasse erzielen, als die forgeschrittenen Kapitale. Dies ist Bindung dafür, daß sie den Fortschritt ihrer Konkurrenten in der Entwicklung der Produktivkraft der Arbeit aufholen. Ergibt sich daraus jetzt

18) Lenin, Werke Bd. 3, S.615.

20) ebda, 5. 54. 
eine ungleiche Entwicklung der Profitrate innerhalb des nationalen Kapitals, je nachdem, ob es auf dem Weltmarkt agiert oder nicht?

2. Die notwendigerweise niedrigere organische Zusammensetzung der zurückgebliebenen Kapitale müßte sich in einer höheren Profitrate für das eingesetzte Kapital auswirken. Demgegenüber verwertet sich die weniger produktive nationale Arbeit auf dem Weltmarkt als Arbeit von niedrigerem spezifischem Gewicht, verglichen mit der Arbeit des Landes, welches höhere organische Zusammensetzung des Kapitals aufweist. Was bedeutet das für die Durchschnittsprofitrate der Kapitale des zurückgebliebenen Landes, was für diejenigen, die auf dem Weltmarkt, was für diejenigen, die nicht auf dem Weltmarkt agieren? Gibt es überhaupt Unterschiede zwischen diesen Kapitalen?

3. Was bedeutet die Darstellungsform der unterschiedlichen nationalen Arbeitstage im unterschiedlichen Verhältnis der nationalen Währungen zum Weltgeld für das Verhältnis zwischen nationaler und internationaler Durchschnittsprofitrate? Da wir diese und andere in diesem Zusammenhang wichtige Fragen noch nicht gelöst haben, können wir auch keine stringente Darstellung des Verhältnisses von Ungleichmäßigkeit der Entwicklung innerhalb und zwischen den nationalen Kapitalen geben.

Geht man davon aus, daß durch die Weltmarktexistenz der nationalen Kapitale ungleichmäßige Entwicklungen der Produktivkraft der Arbeit innerhalb der nationalen Gesamtkapitale hervorgerufen oder verstärkt werden, so läßt sich folgende These formulieren, die durch die empirisctien Erscheinungsweisen des Prozesses der Weitmarktkonstituierung und die Formen der Weltmarktkonkurrenz belegt wird: Expandieren nationale Einzelkapitale in der Form von Waren- bzw. Kapitalexport auf dem Weltmarkt, so müssen diesem Export in der Regel Waren- bzw. Kapitalimporte entsprechen. Sieht man von Rohstoffimporten ab, also vom Import von Waren, die im Land selbst womöglich gar nicht produzlert werden können, so werden die Warenimporte vor allem mit den Waren der Produktionszweige konkurrieren, welche im Stand der Entwicklung zurückgeblieben sind, oder aufgrund höherer ,Lohn- oder Materialkosten' ihre Waren teurer verkaufen müssen. Der Import von Waren kann demnach zur progressiven Vernichtung zurückgobliebener Produktionszweige führen. Der ProzeB läuft auf die Ausbildung einer weltweiten Arbeitsteilung zwischen den kapitalistischen Ländern hinaus. ${ }^{21}$ )

Die Funktion des Wertgesetzes, das Kapital in die verschiedenen Sphären gemäß den Bedürínissen der Kapitalakkumulation zu verteilen, setzt sich dann auf Weltmarktebene in der Form der Ausbildung einer internationalen

21) So ist Z. B. die Zurückgebliebenheit der US-Textilindustrie bekannt, welche die Grundlage für japanische Konkurrenz bildet. Wio dies auf weltweite Arbeltsteilung hintendierte, wurde in den Verhandlungen zwischen TextilgroBindustriellen der USA und Japans deutlich: Das US-Kapital plante, sich in die japanische Textllindustrite einzukaufen und die Textilproduktion so schwergewichtig nach Japan zu verlagern. Die Produktivitätsentwicklung in der Textilindustrie stiog $(1962=100)$ bis 1967-68 in der EWG auf 120 , in den USA auf 110 und in Japan auf 148. Vgl.: OECD, Inflation, 1970, S. 105. 
Arbeitsteilung durch. Dies kann allerdings immer nur als Tendenz gelten, denn sobald es auf dem Weltmarkt nicht mehr um die Verteilung des Profits, sondern um die des Verlustes geht, entscheidet die Macht und die List, $d . h$. unter Weltmarktbedingungen auch die Politik der bürgerlichen Nationalstaaten, welche Kapitale vernichtet werden und welche überleben. Die Notwendigkeit des Rückfalls in den Protektionismus unter diesen Bedingungen wird die Tendenz zur Ausbildung einer weltweiten Arbeitsteilung aufhalten.

\section{4. Zur Empirle der Ungleichmäßigkeit}

Das hier zusammengefaßte empirische Material soll die theoretischen Überlegungen zur Ungleichmäßigkeit der Entwicklung illustrieren, wobei einige methodische Überlegungen vorangestellt werden müssen.

Dem Versuch, die Veränderungen der Wertbeziehungen auf dem Weltmarkt empirisch zu belegen, scheint entgegenzustehen, daß sich die Wertgröße selbst, als Resultat eines bestimmten, gesellschaftlich notwendigen Arbeitsquantums, gemessen in der Zeit, in den Warenpreisen, der Geldform der Warenwerte, nicht ausdrückt. An der Oberfläche erscheinen die Waren stets schon mit Preisen behaftet, die den Warenwert ideell in einem bestimmten Geldquantum vorstellen. Die Arbeitszeit als das "immanente Maß" des Warenwerts wird nicht dargestellt. Wie können somit Thesen, wie sie aus der Explikation der Modifikation des Wertgesetzes auf dem Weltmarkt resultieren, anders abgestützt werden als durch bloße Analogien anstelle von Erklärungen des inneren Zusammenhanges und seiner empirischen Erscheinungsformen?

So unüberwindlich diese Schwierigkeit auf den ersten Blick zu sein scheint, so sehr ergibt sie sich aus einer falschen Fragestellung. Denn der Sinn der Werttheorie besteht nicht darin, den Wert einer einzelnen Ware zu erklären, der in der Tat immer nur Marktpreis sein kann, also den Schwankungen von Nachfrage und Zufuhr unterworfen ist. Die Wertgröße schlägt sich also niemals exakt im Einzelpreis nieder. Zweitens resultiert aus der Notwendigkeit der selbständigen Darstellung des Warenwerts in einer Ware, die als allgemeines Aquivalent des Warentausches fungiert, die notwendige Verschleierung des "immanenten Maßes" der Warenwerte und ihre Darstellung in dem bloBen Quantum eines Dinges, dem Geld. Drückt der Preis also nur das Quantum der Geldware aus, welches im Austausch gegen die jeweilige Ware realisiert werden kann, so ist klar, daß der Wertausdruck stets nur relativer Wertausdruck sein kann. Als relative Wertausdrücke stellen die Preise jedoch nichts anderes dar als die quantitativen Austauschverhältnisse der Waren untereinander. Ausgehend von dieser Erkenntnis entpuppt sich das Problem der empirischen Verifikation der werttheoretischen Erklärung als Notwendigkeit (und Möglichkeit) der Darstellung und Vergleichung der relativen Preisentwicklung und damit der relativen Austauschverhältnisse zwischen den Warenverkäufern und -käufern. Hierbei geht es nicht darum, die Entwicklung der Produktivkraft der Arbeit zu einem bestimmten Zeitpunkt im Wertmaß Arbeitszeit exakt auszudrücken, sondern darum, die langfristige Verände- 
rung der Produktivkraft der Arbeit, wie sie sich in den Preisrelationen der verschiedenen Waren, sei es verschiedener Produktionszweige, sei es verschiedener nationaler Kapitale ausdrücken, darzustellen. Es wird hierbei nicht möglich sein, exakt zu unterscheiden zwischen solchen Veränderungen der Austauschrelationen, die allein der ,Inflation' geschuldet sind und solchen, die aus unterschiedlichen Entwicklungen der Produktivkraft der Arbeit resultieren. Festzuhalten ist, daß es zwischen den verschiedenen kapitalistischen Ländern unterschiedliche Inflationsraten gibt, die sich natürlich auf die internationalen Austauschrelationen auswirken. Wir können dieses Faktum hier nur konstatieren, ohne im einzelnen die Gründe der Inflation zu klären. Aber unabhängig von der Inflation ist in dem bislang Entwickelten klar geworden, daß die verschiedene Entwicklung der nationalen Produktivkraft der Arbeit und der Produktivkraft der Arbeit zwischen verschiedenen Produktionszweigen in einem Land sich niederschlagen muß in unterschiedlichen Raten der Preisentwicklung und damit in Verschiebungen der Austauschrelationen. Weil sich die Arbeitszeit als immanentes Maß also nur

1. in einem Quantum einer anderen Ware ausdrücken kann;

2. in Verschiebungen der Austauschrelationen ausgedrückt in den relativen Werten, den Preisen,

kann sich auch das immanente Maß des internationalen Austausches, die universelle Arbeltszeit nur so ausdrücken. Wir können deswegen - und jeder andere Versuch würde dem Sinn der Marx'schen Werttheorie diametral entgegenstehen - keineswegs in Arbeitsstunden die Größe dieser Maßeinheit pro bestimmter Warenmasse eines nationalen Kapitals angeben. Wir können allerdings anhand der Verschiebungen auf dem Weltmarkt die Veränderungen des Abstandes der jeweiligen nationalen Wertproduktion von dieser Maßeinheit angeben, die sich an der Oberfläche ausdrücken muß in Verbesserung oder Verschlechterung der Konkurrenzfähigkeit des jeweiligen Landes auf dem Weltmarkt.

Gehen wir nach diesen Vorbemerkungen dazu über, einige illustrierende Daten zur UngleichmäBigkeit der Entwicklung zusammenzustellen. Wenn wir für das Produktivitätswachstum die statistisch verfügbare Größe der "durchschnittlichen jährlichen Wachstumsrate des Bruttosozialprodukts pro Beschäftigtem" nehmen, dann ergibt sich für die wichtigsten Weltmarktländer folgendes Bild:

Durchschnittliche jährliche Wachstumsrate des Bruttosozialprodukts pro Beschäftigtem

\begin{tabular}{cccccccc}
\hline & USA & Canada & GB & Frankr. & Italien & BRD & Japan \\
\hline $1950-1955$ & 2,8 & 3,2 & 1,7 & 4,1 & 4,9 & 6,2 & 7,1 \\
$1955-1960$ & 1,2 & 1,2 & 2,4 & 4,5 & 4,2 & 4,5 & 7,9 \\
$1960-1965$ & 2,9 & 2,6 & 2,5 & 4,6 & 4,5 & 4,1 & 8,3 \\
\hline
\end{tabular}

Quelle: OECD, Policies for Economic Growth, Paris 1966, S. 16 
Die Zuwachsraten der Produktivität in den drei EWG-Ländern liegen im angegebenen Zeitraum regelmäßig über den Zuwachsraten in den USA und Großbritannien. Einen deutlichen Vorsprung in der EWG hat die BRD nur bis 1955. Japans Produktivitätswachstum übersteigt während des gesamten Zeitraums sowohl dasjenige der EWG als auch dasjenige der USA.

Der hier gewählte Index für die Produktivität umfaßt alle Sphären der Kapitalanlage. In Bezug auf die industrielle Entwicklung bestätigt sich allerdings das Bild:

$$
\begin{aligned}
& \text { Produktionsergebnis pro Beschäftigtem in der Industrie } \\
& \text { im Jahre } 1970(1967=100)
\end{aligned}
$$

\begin{tabular}{ccccccc}
\hline USA & Canada & GB & Frankr. & Italien & BRDa) & Japan \\
\hline 104,6 & 109,8 & 111 & 125 & 117,9 & 120,6 & 144,6 \\
\hline
\end{tabular}

Quelle: OECD, Economic Outlook, 9. Juli 1971, S. 74 f

a) Produktionsergebnis pro Beschäftigtenstunde

Und nehmen wir als letzte Vergleichsgröße die Wachstumsrate der Produktivität in der Maschinenbauindustrie, um das Bild abzurunden:

\section{Durchschnittliche jährliche Wachstumsrate der Produktivität der Maschinenbauindustrie, 1963 - 1968}

\begin{tabular}{cccccc}
\hline USA & GB & Frankr. & Italien & BRD & Japan \\
\hline 2,3 & 3,5 & 4,7 & 4,4 & 3,5 & 14,2 \\
\hline
\end{tabular}

Quelle: OECD, Inflation - the Present Problem, Paris 1970, S. 101

Geht man davon aus, daB die USA nach dem zweiten Weltkrieg einen bedeutenden Vorsprung vor den anderen kapitalistischen Ländern hatten, und das Japan das vergleichsweise zurückgebliebenste Land war, ${ }^{22}$ ) so zeigen

\footnotetext{
22) Angaben über den Antell der verschiedenen kapitalistischen Lỉnder an der kaplthlistischen Weltindustrleproduktion lassen Rückschlüsse auf die zurückgebliebene Situation Japans und Italiens nach dem zweiten Weltkrieg zu.

1950: USA 54,6, Canada 3,3, GB 11,6, Frankreich 4,3, Italien 2,5, BRD 6,6, Japan 1,6. 1968: USA 44,2, Canada 3,2, GB 7,4, Frankreich 4,3, Italien 3,7, BRD 8,8, Japan 7,6. Quelle: Aktuelle Probleme des Imperialismus, DWI Forschungshefte, 5. Jahrg., Hefl 1/1970. Rudi Gündel und Katja Nehls stellen dort in einem Aufsatz ,Zur Wirkungsweise des Gesetzes der ungleichmäBigen, sprunghaften ökonomischen und politischen Entwicklung der kapitalistischen Länder' ebenfalls eine Angleichungstendenz fest, obwohl sie sich dabei nur auf die Masse des produzierten Sozialprodukts beziehen und nicht die zugrundeliegenden Veränderungen in der Wertproduktion untersuchen; nur die Gebrauchswertseite des Prozesses - "Nivellieung des technologischen Niveaus" (S. 48) wird benannt; so gelingt es den 'Verfassern auch nicht, eine Vermittlung $z w i-$ schen den von ihnen benannten Nivellungsprozessen und den Währungskrisen zuf der Grundlage der Wertheorie zu finden.
} 
die langifristigen Trends eine deutliche Angleichungstendenz in der Entwicklung der Produktivkraft der Arbeit, welche auf elne Minimlerung des Produktivitätsvorsprungs der USA hinauslâuft.

Auf der Grundlage der vorangehenden methodischen Überlegungen über das Verhältnis von langfristigen Veränderungen in der Entwicklung der Produktivkraft der Arbeit und langfristigen Preisbewegungen, wollen wir jetzt am Beispiel Japans das Phänomen der UngleichmäBigkeit der Entwicklung zwischen den verschiedenen Produktionszweigen innerhalb eines Landes bei gleichzeitigen Angleichungsprozessen der Produktivkraft der Arbeit ans Weltmarktniveau zwischen den nationalen Kapitalen anhand der Preisbewegungen illustrieren.

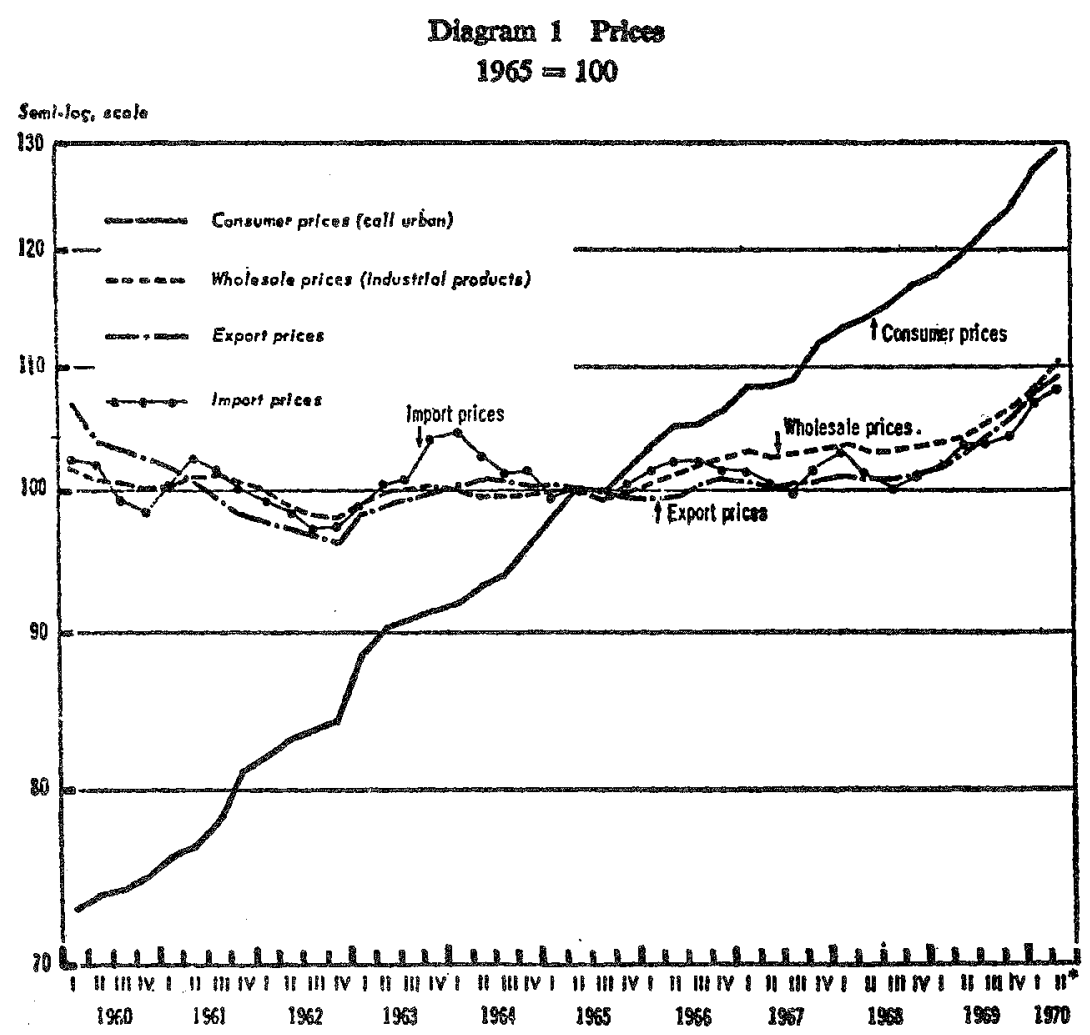

Source: Prime Ministers' Office and Bank of Japan.

Quelle: OECD Länderberichte, Japan, 1970, S. 7

Das Diagramm zeigt ein außerordentlich steiles Ansteigen der Verbraucherpreise bei nahezu gleichbleibenden Export- und GroBhandelspreisen (wholesale prices). Die Großhandelspreise umfassen die Preise für Industrlo- 
produkte, welche gleichzeitig die Waren sind , die auf dem Weltmarkt gehandelt werden. Der parallele Verlauf der Kurven der Export- und Großhandelspreise zeigt demnach an, daß Inlands- und Weltmarktpreise der Industriewaren annäherungsweise gleich sind. In Zahlen ausgedrückt besagt das Diagramm: Der Preisindex für Exportwaren lag 1960 bei 104.2, 1962 und 1963 sank er unter $100 \mathrm{ab}$, bewegte sich während der Jahre 1964 bis 68 um hundert und zeigte erst 1969 einen Anstieg auf 103,7, 1969 waren demnach die Preise der Exportwaren noch niedrger als 1960. Der Lebenhaltungsindex stieg demgegenüber von $74.0 \mathrm{im}$ Jahre 1960 auf $121.1 \mathrm{im}$ Jahre 1969. Davon lag der Index für Dienstlelstungen im Jahre 1969 bei 125.3, für landwirtschaftliche Produkte bei 128.1, für Baupreise bei $\left.134.4(1960=65.5) .{ }^{23}\right)$ Diese Preisentwicklungen zeigen außerordentliche Ungleichmäßigkeiten der Entwicklung der Produktivkraft zwischen Industrieproduktion auf der einen Seite, Bausektor, Dienstleistungssektor, Handel und landwirtschaftlicher Produktion auf der anderen Seite. Die hohen Produktivitätszuwachsraten in der industriellen Produktion, die auf eine Angleichung der Entwicklung der Produktivkraft der Arbeit an die fortgeschrittenen Länder hinausläuft, und die damit einhergehende Senkung der relativen Warenwerte dieses Sektors, fand keinen Niederschlag in einem dementsprechenden Sinken ihres Preisausdrucks. Das relative Sinken des Geldwerts spiegelt sich in den Sektoren geringer Entwicklung der Produktivkraft als hohe Preissteigerungsrate wider. Der Sachverständigenrat zur Begutachtung der gesamtwirtschaftlichen En!wicklung stellt in seinem Gutachten 1967/68 ähnliche, wenn auch unglsicn weniger scharf ausgeprägte Ungleichmäßigkeiten für die BRD fest. Die un Kapitalkosten bereinigte durchschnittliche jährliche Veränderung der Arbeitsproduktivität betrug in den Jahren 1960 - 65 für die Gesamtwirtschaft 2,5\%, für den Exportsektor demgegenüber 4,5\%. „Statt einer 2-prozentigen Senkung der Exportpreise, welche allein ein konstantes inländisches Preisniveau hatte garantieren können, fand eine durchschnittlich 2-prozentige Steigerung statt." ${ }^{24}$ ) Die gesamte inländische Preissteigerungsrate habe somit durchschnittlich 4 Prozent betragen. Sie erkläre sich zum einen daraus, daß auf Grund der Preiserhöhungen im Ausland die Exportindustrie nicht unter dem Zwang zur Preissenkung gestanden habe, daß zum anderen die Lohnerhöhungen in den unterschiedlich produktiven Sektoren nicht wesentlich voneinander abgewichen seien, was zu einer unterschiedichen Kostenentwicklung der einzelnen Sektoren mit der Folge unterschiedlicher Preissteigerungsraten geführt habe. ${ }^{25}$ )

Eine Korrelationsstatistik zwischen Preis- und Produkivitatsentuickingen verschiedener kapitalistischer Länder" ergibt für den Zeitraum 1955-1965 unterschiedliche Raten der Geldeniwertung und der Produktivitätsentwicklung von Land zu Land, wobei sich iolgende Beziehung hersielien läßt: Ein Land, welches In seinen Außenhandeisberoichen grutase Brodukivitätsfort-

${ }^{23)}$ OECD Länderberichte, Japan 1970, S. 30.

24) Sachverständigenrat zur Begutachtung der gesamiwirtschaftichen Entwioklums: Jahresgutachten 1967/68, Stuttgant 1067 (3. 209-210).

${ }^{25)}$ ebda S. $208 \mathrm{ff}$. 
schritte erzielt als das andere, zeigt ein stärkeres Ansteigen des Prelsniveaus in den Bereichen unterdurchschnittlicher Produktivitätsentwicklung (vor allem Dienstleistungssektor), welche nicht im internationalen Wettbewerb stehen. ${ }^{26}$ ) Dieser Zusammenhang drückt sich daher darin aus, daß die Unterschiede in den Bewegungen der industriellen Erzeuger- und der Großhandelspreise von Land $\mathrm{zu}$ Land geringer sind als die Unterschiede in den Steigerungsraten des Preisindex des Bruttosozialprodukts, wie folgendes Schaubild zeigt:

\section{EXPORT PRICES AND DOMESTIC PRICES}

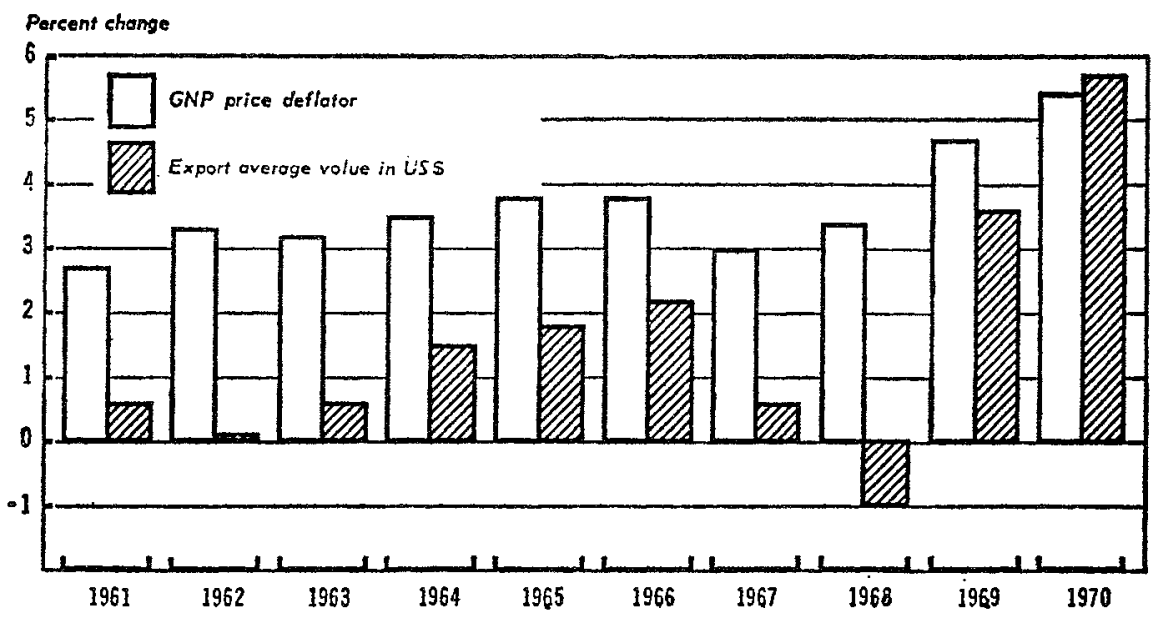

1) Gewichtet nach dem Anteil des Landes am OECD-Export.

Quelle: OECD, Inflation ..., S. 24.

28) ebda S. 214; zur Frage der importierten Inflation, die hier vom Sachverständigenrat angesprochen wird: vgl. Teil 2,1 und 2,2.

Eine Ubersicht in der Studie der OECD, Inflation, The Present Problem, Report by the Secretary General, Dezember 1970, über die unterschiedlichen Preissteigerungsraten der verschiedenen Sektoren in den einzelnen kapitalistischen Ländern bestätigt die These des Sachverständigenrats:

\section{Prelssteigerungen nach Sektoren}

Jährliche Durchschnittsraten 1958-1968

$\begin{array}{lccccc}\text { Land } & \text { Landwirtschaft } & \text { Industriewaren } & \text { Bausektor } & \text { Dienstleistungen } & \text { BSP } \\ \text { USA } & 0,9 & 1,1 & 5,2 & 2,6 & 2,1 \\ \text { GroBbritannien } & 0,3 & 2,1 & 3,5 & 4,5 & 2,8 \\ \text { Frankreich } & 2,6 & 2,5 & 4,8 & 5,1 & 3,9 \\ \text { BRD } & 0,1 & 1,8 & 4,4 & 4,2 & 2,8 \\ \text { Italien } & 1,9 & 1,8 & 6,1 & 5,1 & 3,7\end{array}$

Quelle: Vgl. oben, S. 60. 
Die Preissteigerungen des Bruttosozialprodukts liegen, zieht man einen Durchschnitt durch alle OECD-Länder, mit Ausnahme der letzten beiden Jahre weit über den Steigerungsraten der Exportpreise. (Dabei fällt auf, daß die Bewegung der Weltmarktpreise eine ausgeprägte zyklische Bewegung gegenüber derjenigen der BSP-Preise hat.) Im Widerspruch zu der langfristigen Bewegung steht jedoch die Preisentwicklung im Jahr 1969, vor allem aber im Jahr 1970.

Sie ist durch den ersten Boom der Weltmarkipreise seit der Koreakrise gekennzeichnet. Die OECD-Inflationsstudie erklärt dies aus der entscheidenden Rolle, welcher der Preisbewegung in den USA als dem Land mit dern größten Anteil am Welthandel für die internationale Preisbewegung zukommt: "So stiegen zwischen 1960 und 1968 die Exportpreise der OECDLänder mit einer jährlichen Durchschnittsrate von $0,75 \%$, verglichen mit $3,25 \%$ jährlichen Anstiegs des inländischen Preisniveaus. Während der ersten Hälfte der sechziger Jahre hatte die außerordentliche Preisstabilität der USA ohne Zweifel einen weitreichenden Preisdämpfungseffekt ... Dann aber stiegen die Exportpreise der USA 1966 sowie 1968 und 1969 scharf an. " ${ }^{27}$ )

Das folgende Schaubild zeigt die Bewegungen der Exportpreise in den Jahren 1960-70 in verschiedenen OECD-Ländern, die Aufschluß über die unterschiedliche Konkurrenzposition der verschiedenen kapitalistischen Länder auf dem Weltmarkt geben (vgl. dazu Teil 2, 2).

Die unterschiedlichen Kurven in nationaler Währung bei einzelnen Ländern (Frankreich, BRD, Canada, Beneluxländer und Großbritannien) erklären sich aus den Auf- bzw. Abwertungen der nationalen Währungen; (z. B. Großbritannien 1967: Pfundabwertung um 14,3\%; Frankreich 1969: Francabwertung um 12,5\%; BRD 1961: Aufwertung der DM um 4,76\% und 1969 um $8,5 \%$ ). Entscheidend für die Weltmarktposition ist also die Bewegung der "Durchschnittswerte der Ausfuhr" in Dollarpreisen. Auf- bzw. Abwertungen nationaler Währungen haben die Wiederangleichung der Exportpreise eines Landes an die Weltmarktpreise zum Zweck.

77) OECD, Inflation, a. a. O; S. 24, vgl. auch Sachverst"ndigengutachten $1967 / 68$, a. a. O. S. 202: "Für die ausiändischen Märkte sind di Dollappreise bedeutsam." 
IMPLICIT PRICE DEFLATORS AND EXPORT AVERAGE VALUES OF SELECTED OECD COUNTRIES OR AREAS

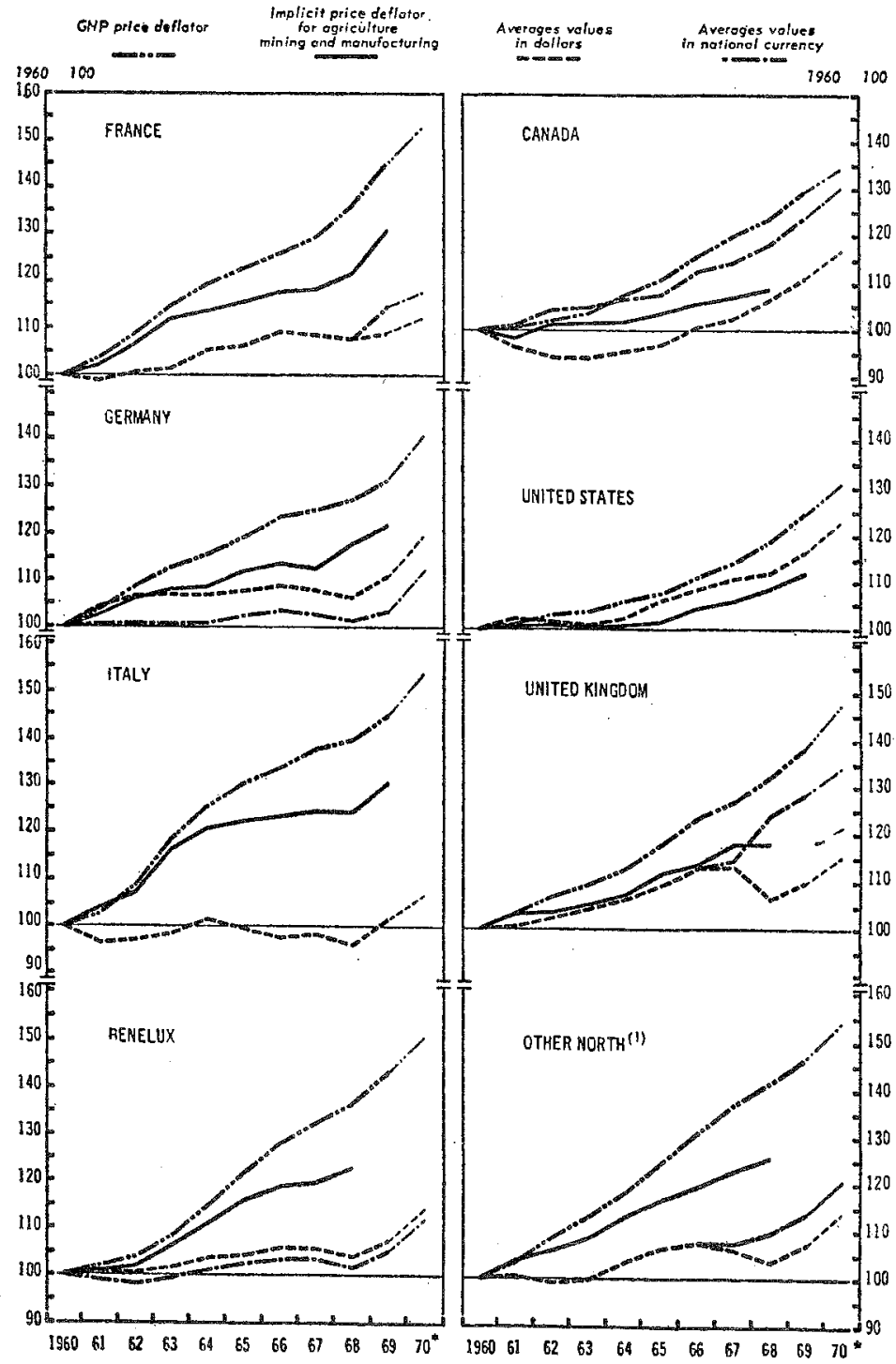

1. Austria, Denmark, Finland, Norway and Sweden.

* Secretariat estimates.

Quelle: OECD, Inflation ..., S. 67 


\section{Das Soulalistische Puro}

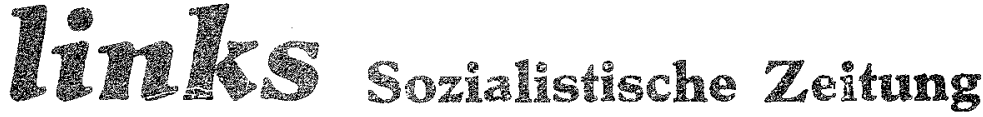

bringt monatlich auf ewwa 24 Seiten Aktionsmodelle, Beiträge zur sozialistischen Theorie und Strategie, Berichte aus der Linken international.

"links" ist illusionslos, undogmatisch - eine Zeitung für Theorie der Praxis und für Praxis der Theorle.

Einzelpreis DM 1,20

Bezugspreis, jährlich, DM $15,-$.

\section{Sozialistische}

\section{Retrobsererespondenz}

Sprachrohr der Kollegen und Genossen, die sozialistische Betriebsarbeit machen. Iniormationen über die Auseinandersetzung zwischen Kapital und Aroeit. Beiträge, die man nich in den Gewerkschaftszeisungen findet.

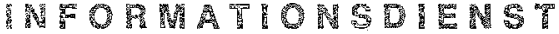

\section{des Soziantistschen Lehrerbundes}

Der Mormationsdienst soll dern Aubbau einer besseren Kommunikation unter den progressiven Lehrem in der Bundesrepublik dienen und erschein sechs Mal im Jahr.

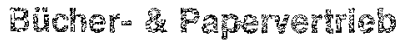

Schrifen fun die theoretische Arbeit, für Schulung, fur die Praxis in strategisch wichtigen Feldem, Erianrungsberichte ôthicher und projektbezogener Aktivitäten sic.

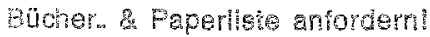

In? 
In Zahlen ausgedrückt ergibt sich zwischen $1960(1960=100)$ und 1969 eine Steigerung des Preisindex der Durchschnittswerte der Ausfuhr in Dollarpreisen für Frankreich auf ca. 108, für die BRD auf ca. 110, für Italien auf ca. 102, für die USA auf ca. 117, für Großbritannien auf ca. 110. Die Steigerung des Preisindex, ausgedrückt in nalionalen Währungen, betrug demgegenüber in Frankreich ca. 114, in der BRD ca. 103, in GroBbritannien ca. 127. Der vergleichsweise hohe Preisindex der westdeutschen "Durchschnittswerte der Ausfuhr", ausgedrückt in Dollarpreisen, erklärt sich aus der zweimaligen Aufwertung der DM seit 1960. Für die Konkurrenzposition der BRD im Vergleich zu anderen europäischen Ländern muß dabel allerdings beachtet werden, daß während der $50 e r$ Jahre die Preissteigerungsraten in der BRD unter denen der anceren europäischen Lënder lagen. ${ }^{29}$ ) Für die Periode 1955 bis 1965 läBt sich ,bel den exportierten Fertigerzeugnissen eine völlige Parallelität zwischen der westdeutschen und der ausländischen Preisentwicklung beobachten." Die durchschnittliche jährliche Steigerungsrate betrug in cer BRD sowie bei ihren Konkurrenzländern $1,4 \%$ innerhalb dieses Zeitraums. ${ }^{30}$ ) Da die USA in diesem Zeitraum unterdurchschnittliche, GroBbritannien und Frankreich demgegenüber überdurchschnittliche Preissteigerungen bei den Exportertigerzeugnissen zu verzeichnen hatten, muß für die BRD ein Konkurrenzvorsprung gegenüber den anderen europäischen Ländern angenommen werden.

Als Ergebnisse können wir festhalten:

(1) Die Walmarkigreism steigen weitaus geringer als die Preise des BSP (Ausnahme: Koreaboom und Preisboom auf dem Weltmarkt seit 1969).

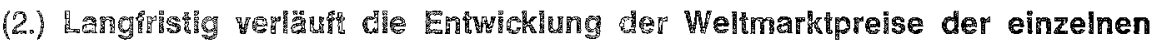

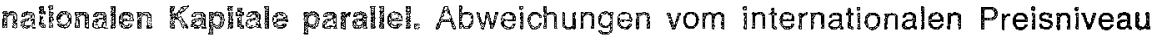
werden durch Auf- bzW. Abwertungen der nationalen Währungen früher oder später ausgeglichen.

28) In den "Durchschnittswerten der Ausfuhr" wird die Preisentwicklung mit den Mengen der exportierten Waren aus dem jeweiligen Berichiszeitraum gewichtet. In den "Exportpreis" indices dagegen werden die Preise mit den Mengen aus dem Basiszeirraum gewichtet. Dadurch können erhebliche Unterschiede zwischen diesen beiden Indices entstehen, insbesondere dann, wenn sich die Struktur der exportierten Waren veränderte und die Preisentwicklung einzelner Varengruppen unterschiedlich verläuft.

29) Vgl. Werner Hoimann, Die säkulare Inflation, Berlin 1962, S. 13. Zum Problem der Inflation, auch aû̂ internationaler Ebene, vgl. Heff $\mathrm{Nr} .2$ von "Critiques de l'économie Poltique": La Crise du Systeme monetaire International", Paris, Januar-März 1971. In dem Hett wird, ahnlich wie hier, versucht, die Weltwährungskise aus der Krise der Produktionsbedingungen herzuleiten. Allerdings ist es den Autoren nich gelungen, die Vermittung der Wertverhëlnisse zu den Geldausdrücken auf dem Weltmarkt aufzuweisen. Für sie wird diese Vermittlung, deren Nowwendigkelt sie natülich sehen, durch ökonomisch-politische Beziehungen der Dominanz der USA hergestellt. Diese Dominenz selbst ist nicht mehr auf hron Urspung reflektiert.

30) Sachversiandigengutachten $1967 / 68$, a. a. 0.9 .202$. 
Über die Entwicklung der Lage der Arbeiterklasse in den verschiedenen kapitalistischen Ländern erhalten wir aus der offiziellen Statistik nur ansatzweise Auskunft ${ }^{31}$ ).

Preis- und Lohnentwicklung in wichtigen Industrieländern, $1963=100$

\begin{tabular}{lcccccccc}
\hline Zeitraum & BRD & Frankreich & Italien & Grbr. & USA & Kanada & Japan \\
\hline \multicolumn{7}{c}{ Verbraucherpreise } \\
$1970(1 . \mathrm{Hj})$ & 120 & 129 & 127 & 133 & 125 & 125 & 142 \\
& Löhne (Bruttostundenverdienste in der & Industrie) \\
$1970(1 . \mathrm{Hj})$ & 165 & 169 & 178 & 150 & 135 & 153 & 192
\end{tabular}

Quelle: Sachverständigengutachten 1970/71, S. 176/177

Subtrahieren wir den Verbraucherindex vom Index der Bruttostundenverdieste, so erhalten wir annährungsweise Auskunft über die Reallohnentwicklung; (nur annäherungsweise deshalb, weil die relative Höhe und die Entwicklung der Belastung der Bruttolöhne durch Steuern und Sozlalabgaben hier nicht wiedergegeben wird). Die höchsten Zuwachsraten der Reallöhne ergeben sich für Japan und Italien ( 50 und $51 \%$ ), gefolgt von der BRD mit $45 \%$ und Frankreich mit $40 \%$. Nahezu stagnierend sind demgegenüber die Reallöhne in den USA. Sie stiegen in den letzten 7 Jahren nur um $10 \%$. Es ergibt sich daraus eine Tendenz zur Angleichung der Reallöhne zwischen dem fortgeschrittensten kapitalistischen Land (USA) und den zurückgebliebenen Ländern. Daß allerdings immer noch bedeutende Lohnunterschiede bestehen zeigt sich daran, daB das Lohnniveau in Japan um $80 \%$ unter dem in der BRD liegt.

Beziehen wir die vorläufigen Ergebnisse aus dem empirischen Material noch einmal auf die Kategorie der universellen Arbeit als Tauschabstraktion für die Waren, welche auf dem Weltmarkt gehandelt werden, zurück, so ergibt sich die Tendenz zur Durchsetzung des Wertgesetzes auf dem Welżmarkì als Kategorie der Zirkulation und Produktion. Die Produktionsbedingungen der Waren in den einzelnen kapitalistischen Ländern gleichen sich progressive aneinander an. Die gegenwärtige Weltwährungskrise muß in diesem Zusammenhang als Ausdruck der Krisenhaftigkeit des Prozesses der Durchsetzung des Wertgesetzes auf dem Weltmarkt angesehen werden.

31) Eine wirkliche Vergleichung der Lage der Arbeiterklasse in den verschiedenen ka. pitalistischen Ländern würde neben Angaben über Arbeitslohn und Arbeitszeit auch solche über Arbeitsunfälle, Berufskrankheiten, soziale Leistungen, Bildungswesen usw. erfordern. 


\section{Werigesetz und Wert der Währung}

\section{1. Wechselkurs als ,Preis" der Währungen}

Die Modifikationen der Durchsetzung des Wertgesetzes auf dem Weltmarkt schlagen sich - wie wir gesehen haben - in Preisbewegungen nieder. Die Art und Weise, in welcher die Waren auf dem Weltmarkt ihren Wert universell entfalten, muß sich niederschlagen in der Art und Weise, in welcher das Geld als die verselbständigte Wertgestalt der Waren sich auf dem Weltmarkt als Weligeld entfaltet. In seiner Funktion als aligemeines Wertmaß muß das Weltgeld auch die Modifikation des Wertgesetzes, d. h. der internationalen Warenwerte zum Ausdruck bringen. Das Verhältnis der nationalen Wertproduktion zur universellen Arbeit bedingt somit ein ganz bestimmtes Verhältnis der nationalen Geldform des Werts zum Weltgeld. Dieses Verhältnis ist in dem Begriff des Wechselkurses gefaßt, der zugleich die Oberfläche der vergangenen und gegenwärtigen Währungskrisen benennt.

In der Diskussion um die Dollar-Krise und ihre mögliche Beilegung scheint der Wechselkurs tatsächlich die Hauptrolle zu spielen. So konzentrierte sich z. B. die bürgerliche Presse - wie schon früher, so auch jetzt nach Nixons Maßnahmen - auf die Frage, welches System das bessere sei, das flexibler oder dasjenige fester Wechselkurse. ${ }^{32}$ ) Auch die Maßnahmen und Diskussionen der EWG-, „Zehner-Club“- und IWF-Konferenzen und der einzelnen kapitalistischen Staatne scheinen sich ausschließlich um das Problem gespaltener Devisenmärkte, um Auf- und Abwertung etc. zu drehen. Der Oberflächlichkeit der Debatten entspricht die Oberflächlichkeit der Erklärung des Problems der Wechselkurse in den Lehrbüchern der bürgerlichen Ökonomie. Dem Ratsuchenden wird der Wechselkurs schlicht als "der Preis je Einheit der Währung des Landes 1 (DM), ausgedrückt in Einheiten der Währung des Landes 2 (Pfund/Dollar)" definiert. Mit den Kategorien der bürgerlichen Preistheorie erklärt sich dieser Preis "aus dem Zusammentreffen von Angebot und Nachfrage am Devisenmarkt". ${ }^{33}$ )

${ }^{32}$ ) In einem "Lexikon der Währungskrise" erklärt die „Zeit" ihren Lesern ausschließ. lich Begriffe wie Floating, erweiterte Bandbreiten, gesaltener Devisenmarkt, Abwertung. Vgl. Die Zeit, Nr. 35, 27. 8. 71, 18.

33) Rolf Funck: Außenwirtschaft, in: Kompendium der Volkswirtschaftslehre, Band 2, S. 84 - Wir sehen hier davon ab, daß der Devisenmarkt selbst wiederum je nach Art der gehandelten Devisen unterteilt wird. Die Unterscheidung bezieht sich dabei wesentlich auf die Fälligkeit der gehandelten Devisen. Sofort fällige werden am „Devisenkassamarkt" gehandelt; zu einem späteren Zeitpunkt (etwa in drei Monaten) fällige Devisen am "Devisenterminmarkt". Die Kurse am Terminmarkt unterscheiden sich von denen am Kassamarkt durch Zuschläge bzw. Abschläge (Reports und Deports), je nachdem ob eine Kurssteigerung oder Kurssenkung der gehandelten Währung zum Termin erwartet wird. Da aber beide Kurse eng zusammenhängen, ist es für unsere Zwecke sinnvoll, von einem einheitlichen Devisenmarkt zu sprechen, um die Darstellung zu vereinfachen. Zur Technik des Devisenhandels vgl. Helmut Lipfert: Internationaler Devisen- und Geldhandel, Frankfurt 1967. Vgl, auch zur Technik der Swap-Geschäfie E. Altvater: Die Weltwährungskrise, Frankfurt 1969, S. 55 ff. 
Niemand scheint sich über den Tatbestand zu wundern, daß das Geld selbst Maß der Werte und Maßstab der Preise, oder in bürgerlichen Kategorien: "Recheneinheit" ${ }^{4}$ ) - einen Preis hat, der selbst wiederum nur in Geld ausgedrückt werden kann. Dieser irrationelle Ausdruck wird zunächst nur deswegen nicht zur Tautologie, weil es sich beim Wechselkurs um den Preis einer "Lokalform" des Geldes ausgedrückt in einer anderen Lokalform handelt. Diese Verschiedenheit der Lokalformen findet ihren Niederschlag in dem Begriffspaar "Geld" und "Währung" (AuBengeld). ${ }^{35}$ ) Aber diese bloße Unterscheidung der Form erübrigt nicht die Frage nach dem gemeinsamen Dritten, das diese verschiedenen Lokaliormen des Geldes vergleichbar macht.

Nehmen wir an, die verschiedenen nationalen Währungen seien bloBe Papiersymbole für Gold (Wertzeichen). Das Gold funktioniert als Wertmaß für die nationalen Währungen, miBt deren "Goldgehalt" und stellt ihn in einem bestimmten Coldquantum dar, dem Goldpreis der Währungen. in diesem Fall wird jede nationale Währung, tritt sie über die Grenze ihres Ceitungsbereiches, ihres Geldcharakters entkleidet Mag die DM oder das Pfund oder gar der Dollar innerhalb der Zirkulation des jeweiligen Landes noch so sehr als Geld in seinen verschiedenen Funktionen, $d . h$. auch als die einzige und allgemein gültige Inkarnation des gesellschaftlichen Fieichtums gelten, jenseits der Landesgrenzen stellen sie nur verschieden farbige Papierzettel dar, deren einziger "Wert" in Papier- und Druckkosten oder im "Sammlerwert" einer Kuriositäl bestent. Hier zeigt sich, daB das Papiergeld eben selbst nur Zeichen für Wert ist, $d . h$. auch das nationale Geld im Kern Weligeld sein muB, universelle "gesellschaftliche Materiatur des Reichtums" (MEW, 23, S. 157). Eine von dieser Notwendigkeit ausgeschlossene nationale Währung kann es nicht geben, solange jedes Land in irgendeiner Form am Weltmarkt teilhat, also der Durchsetzung des Wertgesetzes unterworfen ist. Mit der Durchsetzung des Wertgesetzes auf dem Weltmarkt setzt sich auch die Abhängigkeit des nationalen Geldes vom Weltgeld durch. ${ }^{36}$ ) Wir sehen hier zunächst von der Entwicklung des Geldwesens und den Mechanismen des internationalen Währungssystems ab.

Das Papiergeld als Wertzeichen fält, sofern es nicht als Symbol für Gold gilt, noch hinter die Stellung jeder ordinären Ware zurück, wall mit dem

34) Werner Ehricher: Geldtheorie, in Kompendium, Bd. 2, 5. 5 - George N. Halm (Geld, AuBenhandel und Beschäftigung, München 1957) spricht ebenfalss vom Geld als "Rechnungseinheit". Nach seiner Aufassung wird das Geld erfunden, um den Tauschverkehr zu erleichtern. Das Geld als Rechnungseinheit nennt or im gleichen Atemzug auch "Wertmesser", da nach Haim das Geld min der Basis "Preis des Geldes) ausgestattet alle Warenwerte als Vielfache von der Basis 1 miBo Welches Geld aber erhält nun im intemationaten Bereich die Dasiszint is?

s) Vgl. Albrecht Forstmann: Vokswirtschatiche Theorie des Geldes, Bd, 1, Berlin 1943 , S. 516 f.

4e) Vgl. Harald-Dietrich Kühne: Die Marxsche Theorle von der Funkton des Geldes als Weltgeld und deren Bedeutung fur die cestatung und Beurtelung der AuBenwirtschaftsprozesse in der Gegenwert, in: Aubenwirtschaft und Wachsum, Theopetieche Problem des okonomischen Wachstums-im Sozialismus und Faplandimus, Eand III. Berlin (DDP) $1968,3.155$ กิ。 
Verlust ihres Werts als Åquivalent die Papierzettel auch ihren Gebrauchswert, nämlich gegen Waren ausgetauscit werden zu können verlieren. Wenn sie jedoch gegen Gold - oder eine andere Währung - getauscht werden, erhält sich ihr Geldcharakter, den sie in der inländischen Zirkulation haben, durch Übertragung auf ein anderes Geldmedium. In diesem Austauschakt fungieren die Papierzettel als Waren ${ }^{37}$ ). Die DM oder der Dollar werden auf dem Devisenmarkt gegen andere Lokalformen des Geldes gehandelt, wobel wechselseitig die Währung die Stellung der Ware einnimmt, die gegen eine andere Währung getauscht werden soll, und die Währung ais Geld fungiert, in der der Wert der zu tauschenden Währung ausgedrückt wird. ${ }^{38}$ ) Beim Tausch gegen Gold ist klar, daß nur Gold die Stellung des Geldes einnehmen kann.

Wir haben es also formell mit einem ganz normalen Zirkulationsakt $W-G$ zu tun. Der DM-Besitzer präsentiert seine Ware auf dem Markt, dem Devisenmarkt; er "verkauft" eine bestimmte Summe DM und erhält vom Käufer eine bestimmte Summe Geld, Dollar oder Pfund oder Gold. Wodurch wird nun die GröBe der Geldsumme bestimmt die der Verkäufer für seine Ware erhält?

Wir wissen, daß Waren nicht ohne Preis auf den Markt kommen. In ihrem Preis wird ihr Wert zunächst nur ideell vorgestellt; der Preis bezieht sie auf das gegenüberstehende Geld (Gold), und zwar auf ein bestimmtes Quantum, als ihre reelle Wertgestalt ${ }^{39}$ ). Der Preis kommt also nicht erst zustande durch das zufällige Vergleichen einer bestimmten angebotenen Masse an Waren und einer bestimmten vorhandenen Masse an Geld. Scheint dies noch einsichtig bel ganz normalen Waren, so bereitet der gleiche Sachverhalt beim Geld, $d$. $h$. beim Austausch von nationalen Währungen einige Schwierigkeiten. Der DM-Besitzer wirft seine DM-Ware ja nicht auf den Markt und setzt aufgrund von Kostenberechnungen für die Produktion einer Einheit DM einen Preis fest, den er realisieren mag oder nicht, sondern tut dies, um eine bestimmte Summe anderer Währung zu erhaiten, die er benötigts um ein ganz bestimmtes Produkt, sagen wir eine Maschine, in einem anderen Land zu kaufen, um es zu importieren, oder sein Kapital zu "expor-

4) „Devisenmärkte habon aber die Eigentümlichkeif, daß die "Ware", die zum Kaug angeboten wird, Geld ist, so daß wir also Geld sowohl auf der Angebots- wie aut dar Nachfrageseite des Devisenmarktes finden". G. N. Halm, a. a. O., S. 125.

48) Im derzeitigen internationalen Währungssystem scheint der Charakter der Leit. währung Dollar darin auf, daB alle Währungen des IMF in einer Einheit Dollar ausgedrückt werden. Die Basiszahl 1 ist also ein Dollar (siche Anm. 34). In der Teminclo. gie von Halm: Der Preis des Standardgutes, in dem die Ware der anderor Güar (sprich Währungen) ausgedrückt werden, ist gleich 1. Ein Dollar war dann 1966 gleich 4,93706 Franc, gleich 625,000 Lire usw. Nur das britische Prund druckt sich nichl In einer Dollareinheit aus, sondern Dollars in einer Pfundeinhoit. In dieser tachnisch erscheinenden Regelung versucht Grobbritannien seinen Anspruch, selbst Leitwährungsland zu sein, zu erhalten. Da England aber diese Polle gar nicht spielen kann außerhalb des Stering-Blocks (vgl. Altvater, Währungskrise, $a_{0} a_{\text {. }} \mathrm{O}_{\text {. }} \mathrm{S}$. $49 \mathrm{fo}$ ) ist diese Umkehrung des relativen Wertausdrucks wirklich nur eine technische Belang losigkeit.

39) Kapital 1, 8. 2. O., S. 112 \%?. 
tieren", d. h. die Maschine nicht zu importieren, sondern nach dem Kauf im Ausland zu belassen, Arbeitskräfte dazuzukaufen und produzieren zu lassen, um einen Profit zu erzielen. ${ }^{40}$ ) Die Summe DM, die der DM-Besitzer auf den Devisenmarkt wirft, sehen wir einmal vom reinen Geldhandel ab, ist quantitativ bestimmt durch die Preissumme der Waren, die mit der gekauften Währung anderer Nationalität auf dem Weltmarkt gekauft werden sollen. Kauf und Verkauf von Währungen (Geld) sind somit zunächst quantitativ bestimmt von zugrundeliegenden Käufen und Verkäufen auf dem internationalen Warenmarkt. Angebot von und Nachfrage nach Währungen auf dem Devisenmarkt werden reguliert durch Angebot und Nachfrage auf dem internationalen Warenmarkt.

Wenn man davon ausgeht, daß die Bewegungen auf dem Devisenmarkt bloß "monetäre" Ausdrücke der Bewegungen auf dem Warenmarkt, d. h. der "realwirtschaftlichen internationalen Transaktionen" ${ }^{41}$ ) sind, begreift man das Geld zunächst nur in seiner Funktion als "Kaufmittel" (Zirkulationsmittel, Zahlungsmittel sofern es sich nur um einfachen Handelskredit dreht). ${ }^{42}$ ) Das Geld wäre dann auf dem Weltmarkt ebenso bloß verschwindende Wertgestalt, der Waren wie im Rahmen der nationalen Warenzirkulation .Es würde auschließlich in dieser Funktion des Vermittlers der Warenzirkulation existieren. Die Frage nach dem Wesen des Geldes, d. h. nach seinem eigenen Wert, aufgrund dessen das Geld selbst überhaupt nur WertmaB sein kann, tritt hinter die Betrachtung einer seiner Funktionen zurück. Auch die Tatsache, daß es sich bei dem im internationalen Rahmen gehandelten Geld bloß um Wertzeichen, nämlich Papiergeld handelt ${ }^{43}$ ) scheint zunächst unproblematisch. Denn solange der Handel floriert, hat zumindest der am Handel interessierte Warenbesitzer kein spezifisches Interesse am Geld als

$\left.{ }^{40}\right)$ Um Mißverständnisse zu vermeiden, sel betont, daß es sich bei dieser Darstellung um die Rekonstruktion des "Werts der Währung" handelt, nicht um die Darstellung 'der Überlegungen und Abläufe, die ein Waren- und Geldhändler anstellt, wenn er sich als Austauschender auf den Markt, hier den Devisenmarkt, begibt. Schließlich hat für inn in der Realität jede Währung einen durch den IMF festgesetzten Preis, den bis zur Einführung des Floating festen Wechselkurs. Unsere Frage ist jedoch, wie die Geldpreise (Währungsparitäten) zustandekammen und warum nach Jahren, in denen das Abkommen von Bretton Woods mit seinen festen Wechselkursen funktionierte, immer wieder Preisänderungen (Aufwertungen und Abwertungen) notwendig wurden, welche preis- und wertbestimmenden Momente also den Zwang zu Änderungen ausgeübt haben.

$\left.{ }^{41}\right)$ Funck, a. a. O., S. 83.

49) Der Begriff des "Kaufmittels" wird von uns hier für Zirkulations- und Zahlungsmittel gemeinsam verwendet, um den einfachen Handelskredit von den entwickelten Formen des Kredits abzugrenzen. Marx spricht beim Zahlungsmittel vom "ideellen Kaufmittel" (MEW 23, S. 150).

43) Die Definition der Devisen nach Lipfert (a. a. O., S. 44) lautet: „Devisen sind Ansprüche auf Zahlungen in fremder Währung an einem ausländischen Plaiz. Solche Ansprüche haben die Form von Guthaben bei ausländischen Kreditinstituten sowie von im Ausland zahlbaren Wechseln und Schecks, die auf fremde Währung lauten. Im Devisenverkehr zwischen Nicht-Banken und Kreditinstituten haben alle drei aufgeführten Formen von Fremdwährungs-Zahlungsansprüchen Bedeutung. Unter Ban. ken sind jedoch ausschließlich auf fremde Währung lautende Guthaben bei ausländischen Banken Gegenstand des Devisenhandels". 
Geld. Formelhaft stellt sich der Prozeß, wie wir inn bislang entwickelt haben, so dar:

Warenkäufer $A=$ Geldbesitzer von $\times D M$

kauft von Warenbesitzer B z Ware zum Preise von y $\$$

Warenkäufer $\mathrm{A}$

kauft auf dem Devisenmarkt y \$

verkauft auf dem Devisenmart $x \mathrm{DM}$

(DM als Ware, Geldware GW)

Dieser Abschnitt der Zirkulation lautet:

$$
G W-G-G-W
$$

Wenn vorausgesetzt wird, daß der Warenkäufer A selbst nur kaufen kann, weil er zuvor verkauft hat, dann stellt sich der gesamte Zirkulationsakt für $\mathrm{A}$ so dar:

$$
\begin{gathered}
W-G W-G-G-W \\
\text { Ware } \quad \begin{array}{c}
D M \quad \$-\$-W a r e \\
\text { Devisen- } \\
\text { markt }
\end{array}
\end{gathered}
$$

Es zeigt sich schon hier, daß der Preis der Währungen keineswegs aus Argebot und Nachfrage am Devisenmarkt abgeleitet werden kann. Vielmehr liegt das Spezifikum des internationalen Handels gerade darin, daß die Zirkulationskette $W-G-W$ nicht wie in der nationalen Zirkulation nur über den Warenmarkt, sondern außerdem über den Devisenmarkt als Zirkulationskette Ware - Geld, Geld - Devisen, Devisen - Ware vermittelt ist (vgl. auch Teil 3). Wir werden auf diese Komplizierung der Zirkulation auf dem Weltmarkt noch unter dem Aspekt der Weltmarktkrise zurückkommen. Dort kann auch geklärt werden, welche Bewegungen im internationalen Waren- und Geldkapitalverkehr sich in Angebot und Nachfrage auf dem Devisenmarkt niederschlagen und in der Zahlungsbilanz festgehalten werden.

Da die Preise der gehandelten Waren - wir schließen hier das Phänomen der Inflation aus - nur "Exponent der WertgröBe" (MEW, 23, S. 116), ideeller Geldausdruck des Wertes der Waren sind, sind die gehandelten Devisen ebenfalls quantitativ genau bestimmte Geldausdrücke der im internationalen Austausch zirkulierenden Wertgrößen. Da sich die Warenwerte stets nur als relative Wertausdrücke, d. $h$. eben als Preise, zueinander ausdrücken können, stellt auch der Preis der Währung, der auf dem Devisenmarkt den Austausch reguliert, nur einen relativen Wertausdruck dar. Wir wissen schließlich, daß der Preis zwar als Exponent der Wertgröße der Ware Exponent ihres Austauschverhältnisses mit Geld ist, daß aber deshalb noch keineswegs "der Exponent ihres Austauschverhältnisses mit Geld notwendig der Exponent ihrer WertgröBe ist" (MEW, 23, S. 116). Im Gegenteil. Gerade weil die 
Möglichkeit der quantitativen Inkongruenz von Preis und Wertgröße die adäquale Form ist, in der sich die Schwankungen der Wertverhältnisse durchsetzen können, wird der Preis vom Wert so lange abweichen, bis durch Veränderungen der Wertproduktion und dadurch der quantitativen Austauschverhältnisse der Waren als Gebrauchswerten sich der Wert (die gesellschaftlich notwendige Arbeitszeit) als Maß des Austausches durchetzt, d. h. WertgröBe und Preis identisch werden ${ }^{44}$ ). So wenig die Kategorien "Angebot" und "Nachfrage" den Gleichgewichtspreis auf den Warenmärkten erklären können, allenfalls die Schwankungen um diesen Punkt, so wenig können sie den Gleichgewichtspreis der Währungen, also ihren Wert, auf dem Devisenmarkt, $d . h$. den Wechselkurs einer Währung erklären, bei dem sich Angebot und Nachirage decken. Uber dieses Problem wird in der bürgerlichen Außenhandelstheorie elegant hinweggesehen. Zunächst abstrahiert man schlicht davon, daß der internationale Handel Warenhandel ist, also das Geld notwendig als Wertmaß auftreten muB und behandelt den internationalen Austausch der "Einfachheit halber" als "Naturaltausch". Dann aber erklärt man: "Sobald die Annahme aufgegeben wird, daß die internationalen Wirtschaftsbeziehungen sich in der Form des Naturaltausches volziehen, treten neben (!!) die realwirtschaftlichen internationalen Transaktionen solche monetärer Art". ${ }^{45}$ ) Sind die Geldbewegungen solchermaßen analytisch von den "realwirtschaftlichen Transaktionen" getrennt, fällt es nicht schwer, den Wechselkurs nur noch aus reinen Geldbewegungen (Angebot und Nachfrage auf dem Devisenmarkt) zu erklären und sogar einen Schritt weiter zu gehen: die Geldbewegungen umgekehrt aus dem jeweiligen Stand des Wechselkurses abzuleiten.

An der Oberfläche scheint eine solche Betrachtungsweise ihre Rechtfertigung zu finden. Das in der Zeit vor und nach Nixons Maßnahmen meist diskutierte Problem war die "internationale Spekulation". Jedermann erinnert sich an die auslösenden Faktoren der Krise um die DM-Aufwertung von November 1968 bis Oktober 1969 und die Freigabe des Wechselkurses der DM im Mai 197\%. Stets war es das "heiBe Geld" ("Dollarinvasion"), das in Erwartung einer DM-Aufwertung ins Land strömte. Hier handelte es sich in der Tat um Geldbewegungen, die rein aufgrund der erwarteten Veränderung des DMWechselkurses entstanden sind. Der Geldhandel war hier klein bloßer ReIlex des Warenhandels oder Geldkapitalverkehrs, sondern Geld wurde als Hare gehandelt (allerdings von Kapitalisten) zwecks Erzielung eines kurziristigen Profits in Form des sogenannten "Aufwertungsgewinns". Dies war jedoch nur möglich, weil die Wechselkurse sich selbst nicht mehr aufgrund von Bewegungen auf dem Devisenmarkt direkt bildeten, sondern fixiert waren. ${ }^{46}$ ) Notwendige Veränderungen der Wechselkurse, die aus langfristigen Verschiebungen des internationalen Austausches resultierten, konnten zum AnlaB von Bewegungen des "Spekulationskapitals" werden, sich in die Währung umzulauschen, deren, Wert" in absehbarer Zelt erhöht werden solite.

Magl Kaphel I Bber das Wentgesetz.

43) Funck, a. a. O.s. 83.

40) Siehe weiler unien die kurze Darsteilung des Systems von Eretten Woods. 
Aber bei genauerer Betrachtung zeigt sich, daß die Geldbewegungen nicht aus einer bestimmten Hohhe des Wrchselkurses resultierten, sondern auf-

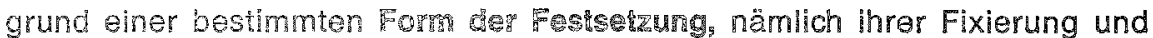
damit itrer Verënderung zu einem bestimmten, vorhersehbaren Zeitpunkt. Bevor wir das Problem der festen Wechselkurse weiter erörtern, wollen wir

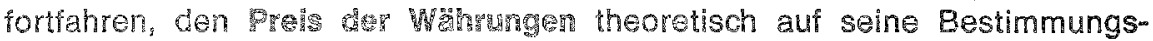
faktoren zurickzurühren.

Wir haben gesehen, wie der Preis der Währungen einen relativen Wertausdruck beinhaltet, nämlich den relativen Nertausdruck der international gehandelten Wertquanta (Waren/Geldkapilal). Wie geht dies vor sich?

Nehmen wir an, zwe Länder $A$ und $B$ treten in Handelsbeziehungen. Für die Export- und Imporbowegungen müssen - wenn nicht in Gold bezahlt wird die jeweiligen nationalen Währungen beschafft, auf dem Devisenmarkt gekauft werden. Wenn in Land A. (z. B. USA) die Waren zu relativ niedrigen Werten produzient und entsprechend relativ niedrigeren Preisen angeboten werden (also "billiger" sind) als in Land $B$, werden die Kapitalisten in Land $B$ versuchen, Waren in Land $A$ zu kaufen. Un die Waren bezahlen zu können, benötigen die Kapitalisten $B$ die Währung des Landes A. Die "Nachrage" nach Währung aus A (WA) steigt. Diese Nachirage ist Spiegelbild der Nachfrage nach Waren aus $A$. Diese Nachfrage nach Waren aus $A$ ist die Kehrseite des billigen Aagebole aus $A, d . h$. der Wertsumme ausgedrückt in Preisen der Waren A. Wir stellen fest: die Nachfrage nach WA ist hoch, das Angebot ist eine gewisse Zet knapp. Scheinhar ergibt sich aus dem Mechanismus von Angebot und Nachrrage auf dem Devisenmarkt eine Sreigerung des

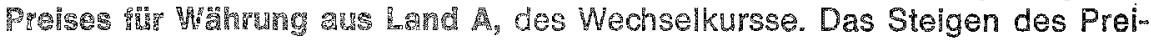
ses für WA resultiert jedoch nur formell aus den Bewegungen am Devisenmarkt. Re\&ll drückt sich in der Tatsache, daB für WA mehr Währung aus $B$ (WB) bezahit werden muB, nichts anderes aus, als daB mit ainer Einheit WA mehr Waren gekauit werden können als mir einer Einheit WB. Bei einem niedrigeren Preisniveau oder sinkenden Preisen in Land $A$ ist relativ weniger WA notwendig, un ane beshmmte Warenmasse zu zirkulieren oder - anders ausgedrückt - es können mit der gleichen Summe WA mehr Waren gekauft werden als vorher. Bei flexiblen Wechselkursen, d. h. bel einer direkten Verånderung des Prolses der Währung augrund von Preisveränderungen der Waren drück in gestiegener (oder gefallener) Wechselkurs nichts anderes aus als ein sirkendes (oder steigendes) Preisniveau in den entsprechenden Land. Wir wollen dies Comahaft verdeutlichen:

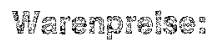
In Land A Ho Foll
5 5tuck Were $x=5$ Dollar
2. Fall S Stück Ware $x=4$ Dollar (Preissenkung)
In Land $B$ 1. Fall 5 shuck Ware $X=100 M$
2. Fall 5 stiol Mare $x=10$ DM (konstante Preise)

แด้

$$
\begin{aligned}
& \text { 1. Fall B Dollar = }
\end{aligned}
$$

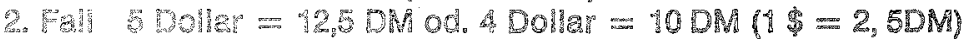


Diese Beziehung drückt einen Sachverhalt aus, den die bürgerliche Ökonomie mit dem Begriff des "Geldwertes" als Kaufkraft bezeichnet: "Der Geldwert, das heißt eine bestimmte Kaufkraft, ist mit Hilfe eines, typischen Warenbündels', das mit einer gewissen Geldsumme gekauft werden kann, meßbar. Der Geldwert hängt demnach von der einer konkreten Warenmenge gegenüberstehenden Geldmenge (oder umgekehrt) $a b "{ }^{47}$ ). Der so bestimmte "Geldwert" ist nicht nur selbst ein relativer Wert (Preis), sondern drückt die relativen Werte der Waren aus Land $A$ und $B$ aus ${ }^{43}$ ). Da der Wechselkurs stets bezogen auf eine Einheit einer Währung ausgedrückt wird, stellt er sich in unserem Beispiel dar als:

$$
\begin{array}{ll}
\text { 1. Fall } & 1 \text { Dollar }=2 \mathrm{DM} \\
\text { 2. Fall } & 1 \text { Dollar }=2,5 \mathrm{DM}
\end{array}
$$

Aligemein kann man festhalten: Der relative Wert einer Währung (Preis, Wechselkurs) fältt (steigt), wenn der relative Wert der Waren (die Preise) in dem entsprechenden Lande steigt (fällt).

Dem mit der Marx'schen Theorie vertrauten Leser wird auffallen, daß wir bislang mit zwei Voraussetzungen gearbeitet haben:

1. der Preis ist Exponent der Wertgröße der Waren, d. h. Wertgröße und Preise sind identisch;

2. das Geld dient rein als Rechengeld, als Maßstab der Preise. Es hat keinen eigeren Wert, der "Geldwert" drückt letztlich nur Warenwerte aus.

Die erste Voraussetzung ist hier unproblematisch, die zweite muß noch näher geklärt werden. Wenn wir vom Gold als Geldware ausgehen, dann ist klar, daß Gold einen eigenen Wert hat: Resultat der im Gold inkorporierten gesellschaftlich notwendigen Arbeitszeit. Dieser Wert des Goldes bestimmt ebenso wie die Werte der Waren die quantitativen Austauschverhältnisse $z$ wischen dem Geld und den Waren (d. h. die Preise) wie die so zustandegekommenen relativen Werte (Preise) den Austausch zwischen den einzelnen Waren regulieren ${ }^{49}$ ). Schon bei der Entfaltung der Äquivalentform wies Marx nach: "Sobald die Warenart Rock im Wertausdruck die Stelle des Aquivalents einnimmt, erhält ihre Wertgröße keinen Ausdruck als Wertgröße. Sie figuriert in der Wertgleichung vielmehr nur als ein bestimmtes Quantum einer Sache". (MEW, 23, S. 70) Der Wert des Geldes wird also in den relativen Wertausdrücken der Waren nicht ausgedrücki, dies kann nur geschehen, indem man die Formel

$$
X \text { Ware } A=Y \text { Pfund Gold }
$$

47) NZZ, 29. 8. 71. Es handelt sich um die Definition von F. A. Luiz.

48) Demgemäß definiert der bürgerliche Geldtheoretiker Forstmann die Währung als „die als Einheit aufgefaßte staatlich geordnete Geldverfassung im wertmäßigen Verw gleich zu denen anderer Nationalwirtschaften" (Forstmann, a. a. O., S. 257). Neuere bürgerliche Geldtheorien erklären diesen Geldwert auch als relativen Preis "im Rah. men des System der relativen Preise" (Ehrlicher, a. a. O., S. 43).

s9) Vgl. zum allgemeinen Verhältnis von Warenwerten und Geldwert unter dem Aspekt der allgemeinen Preisbewegung, Kapita! I, S. 114. 
rückwärts liest, also den Geldwert selbst in Warenwerten, d. h. relativ, ausdrückt (MEW, 23, S. 106). Der Geldwert wäre dann in einer pro Ware wechselnden, aber jeweils bestimmten Summe an Warenwerten ausgedrückt:

$$
1 \text { Pfund Gold }=Y \text { Ware } A \text {. }
$$

Nehmen wir an, 1 Maßeinheit der Währung des Landes A (1 WA) drücke ein bestimmtes Goldquantum aus (1 Pfund) und

$$
X \text { Ware } A=Y W A \text {, }
$$

dann würde sich der "Geldwert" von WA in Ware so ausdrücken:

$$
1 \text { Pfund Gold }=1 \text { WA }=X / Y \text { Ware } A \text {. }
$$

Wechselt nun der "Goldgehalt" der WA aufgrund von Münzfälschung oder staatlicher Festsetzung, sagen wir er sinke um die Hälfte, die Preise blieben aber konstant, dann ergeben sich folgende Relationen:

$$
\begin{aligned}
& X \text { Ware } A=Y \text { WA } \\
& 1 \mathrm{WA}=X / Y \text { Ware } A \\
& 1 \mathrm{Wa}=1 / 2 \text { Pfund Gold } \\
& 1 / 2 \text { Pfund Gold }=X / Y \text { Ware } A=1 \mathrm{WA} .
\end{aligned}
$$

Der Goldwert der Währung A wäre gefallen, ebenso der Goldpreis der Ware A. Aber da (aus Gründen, die wir hier nicht behandeln) die Preise - ausgedrückt in WA, $d$. $h$. in einem Wertzeichen, Papiergeld - nicht geändert wurden, ist als einziges Resultat der ganzen Entwicklung eine Verringerung des Quantums Gold festzustellen, welches durch eine Einheit des Papiergeldes repräsentiert wird. Dies kann innerhalb der nationalen Zirkulation so weit gehen - und historisch beschreibt es genau den Prozeß der Verdrängung des Goldes aus der Zirkulation und seine Reduktion auf die Funktion einer Minimalreserve -, daß die gesamte Papiergeldmasse, die im Lande zirkuliert, nur noch einen Bruchteil des Quantums Gold wirklich repräsentiert, den es nominal angeblich darstellt ${ }^{50}$ ). Das Repräsentationsverhältnis des Papiergeldes zum Gold wird, sofern das Papiergeld als Rechengeld und Zirkulationsmittel dient, ein rein ideelles. Soll der "Wert" dieses zirkulierenden Papiergeldes anders als in seinem Repräsentationsverhältnis zum Gold gemessen werden, so wird er in der Tat nicht anders meBbar sein als durch das Quantum an Waren, welches mit einer Einheit einer Währung (z. B. 1 DM) jeweils gekauft werden kann ("Kaufkraft des Geldes"). Diese Messung des Geldwertes bleibt die einzige, wenn das nationale Papiergeld in überhaupt keinem Repräsentationsverhältnis zu Gold mehr steht, die Konvertibilität des Papiers in Gold also - wie dies in Deutschland z. B. 1914 geschehen ist im nationalen Rahmen völlig ausgeschlossen wird. Solange die nationale Zirkulation reibungslos funktioniert, spielt dies auch keine Rolle. Es ist ganz gleichgültig, ob für eine bestimmte Warenmasse 1 DM oder 5 DM oder 20 DM

so) Vgl. Kapital I, S. $138 \mathrm{ff}$ - auch Alex Schubert: Warenzirkulation und Formen des Geldes, in SOPO, Nr. 5, 1970, S. $50 \mathrm{ff}$. - Dieser Übergang wird gemeinhin als Ubergang von der "Goldumlaufs" = zur "Goldkernwährung" bezeichnet. 
bezahit werden müssen, sich das MeB der preiss also andert. Hierür sind jedoch zwei Bedingungen einzuhalten:

1. innerhalb der nationalen Zirkulation muß die Verdoppelung oder Verdrel. fachung oder Halbierung des Paplergeldausdrucks alle Waren gleichzeitig treffen;

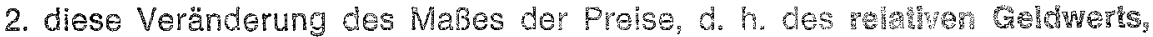
darf nicht kontinuierlich oder gar "galoppierend" stattinden. Ware eine sol che galoppierende oder auch nur schleichende infetion der Fall, dann würe

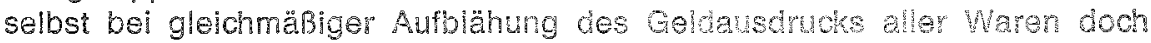
das Geld seiner Funktion als 2 ahm Schuldner allein durch Herauszögerung der Schubzahung in celoform real eine geringere Wertgröbe zurückahen als ar vom entubser ureprungich erhalten hatre. (Natülich ist es historisch eine nur wur wenge falle gülige Annahme, von einer gleichmäbigen Veränerung des coldausdrucks aller Waren auszugehen ${ }^{5}$ ). Uns geht es jedoh her um dis the? arte berstollung und Lösung der Frage des "Geldwerts").

3. auch international spielt die Veräncerung des "Ceidwortes" in Gestali der" Aufblähung des Papiergeldausdruckes keine Rolle ${ }^{52}$ ), soferm sich die Verär. derungen der "Kaufkraft" der Geldeinheiren in Verandemungen der wahsech kurse ausdrücken. Um dies an einem Beisple zu demonstrieren:
1. Fall
2. Fall

Wechsekurs:
1. Fall
2. Fall

$X$ Ware $A=10 D N$

$X$ Ware $A=1000 \mathrm{M}$

(gleichzeltige Verzehnfachung des Geidausdruckes tur alle Waren ohne Wertänderungt

$$
\begin{aligned}
& X \text { Ware } A=10 \mathrm{DM} \\
& X \text { Ware } A=5 \text { Dollar } 1 \text { Dollar }=2 \mathrm{DM} \\
& X \text { Ware } A=100 \mathrm{DM} \\
& X \text { Ware } A=5 \text { Dollar } \quad \text { Doller }=20 \mathrm{DM}
\end{aligned}
$$

Wenn die Wechsekurse sich nicht ändom, obwoh dios aurgme der Aur blähung des Geldausdruckes in einem Lande nötig wärs, kann dis "

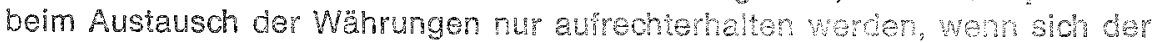
Geldausdruck in dem anderen Lande in gleichem Mase sublaks:

3. Fell

$$
\begin{aligned}
& X \text { Ware } A=400 \text { DH } \\
& X \text { Ware } A=50 \text { poler } 1 \text { Dollar }=2 \mathrm{DW} \\
& \text { Hesien Wochesture) }
\end{aligned}
$$

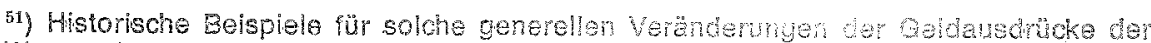

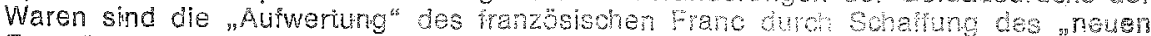

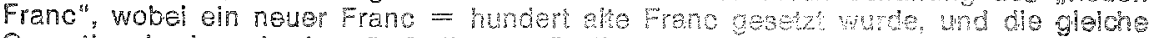

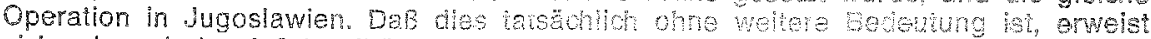

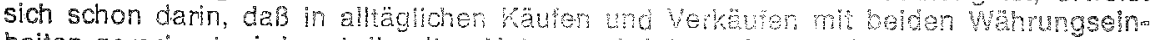
helten gerechnet wird und de ahen Noten auch intomehonal zirkieren.

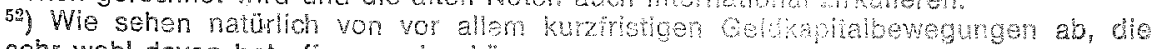
sehr wohl davon betrofer wergen kenen. 
In der Realität haben wir es jedoch im internationalen Verkehr mit einer unterschiedlichen Aufblähung des Geldausdruckes je nationalem Kapital zu tun. Im Zusammenhang mit der Frage des Wechselkurses interessiert uns dieses Phänomen unter dem Stichwort der "importierten Inflation". Im Gegensatz zum Problem der Inflation im nationalen Rahmen können wir hier wenigstens von einer Form der Gleichmäßigkeit ausgehen, nämlich von der gleichmäBigen Veränderung des Wertes des Geldes pro Land im internationalen Rahmen. Da der Wechselkurs den relativen Wert der auf dem Weltmarkt gehandeiten Waren eines Landes mim Durchschnitt darstellt, schlägt sich in ihm auch die durchschnittilche Veränderung des Geldausdruckes der Waren nieder. Wenn die Preise der einzelnen Waren national unterschiedlich steigen, so wird doch die Veränderung des Werts der Währung im internationalen Vergleich immer einen gewogenen Durchschnitt durch diese Preisveränderungen wiedergeben. Wir wollen hier - ohne Untersuchung der konkreten Gründe für einen inflalionären ProzeB - das Problem der importierten Inflation kurz abhandeln. Für unseren Zweck genügt es, die Inflation nur unter dem Aspekt der unterschiedichen Inflationsraten zu beirachten.

An der Oberfläche stellt sich die importierte Inflation dann so dar: Der Export der inflation aus einem Land in ein anderes ist nur möglich bel festen Wechselkursen. Wenn der Wechselkurs einer Währung zu einem bestimmten Zeitpunkt das Verhältnis der Preise der Waren in einem Land zu den Waren anderer Länder auf dem Weltmarkt ausgedrückt hat, dann wird, wenn die Preise in dem entsprechenden Lande gestiegen sind, der Geldwert sinken. Mit einer Einheit \$ z. B. kann jetzt weniger gekauft werden als zuvor. Dementsprechend müßte der internationale "Geldwer" fallen, der Wechselkurs. Ist dieser Wechselkurs jedoch fixiert, kann dieses Land mehr auf dem Weltmarkt kaufen, als entsprechend der tatsächlichen Relation der Warenwerte (und damit der relativen Geldwerte) möglich wäre. Es wird also mehr importieren. Höhere Importe in dem einen Land ziehen logischerweise höhere Exporte aus einem anderen nach sich. Dem exportierenden Land werden laufend Teile seines Wertprodukts entzogen. Aufgrund seiner gestiegenen Preise kann das Land mit der höheren Inflationsrate aber auf der anderen Seite weniger Waren auf dem Weltmarkt verkaufen. Was sich auf der Wert ebene als Wertübertragung von dem Land mit niedrigen in das Land mit hohen Inflationsraten ausdrückt, erscheint auf der Ebene der konkurrieren den Einzelkapitale als Verschlechterung der Konkurrenzposition der Kapitalisten des Landes mit höheren Inflationsraten. Auf dem Binnenmarkt geraten sie unter den Druck der ausländischen Konkurrenten, auf dem Weltmarkt werden sie ihre Waren aufgrund der, überhöhten Preise nicht mehr los. Die Zahlungsbilanz des Inflationslandes tendiert dahin, negativ zu werden, die der Länder mit geringeren inflationsraten tendieren zu hohen ubberschüssen der Zahlungsbilanz. Devisen werden laufend in ihre nationale Zirkulation gepumpt, die mitiels des Umtausches in nationales Geld die nationale Zirkulation erweitern, ohne daß der Erweiterung der Zirkulation eine entsprechende Steigerung des Wertprodukts entsprechen würde. Auf dieser Ebene wirken die Mechanismen von Angebot und Nachfrage. Die Nachfrage, aus- 
gedrückt in einer bestimmten Geldsumme (zahlungsfähige Nachfrage) steigt, das Angebot, ausgedrückt in einer bestimmten Warenmasse mit einer bestimmten Preissumme, bleibt zurück. Die Möglichkeiten, der gestiegenen Nachfrage durch eine Ausdehnung der Produktion zu begegnen, sind durch viele Faktoren bestimmt (Zyklische Bewegung, Kapazitätsauslastung, Profitrate). Wir wollen annehmen, die Produktion kann nicht ausgedehnt werden. Dann muß zum Ausgleich die Preissumme der nationalen Warenmasse steigen. Das Steigen der Preise in dem exportierenden Land bewirkt aber nun eine Umkehrung der Entwicklung auf der Ebene der Wechselkurse: durch das Sinken des relativen Geldwertes in dem exportierenden Land sinkt auch der internationale Geldwert der entsprecinenden Währung und die Kursrelationen der verschiedenen Währungen können bei einer Angleichung der Inflationsraten wieder reell zur Entsprechung der nominell fixierten Austauschrelationen der nationalen Währungen werden. (In der Realität findet diese Angleichung natürlich nur in längeren Perioden statt, so daß sich hierdurch Verschiebungen der Austauschrelationen zwischen den verschiedenen Ländern, z. B. eine anhaltende Exportsteigerung aus einem Lande, ergeben können.). Wir müssen aber davon ausgehen, daß in der Wirklichkeit der Prozeß so verlăuft, daß die Preissteigerungen des inflationåren Landes den sogenannten ,Preisspielraum' seiner Weltmarktkonkurrenten erhöht. Die Preissteigerungen, bzw. die höheren Inflationsraten in einem relevanten Weltmarktland führen - zumindest unter der Bedingung von Hochkonjunkturen - dahin, das Niveau der Weltmarktpreise insgesamt ansteigen zu lassen. Steigen aber die Preise der Welthandelswaren, so erst recht die der auf den ,lokalen Märkten' gehandelien Waren (vgl. Teil l, 4).

\section{2. Modifikation des Wertgesetzes und fixe Wechselkurse}

Wir haben gesehen, da $B$ bei flexiblen Wechselkursen die vergleichsweise größere Steigerung der Produktivkraft der Arbeit in einem Land, wenn sie sich in einem Fall der Warenpreise ausdrückt, den Preis der Währung dieses Landes in die Höhe treibt. Die Preissteigerung der Währung ist vermittelt über die vermehrte Nachfrage nach Waren aus diesem Land. Flexible Wechselkurse wären demnach der Geldmechanismus, über den sich die unterschiedlichen Gewichte der nationalen Arbeit aufgrund unterschiedlicher Produktivität gegenüber dem Weltmarktdurchschnitt darstellen. Das Steigen des relativen Wertes der Währung eines Landes A (Wechselkurs von WA) drückt sich darin aus, daß eine steigende Summe aller anderen Währungen pro Einheit WA auf dem Devisenmarkt bezahlt werden muß. Alle anderen Länder müssen, um Waren aus $A$ zu importieren, eine größere national produzierte Wertsumme (ausgedrückt in nationalem Geld) bezahlen. Die gestiegene Produktivkraft in A drückt sich in einem höheren für WA zu zahlenden Geldquantum aller anderen nationalen Währungen aus. (Der gleiche Effekt träte ein, wenn an Stelle verschiedener konvertibler nationaler Währungen allein Gold als Weltgeld fungieren würde. Die gestiegene Produktivkraft in Land $A$ würde sich dann in einem höheren Geldquantum ausdrücken, welches den Wert der Waren aus $\mathrm{A}$ zu realisieren hätte). 
Durch die Preissteigerung der Währung des produktiveren Landes würde sich dessen Arbeit nun als Arbeit von höherem spezifischem Gewicht auf dem Weltmarkt verwerten. Dies bedeutete aber gleichzeitig, daß der Konkurrenzvorsprung des exportierenden Einzelkapitals, welches Arbeit von höherem spezifischem Gewicht anwendet, wieder eingeschränkt würde. Die Erhöhung der Währungswerte würde wenigstens zum Teil die Verbilligung der Waren kompensieren.

Der Mechanismus, soweit er rein verläuft, würde - was die Konkurrenz der unterschiedlich entwickelten Kapitale auf dem Weltmaskt angeht - den Druck der Konkurrenz der entwickelteren auf die weniger entwickeiten nationalen Kapitale abschwächen. Er ließe ihnen Zeit, den Produktivitäisvorsprung der entwickelten Kapitale aufzuholen. Er garantierte gleichzeitig dem Gesamtkapital des entwickelteren Landes die Realisierung eines Extramehrwerts auf dem Weltmarkt.

Anders dargestellt: Es muß davon ausgegangen werden, daß sich der Zusammenhang der verschieden entwickelten nationalen Kapitale auf dem Weltmarkt darin ausdrückt, daß in der Tendenz gleiche Waren auf dem Weltmarkt gleiche Preise haben. „Die Dieselbigkeit des Markipreises für Waren derselben Art ist die Weise, worin sich der gesellschaftliche Charakter des Werts auf Basis der kapitalistischen Produktionsweise und überhaupt der auf Warenaustausch zwischen einzelnen beruhenden Produktion durchsetzt." (MEW, 25, S. 674). Sinken die Warenpreise der produktiven nationalen Kapitale gemäß ihrem gesunkenen gesellschaftlichen Wert auf nationaler Ebene, so liegen die Preise ihrer Waren unter den Weltmarktpreisen. Innerhalb eines nationalen Gesamtkapitals führte eine Preissenkung des produktiveren Kapitalisten dazu, daß die Kapitalisten des gleichen Produktionszweiges gezwungen wären, ebenfalls die Produktivkraft zu erhöhen. Gelingt ihnen das nicht, so würden sie über kurz oder lang pleite gehen, bzw. von den fortgeschrittenen Kapitalen geschluckt werden.

Die Tatsache nun, daß auf dem Weltmarkt zwischen dem Warenkauf und Verkauf der Kauf und Verkauf nationaler Währungen eingeschoben ist, bøwirkt, daß die Preissenkung der Ware durch eine Preiserhöhung der Währung vermindert werden kann, sich tendenziell über diesen Mechanismus a!so ein gleicher Weltmarktpreis herstellt, ohne daß sich die unierschiedlichen Niveaus der nationalen Produktivkraft der Arbeit angeglichen hälten.

Im folgenden wollen wir uns darüber klar zu werden versuchen, wie sich Ungleichmäßigkeiten der Entwicklung der Produktivkraft der Arbeit bei festgesetzten Wechselkursen auf die internationalen relativen Geldwerte der Währungen und auf die Kapital- und Warenbewegungen auf dem Weltmarkt auswirken. Nehmen wir zur Illustration die historische Entwicklung der Produktivkraft der Arbeit in der BRD bzw. in Japan. Sie ist in den letzten zwanzig Jahren schneller gestiegen als in den USA ${ }^{53}$ ). Für das Ausgangsstadium,

$\left.{ }^{33}\right)$ Für die folgenden Ausführungen gelte ndie methodischen Vorbemerkungen zum Teil 1,4: Empirie der Ungleichmäßigkeî́. 
in welchem die Wechselkurse gegeneinander festgesetzt wurden (Bretton Woods, 1944), muß eine höhere Produktivkraft der Arbeit in den USA angenommen werden. Die Arbeit in den USA stelle auf dem Weltmarkt Arbeit von höherem spezifischem Gewicht dar, sagen wir 1 Arbeitstag (AT) USA $=2$ AT universelle Arbeit (u. A.) ${ }^{54}$ ), die Arbeit in der BRD repräsentiere die Durchschnittsarbeit auf dem Weltmarkt, also 1 AT BRD $=1$ AT u. A. Arbeit in Japan verwerte sich unterdurchschnittlich auf dem Weltmarkt: 1 AT Japan = $1 / 2$ AT u. A. Nehmen wir weiterhin an, eine nationale Währungseinheit repräsentiere einen nationalen Arbeitstag und der Dollar fungiere als Weltwährung. Dann wären die Währungsparitäten folgendermaßen festgesetzt:

1 AT USA $=1$ Dollar $=2$ AT U. A.

$1 \mathrm{AT} B R D=1 \mathrm{DM}=1 \mathrm{AT}$ u. A. $/ 1 \mathrm{DM}=1 / 2$ Dollar $=50$ Cent

1 AT Japan $=1$ Yen $=1 / 2$ AT U. A. $/ 1$ Xen $=1 / 4$ Dollar $=25$ Cent

Sind nun die Währungsparitäten festgelegt, so muB sich nicht notwendig die Arbeit des nationalen Kapitals (BRD, Japan), welches gegenüber einem anderen nationalen Kapital (USA) einen gröBeren Fortschritt in der Entwicklung der Produktivkraft der Arbeit erreicht hat, als Arbeit von gestiegenem spezifischem Gewicht auf dem Weltmarkt verwerten. Zur Verdeutlichung der Herleitung nehmen wir noch hinzu, daß sich die unterschiedliche Produktivkraft der nationalen Arbeitstage in unterschiedlichen Warenmassen ausdrückt.

Ausgangssituation:

10 AT USA $=10$ Dollar $=20$ AT is. A. $=2$ Maschinen

$10 \mathrm{AT} B R D=10 \mathrm{DM}=10 \mathrm{AT}$ u. $\mathrm{A} .=1$ Maschine $/ 10 \mathrm{DM}=5$ Dollar

Steigerung der Produktiykraft in der BRD bei festen Wechselkursen:

10 AT USA $=10$ Dollar $=18$ AT u. $A_{0}=2$ Maschinen

$10 \mathrm{AT} \mathrm{BRD}=10 \mathrm{DM}=13,5 \mathrm{AT}$ u. $\mathrm{A} .=1,5$ Maschinen $/ 10 \mathrm{DM}=5$ Dollar

Durch die Steigerung der Produktivkraft der Arbeit in der BRD verändert sich das Verhältnis der nationalen Arbeitstage zu universellen Arbeit als ihrem Durchschnitt (USA: 20 zu 18 AT u. A., BRD: 10 zu 13,5 AT u. A.) Sinkt aber in der BRD der Preisausdruck der Einzelmaschine gemä $\beta$ der gestiegenen Produktivkraft, so findet bei festen Wechselkursen das veränderte Verhältnis der nationalen Arbeitsiage zueinander keinen Geldausdruck im Verhältnis der Währungen zueinander. Der produktivere Arbeistag der BAD verwertet sich jetzt auf dem Weltmarkt nicht höher, als vorher der weniger produktive. Im Prozeß $B$ des Austauschs fände eine Wertübertragung zugunsten der USA statt, was darin seinen Ausdruck fände, daß die USA jetzt in der BRD mehr Maschinen für das gleiche Geld kaufen könnten, während die BRD im AuBenhandel mit den USA keinen Vortell von ihrer gestiegenen Produktivkraft hätte. Für 10 Dollar $=20$ DM kann die USA in der BRD

54) Zur Verdeutlichung der Herleitungen verwenden wir im folgenden Zahlenmodelle, die sich an die wirklichen Bewegungen anlehnen, jedoch, was die Zahlenverhälthisse angeht, nicht den gringsten Anspruch auf empirische Richtigkeit orheben. 
3 Maschinen kaufen. Für $20 \mathrm{DM}=10$ Dollar kann aber die BRD in den USA nach wie vor nur 2 Maschinen kaufen. Die BRD-Produzenten verkauften ihre Waren in den USA unter, die USA-Produzenten verkauften ihre Waren in der BRD über internationalem Wert ${ }^{65}$ ).

Die nationalen Gesamtkapitale betrachtet, stellt sich der Prozeß als Wertübertragung dar. Wie sieht er aber aus, wenn wir inn aus der Perspektive der konkurrierenden Einzelkapitale betrachten? Die BRD-Warenexporteure erhielten einen bedeutenden Konkurrenzvorsprung auf dem US-Markt durch den gesunkenen Preis ihrer Waren. Die US-Kapitalisten ständen unter verschärftem Konkurrenzdruck der BRD-Kapitalisten, sowohl was den Binnenmarkt der USA angeht, als auch was den US-Warenexport in die BRD betrifft. Die USA-Produzenten müBten ihre Produktivkraft weiterhin steigern, um die Preise gemäB den Preissenkungen der BRD-Korkurrenten herabsetzen zu können. Gelingt dies nicht, so würde zunächst die USA-Handelsbilanz negativ, in den USA fände progressive Kapitalvernichtung statt, trotz fester Wechselkurse müBten die USA den Dollar früher oder später abwerten, bzw. die BRD müBte die DM aufwerten.

Der gleiche Prozeß allerdings, welcher das BRD-Exportkapital begünstigte und den Warenimport aus den USA beschränkte, würde sich als Anzeiz zum Kapital- statt Warenexport für das US-Kapital auswirken. Der Preis von zwei Maschinen beträgt in den USA 10 Dollar; tauscht nun der US-Kapitalist diese 10 Dollar in DM um, so erhält er $20 \mathrm{DM}$, den Preis von drei Maschinen für das BRD-Kapital. Da der US-Kapitalist - läßt er sein Kapital in der BRD fungieren - nun auch durch "Import" von know how, d. h. technologischer und organisatorischer Verbesserungen sowie fortgeschrittenerem fixen Kapital Arbeit höherer produktiver Kraft anwendet, die Arbeitslöhne in der BRD jedoch aufgrund des immer noch bestehenden Abstands zwischen Produktivkraftentwicklung in den USA und in der BRD niedriger liegen werden, so ist für ihn der Kapitalexport nicht nur günstiger als der Warenexport, er macht jetzt zusätzlich gegenüber dem BRD-Kapitalisten einen Extraprofit. $\mathrm{Da} B$ er einen Extraprofit macht, gilt auch für den Fall, daß die Währungsparitäten die modifizierten Wertbeziehungen richtig wiedergeben. Kapitalexport wird dem US-Kapitalisten einen höheren Profit bringen als Warenexport, unabhängig davon, ob die Währung seines Landes überbewertet ist oder nicht. Im Falle der Überbewertung würde der Kapitalexport forciert. Der Akkumulationsprozeß $B$ des Kapltals hätte dann dle Tendenz, sich in das Land zu verlagern, dessen Währung unterbewertet ist, solange dem Kapitalexport keine gesetzlichen Schranken von Seiten der US- bzW. BRD-Staats-

53) BRD-Maschinen kosteten in den USA jetzt 6,70 Dollar, auf dem BRD-Markt verkauft: 13,30 DM. Nach wle vor verkauften die US-Produzenten aber ihre zwei Maschinen für 20 DM auf dem BRD-Markt, für 10 Dollar auf de mBinnenmarkt der USA. Es zeigt sich hier, daß ungleiche Veränderungen der Produktivkraft der Arbeit, sofern sie sich nicht in Währungsparitätsänderungen niederschlagen, die gleichen Auswirkungen auf die Konkurrenzposition der nationalen Kapitale auf dem Weitmarkt haben, wie ungleiche Inflationsraten der einzelnen Länder. Vgl. dazu Teil 2,1. Wir werden darauf am Ende dieses Tells noch einmal gründlicher eingehen. 
gewalt gesetzt würden. Die Verlagerung des Akkumulationsprozesses schlägt sich in Zahlungsbilanzungleichgewichten, in unserem Beispiel in einem Defizit der US-Zahlungsbilanz, nieder.

Betrachten wir die historische Entwicklung, so zeigt sich allerdings, daß zwar das BRD-Kapital gröBere Fortschritte in der Produktivkraftentwicklung zu verzeichnen hatte als das US-Kapital, daß aber seit dem Wiederaufschwung des Weltmarktes nach dem zweiten Weltkrieg kelme Prelssenkungen sondern langfristig parallellaufende, wenn auch geringe Pressteigerungen der Weltmarktwaren in den verschiedenen kapitalistischen Ländern stafttinden $\left.{ }^{66}\right)$. Dies bedeutet nichts anderes, als daß die Steigerung der Produktivkraft der Arbeit im Geldausdruck der Weltmarktwaren keinen Niederschlag gefunden hat. Bleibt im oben dargelegien Fall der Preisausdruck der BPDEinzelware und der Preisausdruck der US-Einzelware konstant, trotz ungleicher Veränderung der Produktivkraft, so tauschen USA und BRD ihre

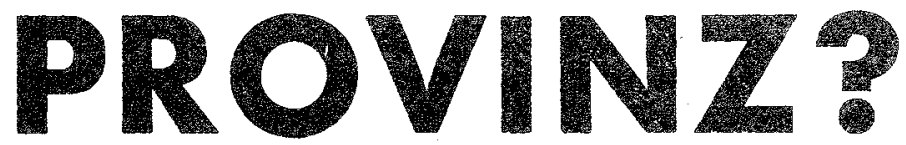

\section{MACHT NICHTS!}

wir versenden unser ganzes sortiment bis ins letzte dorf. ab $\mathrm{dm} 30,00$ sogar portofrei!

prospekte, neuerscheinungsankündigungen, versandlisten - unter besonderer berücksichtigung der nach- und eigendrucke sozialistischer gruppen, linker kleinverlage usw. - erscheinen laufend neu.

bitte anfordern!

\section{POLITLADEN}

BUCHHANDLUNG \& VERLAG GMBH

852 ERLANGEN

Hindenburgstr. 17

Tel.: $09131-25743$

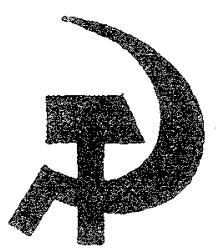

BUCHER - ZEITSCHRIFTEN - AGTTATONSMATERIAE

58) Ausnahme: Koreaboom und Preisboom auf dem Weltmarkt seit 1969, vg: Tell $1,4$. 
Waren zu internationalen Werten aus. 1,5 Maschinen aus der BRD hätten dann einen Preis von $15 \mathrm{DM}=7,50$ Dollar, was genau dem Preis von 1,5 Maschinen, produzlert in den USA, entsprechen würde. Eine längerfristig gleichlaufende Preiserhöhung führte genausowenig zu einer Unterbewertung der Währung des Landes mit größeren Produktivitätsfortschritten, wie konsiante Preise (vgl. Teil 2, 1). Sie bedeutete nur eine noch größere Aufblähung des Geldausdrucks der universellen Arbeit und der nationalen Arbeitstage als in dem Fall, daß die Preise bei Produktivitätsfortschritten konstant bleiben ${ }^{57}$ ).

Produktivkraft steigt stäker in BRD als in USA:

\begin{tabular}{lll|l}
\hline $\begin{array}{l}\text { Wechseikurs } \\
\text { konstant }\end{array}$ & $\begin{array}{l}\text { Preis der } \\
\text { Einzelware konstant }\end{array}$ & $\begin{array}{l}\text { Preis } \\
\text { sinkt }\end{array}$ & $\begin{array}{l}\text { Preise } \\
\text { steigen parallel }\end{array}$ \\
\hline & $\begin{array}{l}\text { Ware zu int. Wert } \\
\text { verkauft }\end{array}$ & $\begin{array}{l}\text { Ware unter int. Wert } \\
\text { verkauft }\end{array}$ & $\begin{array}{l}\text { Waren zu int. Werten } \\
\text { verkauft }\end{array}$ \\
\hline
\end{tabular}

57) Diese internationale Aufblähung des Geldausdrucks der Waren (Inflation) hat natürlich ihre Rückwirkungen auf das Repräseniationsverhältnis der nationalen Währungen und des Weligeldes Dollar zum Gold (sieh日 dazu Teil 2.1). Die feste GoldDollar-Parität von 1 Unze Gold $=35$ Dollar wird in dem Maße fiktiv, wie die Minderung des relativen Werts einer Einheit Dollar aufgrund von inflationären Prozessen fortschreitet. Diese Entwertung des Dollar (und damit aller anderen Währungen) gegenüber dem Gold wird besonders von DDR-Theoretikern betont, die von einem Auseinanderklaffen von konstanter Goldparität und effektivem Goldgehalt der Währungen, $d$. $h$. einer permanenten Verletzung der Repräsentationsgesetze und einer ungesunden Aufblähung des internationalen Kreditsystems sprechen (vgl. Kühne, a. a. $0 ., S .164)$. Falsch ist allerdings der direkte Zusammenhang, der von Kühne zwischen der Minderung des Goldgehaltes der Währungen und dem steigenden Preisniveau konstruiert wird. Wir sind der Ansicht, daß es sich genau umgekehr verhält. Die Aufblähung des Geldausdrucks der Waren (Infilation) führt zu einer Entwertung der Währungen und damit erst zu einer Senkung des Goldgehaltes, und nicht umgekehrt die Senkung des Goldgehaltes zu einer Steigerung der Preise. Der Ruf der südafrikanischen Goldproduzenten nach einer Goldpreissteigerung ist somit keine böswillige Marotie, sondern notwendiger kapitalistischer Ausdruck der internationalen Inflation. Mit Sicherheit konnte die feste Dollar-Gold-Parität, $d$. h. der feste Dollarpreis des Goldes, angesichts der weltweiten Inflation nur aufgrund der unwahrscheinlichen Ausbeutungisraten in den südafrikanischen Goldminen, d. h. auf dem Rücken der im Zustand von Sklayen gehaltenen schwarzen Arbeiterklasse, aufrechterhalten werden. Im übrigen würden sich Produktivitätsfortschritte in der Goldproduktion nicht in einer entsprechend höheren Verwertung des Goldproduktes auf dem Weltmarkt auswirken, sondern sich - da die Fixierung des Goldpreises angesichts der allgemeinen Inflation einer Goldpreissenkung gleichkommt - bei fixiertem Wechselkurs des Rand (südafrikanische Währung) gegenüber dem Dollar in Wertübertragungen auf die Dollarbesitzer auswirken. Schon von daher besteht kein Interesse der Goldproduzenten, die Produktivităt der Arbeit und hierdurch die Masse des produzierten Goldes zu steigern. (Vgl. zu den "Klagen der Goldlobby" über den zu niedrigen Goldpreis, Wirtschaitswoche, N. 38 vom 17. 9. 1971, S. 16). Dio einzige Möglichkeit, den Ausstoß der südafrikanischen Goldminen zu erhöhen, besteht also in der extensiven Ausbeutung dei schwerzen Arbeitskraft. 
Welche Auswirkungen haben nun konstante Preise, bzw. international langfristig parallellaufende Preissteigerungen bei unterschiedlichem Wachstum der Produktivkraft der Arbeit für die Profitratenentwicklung der nationalen Kapitale? Findet für die Waren des nationalen Einzelkapitals, welches einen vergleichsweise größeren Produktivitätsfortschritt gemacht hat, keine Preissenkung statt, $d$. $h$. ist es nicht durch die Weltmarktkonkurrenz gezwungen, den Preis der Ware unter inren internationalen Wert zu senken, so realisiert das Einzelkapital einen Extramehrwert, was sich - bleiben wir bei unserern Beispiel - als Verbesserung der Verwertung und damit der Akkumulationsmöglichkeiten der BRD-Exportkapitale gegenüber den US-Exportkapitalen auswirken muß. Hier liegt ein entscheidender Unterschied zu dem Fall, daß sich die Erhöhung der Produktivkraft der nationalen Kapitale als Wechselkursänderung, $d . h$. in unserem Beispiel als Erhöhung des relativen "Wertes" der nationalen Währung ausdrückt. Denn in diesem Fall verwertet sich die von den Exportkapitalen angewandte produktivere Arbeit als nationale Gesanitarbeit von höheren spezifischem Gewicht auf dem Weltmarkt. Die Voraussetzung für die Wechselkursänderung ist, daß der produktivere Kapitalist

\title{
Die Wissenschaft von der Wissenschaft
}

\author{
PHILOSOPHISCHE PROBLEME \\ DER WISSENSCHAFTSTHEORIE
}

gemeinschaftsarbeit eines kollektivs am institut für philosophle der karl marx-universität leipzig, 1968

340 seiten - format din a $5-8,00 \mathrm{dm}$

wissenschaftstheoretische fragen nehmen in der auseinandersetzung mit der bürgerlichen wissenschaft einen immer wichtigeren platz ein. wissenschaftstheorie erforscht die strukturen von wissenschaft, die zusammenhänge zwischen den einzeinen disziplinen, zwischen den theorien, grundbegriffen und methoden. die analyse dieser fragen fordert nicht nur eine gegenstandsbestimmung und klassifikation der wissenschaften, sondern auch die untersuchung der logischen und erkenntnis-theoretischen natur ihrer konstitutiven begriffe. das buch ist seit einiger zeit vergriffen und eine neuauflage war nicht vorgesehen.

man kann sicher sein, daB dieses buch einfluB nehmen kann auf die wissenschaftstheoretische diskussion innerhalb der marxistisch-leninistischen gruppen in der brd und autmerksamkeit finden wird bei allen an wissenschaftstheoretischen fragen interessierten personen, denn

„im gesamten deutschsprachigen raum dürfte es nicht eine untersuchung geben, welche die behandelten probleme mit ähnilcher brillanz der gedankenführung und einfachheit in der sprache angeht. aus marxistischer sicht gelang daboi eine höchst anregende auseinandersetzung mit dem neopasitivismus". (zitient aus: marxist. blätter $3 / 69$ )

\section{IN ALLEN LINKEN BUCHLADEN}


den Preis seiner Waren unter ihren internationalen Wert gesenkt hat. Die daraushin erfolgende Aufwertung der Währung des Landes bedeutet nichts anderes, als daß das nationale Kapital als Gesamtkapital nun größere Warenmassen zum gleichen Preis auf dem Weltmarkt einkaufen kann. Je nach dem, ob es sich dabei um Produktionsmittel oder Lebensmittel handelt, wird dadurch der Kostpreis der Ware - der Preis des konstanten bzw. variablen Kapitals - gesenkt ${ }^{58}$ ). Der Produktivitätsfortschritt des Exportkapitals wirkt bei fiexiblen Wechselkursen, bzW. im Falle von Paritätsänderungen der Währungen im Rahmen eines Systems prinzipiell fester Wechselkurse wie im System von Bretton Woods, als Verbesserung der Verwertungsbedingungen auf das gesamte nationale Kapital zurück. Die beim Exportkapital angewandte produktivere Arbeit verwertet sich als Arbeit von höherem spezifischem Gewicht des produktiveren Landes. Senkt demgegenüber der Kapitalist, welcher vergleichsweise größere Produktivitätsfortschritte erreichte, den Preis seiner Waren nicht, so findet keine Verallgemeinerung des höheren Verwertungsgrades des Exportkapitals statt. Dieses streicht den ExIramehrwert als Einzelkapital ein. Dies gilt, gleichgültig ob die Wechselkurse fix oder flexibel sind. Denn für den Fall, daß keine Preissenkungen stattfinden, besteht auch kein Anlaß dazu, daß der Preis der nationalen Währung sich erhöht ${ }^{59}$ ).

Die Frage bleibt jedoch bestehen, wie sich die höhere Verwertung des Exportkapitals auf das Verhältris der Einzelkapitale, welche zunächst im nationalen Gesamtkapital zusammengeschlossen sind, auswirkt. Wir kommen hier wieder auf das Problem der Bildung der Durchschnittsprofitrate (vgl. Teil 1.3. des Aufsatzes), welches wir noch nicht gelöst haben. Eines läßt sich jedoch sagen: Von der stofflichen Struktur des Gesamtkapitals sind der

sa) Vgl. dazu die Kritik von Marx an Ricardo, Theorien über den Mehrwert, MEW 26,2, S. $438 \mathrm{ff}$.

59) Die Verbilligung der Importe, Folge einer Aufwertung, ist nur unter der Bedingung im Interesse aller nationalen Eigenkapitale, als die Importwaren nicht in Konkurrenz mit inländischen Waren treten. Anders gesagt: Eine Aufwertung der Währung würde sich als Verbesserung der Verwertung der nationalen Kapitale auswirken, welche jetzt durch die billigen lmporte ihre Waren auf dem Binnenmarkt nur noch nach Preissenkungen losschlagen könnten. Solange der Weltmarkt durch die klassische internationale Arbeitsteilung gekennzeichnet ist - Rohstoffimporte und Industriewarenexporte - kann eine Währungsaufwertung im Interesse aller nationalen Kapitale liegen. Denn die in der Preiserhöhung der nationalen Währung dargestellte höhere Verwersung der nationalen Durchschnittsarbeit wirkt dann ais Verbilligung der Rohstoffeinfuhr, durch welche keinem nationalen Kapital Konkurrenz gemacht wird. Verbilligung der Rohstofie wirkt sich ais Erhöhung der Profitrate des industriellen Kapitals aus. (Vgl. Kapital, Bd. III, 6. Kapitel). Werden demgegenüber durch die Währungsaufwar tung des produktiveren Landes Teile der inländischen industrie unter verschärtte Konkurrenz gsetzt, womöglich durch die Konkurrenz vernichtet, so ist die höhere Verwertung der Arbeit des produktiveren Landes auf dem Weltmarkt fij dasselbe ein Zweischneidiges Schwert, besonders dann, wenn wie im Beispiel Japan - USA; BRD USA die schnellere Produktivitätsentwicklung (BRD, Japan) noch nicht zur Aufholung des Produktivitätsyorsprungs der USA geführt hat. Die Realisierung der produktiver gewordenen Arbeit als Extramehrwert der Einzelkspltale wäre demgegenüber tür die zurückgebliebenen Kapitale die adäquatere Form, den Konkurrenzvorsprung aufzu. holen. 
Wanderung des Kapitals in die Sphären der industriellen Produktion, welche einen Extramehrwert über den Weltmarktzusammenhang realisieren, Grenzen gesetzt. Diese Grenzen gelten auch für die im Teil 1.3. dargestellten Tendenzen zur Ausbildung einer internationalen Arbeitsteilung. So können sich z. B. die von der Bauindustrie gelieferten Waren kaum auf dem Weltmarkt bewegen, hier gibt es demnach keine oder eine sehr begrenzte Weltmarktkonkurrenz des produktiveren Landes. Andererseits erfordert ein flotter AkkumulationsprozeB außerordentliche Erweiterungen dieses Sektors der Kapitalanlage, die Nachfrage nach Waren der Bauindustrie steigt, was Preissteigerungen innerhalb dieses Sektors hervorruft. Extraprofite werden von der Bauindustrie realisiert, Kapital flieBt in diesen Sektor. Die von der stofflichen Struktur der Bauindustrie her gegebenen Beschränkungen der Produktivkraftentwicklung führen mit Notwendigkeit zu Preissteigerungsraten weitaus größeren Ausmaßes für die Waren der Bauindustrie als für die Waren der industriellen Produktion, wenn die Kapitale, welche hohe Produktivitätssteigerungen haben, nicht durch Weltmarktkonkurrenz zu Preissenkungen gezwungen werden. Das gieiche gilt für den Dienstleistungssektor. Die höheren Preissteigerungsraten in den weniger produktiven Sektoren sind aber schon deshaib notwendig, weil sich die Arbeiterklasse in ihrem Kampf um Lohnerhöhungen nicht an den Sektoren der ,Volkswirtschaft' mit der nie-

c'rigsten Produktivität ausrichten wird.

Da die ,Waren' der Sektoren mit den geringsten Produktivitätszuwachs- und den höchsten Preissteigerungsraten (Kleinhandel, Bauindustrie, Dienstleistungssektor) als wesentliche Posten in die Lebenshaltungskosten der Arbeiterklasse eingehen, ist eine Partizipation der Arbeiterklasse an der besseren Verwertung der nationalen Kapitale mit hohen Produktivitätsfortschritten auf dem Weltmarkt kaum möglich, ganz abgesehen davon, daß der Extramehrwert grundsätzlich der Akkumulation des Kapitals und nicht etwa der

Korruption der Arbeiterklasse dient.

Wir wollen wieder auf die Frage nach den Beziehungen zwischen Wechselkursen, Preisbewegungen und ungleichen Entwicklungen der Produktivkraft der Arbeit zurückkommen. Von den möglichen Beziehungen haben wir eine noch nicht behandelt, nämlich den Fall, daß bei konstanten Wechselkursen und ungleichen Entwicklungen der Produktivkraft der Arbeit die nationalen Inflationsraten eine unterschiedliche Höhe aufweisen. Bel diesem Fall handelt es sich keineswegs um ein konstruiertes Beispiel, sondern um reale Bewegungen, die z. B. für die Entwicklungen auf dem Weltmarkt in den letzten Jahren kennzeichnend sind.

Durchschnittswere der Ausfuhr $1963=100$

\begin{tabular}{lrrr} 
Zeitraum & BRD & Japan & USA \\
\hline 1965 & 102 & 98 & 104 \\
1966 & 103 & 98 & 108 \\
1967 & 102 & 101 & 109 \\
1968 & 101 & 101 & 111 \\
1969 & 102 & 105 & 115 \\
1970 (1. Hi) & 103 & 107 & 120
\end{tabular}

Quelle: Sachverständigengutachten 1970/71, S. 177 
Die USA haben in diesem Zeitraum also eine weitaus höhere Steigerung ihres Weltmarktpreisniveaus zu verzeichnen, als die BRD und Japan. Auf dem Hintergrund der bisherigen überlegungen wird klar, daß derartig ungleiche Preissteigerungen, verbunden mit größeren Steigerungen der Produktivkraft in den Ländern geringerer Preissteigerung (vgl. Teil 1.4.) zu einer Unterbewertung der Währungen (DM und Yen gegenüber dem Dollar) führen muß.

Verdeutlichen wir uns dies noch einmal an unserem anfänglichen Zahlenbeispiel:

10 AT USA $=10$ Dollar $=20$ AT U. $A .=2$ Maschinen

$10 \mathrm{AT} B \mathrm{BRD}=10 \mathrm{DM}=10 \mathrm{AT}$ u. $\mathrm{A}_{0}=1$ Maschine $(1 \mathrm{DM}=1 / 2$ Dollar $)$

$10 \mathrm{AT}$ Japan $=20$ Yen $=5$ AT u. $\mathrm{A}=1 / 2$ Maschine $(1$ Yen $=1 / 4$ Dollar $)$

Ungleiche Inflationsraten bei ungleichen Produktivitätssteigerungen und festen Wechselkursen: (10 Dollar $=20 \mathrm{DM}=40$ Yen)

10 AT USA $=20$ Dollar $=18$ AT u. A. $=2$ Maschinen

10 AT BRD $=15$ DM $=13,5$ AT u. $A=1,5$ Maschinen $=7,5$ Dollar

$10 \mathrm{AT}$ Japan $=20 \mathrm{Yen}=9 \mathrm{AT}$ U. A. $=1$ Maschine $=5$ Dollar

Wir haben hier konstante Preise in der BRD und in Japan bei einer Steigerung der Produktivkraft in der BRD um 50 Prozent, in Japan um 100 Prozent angenommen. Für die USA haben wir gleichbleibende Produktivkraft der Arheit und Preissteigerungen um 100 Prozent angenommen. Die japanische Maschine kostet jetzt in den USA 5 Dollar, die BRD-Maschine kostet in den USA ebenfalis 5 Dollar, aber die in den USA produzierte Maschine kostet dort 10 Dollar, sie kostet in der BRD 20 DM, in Japan 40 Yen. Die ungleichmäßige Aufblähung des Geldausdrucks der nationalen Arbeitstage hat demnach die gleiche Wirkung, als hätten die Kapitale, welche einen Produktivitätsfortschritt erhielten, ihre Preise gesenkt. Das US-Kapital gerät auf dem Weltmarkt unter verschärffen Konkurrenzdruck des BRD- und des japanischen Kapitals. Was sich auf der Wertebene als Wertübertragung von der BRD und Japan nach den USA darstellt, wirkt auf der Ebene der konkurrierenden Einzelkapitale als Verschärfung des Konkurrenzkampfes, quasi als Preiskrieg der Länder mit geringeren gegen das Land mit der höheren Inflationsrate. Sind die Wechselkurse fixiert, so führt die Währungsdisparität zu einer negaitven Handelsbilanz und Zahlungsbilanz des Landes mit den höchsten Inflationsraten, da sich ja der Preis der, unterbewerteten' Währungen nicht gemäß der erhöhten, Güternachírage' nach Waren dieser Länder erhöht ${ }^{61}$ ), und da zusätzlich Kapital aus dem Inflationsland abfließt, sel es

0) Hier setzl allerdings die entscheidende Frage nach den Auswirkungen der unterschiedlichen Positionen der nationalen Kapitale auf dem Weltmarkt auf die nationalen Arbeiterklassen ein. Aussagen, die über Banalitäten hinausgingen, bedürfen genauer Untersuchungen.

- Die beiden Länder (USA, BRD), die selt Beginn dep 50er Jahre ununterbrochene Handelsbilanzüberschüsse zu verzeichnen haben, haben gleichzeitig im Gesamtdurchschnitt der letzten zwanzig Jahre die geringsten Inflationsraten von allen kapitalistischen Ländern. Es wäre zu untersuchen, wie die kontinuierlich positive Handelsbillanz der BRD in Zusammenhang mit höheren Inflationsraten in den anderen kapitalistischen Ländem Europas (Frankreich, Grobbritannien) steht. 
als Spekulationsgeld, sei es als Kapitalexport zum Zwecke langfristiger Anlage. Je nach der Gesamtverwertungssituation der nationalen Kapitale und des Weltkapitals und je nach der Rolle des Landes auf dem Weltmarkt und im internationalen Währungssystem kommt es entweder zu einer begrenzten Zahlungsbilanzkrise des Inflationslandes oder zu einer Weltwährungskrise. Umgekehrt erzielen die Länder, welche geringere Inflationsraten haben, Zahlungsbilanzüberschüsse. Ein Ausgleich der Zahlungsbilanzen ohne Währungsparitätsänderungen wäre nur langfristig unter der Bedingung möglich, daß die Inflation in die Konkurrenzländer ,importiert" würde (vgl- Teil 2.1.). In Phasen der Hochkonjunktur wird der Prozeß in dieser Form verlaufen, nicht jedoch in der Krise, wo die verschärfte Konkurrenz der Kapitale, d. h., wie in der gegenwärtigen Situation, der Kampf um die Verteilung des Verlusts zwischen den Kapitalen auf Weltebene zunächst in der Form des Kampfes um die Höhe der Auf- bzw. Abwertungsraten der verschiedenen nationalen Währungen und der in diesen Raten ausgedrückten Preisvorteile bzw. -nachteile der nationalen Kapitale geführt wird.

Wir haben bisher versucht, die Auswirkungen ungleichmäßiger Veränderungen der Produktivkraft der Arbeit und der Inílationsraten verschiedener nationaler Kapitale bei festen und flexibien Wechselkursen auf die Warenund Kapitalbewegungen auf dem Weltmarkt sowie auf die internationale Konkurrenzposition der nationalen Kapitale darzustellen. Wir haben dabei die realen Bewegungen der Weltmarktpreise in den letzten zwanzig Jahren berücksichtigt. Die Frage bleibt, wie es überhaupt dazu kommen konnte, daß bisher keine Preiskämpfe auf dem Weltmarkt - einzeine Branchen ausgenommen - stattgefunden haben, daß im Gegenteil die Weltmarktpreise kontinuierlich gestiegen sind, wenn auch sehr langsam im Vergleich zu den Preissteigerungsraten der nationalen Bruttosozialprodukte. (Ausnahme: Koreaboom und die Jahre seit 1969).

Trifft unsere im Zusammenhang der Darstellung der Modifikation des Wertgesetzes auf dem Weltmarkt entwickelte These zu, daB es einen Weltmarktzyklus geben müsse, welcher die nationalen Zyklen überlagert, so erklären sich die Preisbewegungen anders als durch die gängigen Monopolpreistheorien: Die zyklische Durchsetzung des Wertgesetzes impliziert für die aufsteigende Phase der Akkumulation bis hin zur Schwindelblüte der Konjunktur die Möglichkeit von Preissteigerungen, vermittelt über die quasimonopolistische Position der ,Anbieter' in der Phase sowie durch die Kreditd. h. ,Geldschöpfungsmöglichkeiten' der Banken ${ }^{62}$ ). Die Bestimmung der Warenpreise durch die Wertgrößen setzt sich als Tendenz erst in der zyklischen Bewegung des Kapitals durch. Der Preisfal! in der Krise bzw. die gewaltige Kontraktion des Produktionsprozesses bei stagnierenden oder leicht fallenden Preisen ist die Umkehrung der Aufblähung des Geldausdrucks der Warenwerte in der aufsteigenden Phase der Konjunktur. Geht man nun von der

82) Zu fragen ist, ob die Weltgeldschöpfung der USA (in der Form des Dollars), aus internationaler Ebene die Funktion erfült hat, die auf der Ebene der nationalen Kapitale die Banken erfullen. 
Existenz eines Weltmarktzyklus aus, so gälte für ihn das gleiche, was bisher immer nur als Besonderheit der nationalen Zykien betrachtet wurde: Die langfristige Tendenz leicht steigender Weltmarktpreise seit den 50er Jahren würde sich dann aus der Aufstiegsphase des Weltmarktzyklus erklären lassen. Die gleiche Erklärung gälte für das leichte Steigen der Weltmarktpreise seit der Mitte der 90er Jahre des 19. Jahrhunderts bis hin zur Kriegsinflation. Der erste große Preisfall der Weltmarktpreise - von den Bewegungen im Zusammenhang der Kriegsinflation abgesehen - fand in der großen Weltwirtschaftskrise seit 1929 statt ${ }^{63}$ ). $\mathrm{DaB}$ in dieser Krise die Preise der großen Konzerne geringer fielen, als die der mittleren Kapitale, erklärt sich daraus, daß in der Krise es eine Frage der Macht der Einzelkapitale ist, wer die geringsten und wer die größten Verluste zu tragen hat. Das ökonomische Gesetz der Bildung einer Durchschnittsprofitrate ist in dem Augenblick außer Kraft gesetzt, wo es keine Profite mehr zu verteilen gibt.

Nur die langfristige Tendenz der Weltmarktpreise wäre durch unsere These zu erklären, nicht aber die kurzfristigen und ungleichmäßig erfolgenden Inflationen der Weltmarktpreise einzelner nationaler Gesamtkapitale. Sie müssen aus historisch besonderen Momenten der nationalen Geschichte des Kapitals abgeleitet werden, aus der unterschiedlichen Stärke der Arbeiterklasse, den unterschiedlichen Bewegungen der Klassenkämpfe, aus Staatsschulden wie denen des Vietnamkrieges usw.

Was den Anspruch unserer These auf Richtigkeit angeht, können wir nur das wiederholen, was wir schon bei ihrer ersten Darstellung gesagt haben. Vor allem wäre es falsch, zu sagen, die gegenwärtige Weltwährungskrise sei die internationale Geldkrise, welche dem großen Krach vorangeht. Eine solche Aussage läßt sich bei dem gegenwärtigen Stand der Untersuchung der konkreten Verfassung des Kapitals auf dem Weltmarkt noch nicht verantworten.

\section{Nationale und internationale Zirkulation - Formen des Weltgeldes}

\section{1. Möglichkelt und Ausbreltung von Krisen in der Intern. Zirkulation}

In der Herleitung der Kategorie des Weltgeldes und der Darstellung der Formen, die das Weltgeld historisch annimmt, wurde immer die Unterscheidung von nationaler und internationaler Zirkulation vorausgesetzt. Bevor wir uns jetzt dieser Unterscheidung unter dem Akpekt der Möglichkeit und Ausbreitung von Krisen ausführlich zuwenden, ist es notwendig, auf die die nationale und internationale Zirkulation vermittelnde Instanz zu sprechen zu kommen, auf die Zahlungsbilanz. In der Zahlungsbilanz eines Landes schlagen sich die über die nationale Grenze führenden Bewegungen im Warenkapital- und Geldkapitalverkehr nieder. Die Zahlungsbilanz "stellt so eine Zusammenstellung der Geldwerte der im Verlauf einer Rechnungsperiode zwischen einem einzelnen Wirtschaftssubjekt oder einer Gruppe von Wirtschaftssubjekten auf der einen und dem Rest der Welt auf der anderen Seite ange- 
fallenen Transaktionen dar $\left.{ }^{64}\right)$. Alle diese in der Zahlungsbilanz eines Landes enthaltenen Transaktionen bestimmen wiederum die Angebots- und Nachfrageverhältnisse auf seinen Devisenmärkten ${ }^{65}$ ), und damit die Schwankungen der Wechselkurse. Die Transaktionen selbst können mehreren Ursachen geschuldet sein; sie können aus dem Warenhandel resultieren, aber "eine Nachfrage nach Devisen oder ein Angebot von Devisen kann (auch) aus Kapizalbewegungen entstehen, aus der Rückzahlung alter Schulden und aus einseitigen Zahlungen, wie Zuwendungen oder Feparationen" ${ }^{66}$ ). Aus diesem Grunde werden die Transaktionen in der Zahlungsbilanz gegliedert nach denjenigen, die dem Warenkapital entsprechen (Handeisbilanz), und denjenigen, die dem Dienstleistungsvekehr entsprechen (Dienstleistungsbilanz). Handels- und Dienstleistungsbilanz werden zur "Leistungsbilanz" zusammengefaßt. Zusammen mit den "unentgeitlichen Leistungen" wird die Leistungsbilanz zur "Bilanz der laufenden Posten". Die Geldkapitalbewegungen (langfristiger und kurzfristiger Art) werden in der "Kapitalbilanz" zusammengefaBt und schließlich bilden die Gold- und Devisenbewegungen noch die "Devisenbilanz". Die letztere allerdings isı̀ das Resultat der Transaktionen in Leistungs- und Kapitabilanz zu versiahen.

Eine positive (negative) Zahlungsbilanz bedeutet dann, daß der Saldo von Leistungs- und Kapitalbilanz einen Überschuß (ein Defizit) aufweist, wobei natürlich der Fall eintreten kann, daß eine positive Leistungsbilanz, oder zumindest eine positive Handelsbilanz durch eine negative Kapitalbilanz und Bilanz der unentgeltlichen Leistungen überkompensiert werden kann ${ }^{67}$ ). Eine positive Zahlungsbilanz schlägt sich als Zuwachs zum Bestand an Forderungen gegenüber dem Ausland (Gold und Devisen) nieder, eine negative Zahlungsbilanz als Abbau der Devisenbestände. Daraus ergibt sich aber gegenüber unserer bisherigen Darstellung folgende Modifikation: Der Abbau an Devisenbeständen, bzw. im Falle, daß keine mehr vorhanden sind, der Kauf von Devisen auf Kredit, also die Zunahme der Verschuldung ans Ausland, kann nicht nur auf einem Handelsbilanzdefizit beruhen, also auf einer verschlechterten Konkurrenzsituation auf dem Weltmarkt etwa infolge stark gestiegener Warenpreise im Inland (Inflation), sondern auch aufgrund eines Defizits in der Kapitalbilanz zustandekommen, was auf verschlechterte Bedingungen der Verwandlung yon Geldkapital in Produktivkapital ("mangelnde Investitionsgelegenheiten") oder vergleichsweise niedrige Zinssätze im Inland schießen läßt. Als dritte Möglichkeit ist eine negative Bilanz der unentgeltlichen Leistungen ("Entwicklungs " und Militärhilfe) zu nennen, worin sich die politisch-ökonomische Position eines Landes im imperialistischen Block niederschlägt. Darauf wird noch zurückzukommen sein.

s) Werner Hofmann, Die säkulare inflation, Berlin 1962, S. 12.

84) Funck, a. a. O., S.61.

${ }^{65}$ George N. Halm, a. a. O., S. 123.

38) George N. Halm, a. a. O., 5. 137 .

67) Difs war der Fall bel der Zahlungsbilanz der USA. Sie ist mit Ausnahme des Jahres 1957 (Suezkrieg) nach dem zweiten Weltkrieg negativ. Dazu ausfühlicher weiter unten. 
in der Zahlungsbilanz erscheinen also alle Transaktionen, die zusammengenommen den aktuellen Kurs der Währung bestimmen. Chronische oder strukturelle Zahlungsbilanzüberschüsse bzw. -defizite zeigen an, daß in den Weri- und Verwertungsverhältnissen der nationalen Kapitale auf dem Weltmarkt Widersprüche heranreifen, die sich im Kapitalismus gar nicht anders als in Krisen zu entladen vermögen. Bevor der historische Prozeß der Heranreifung beschrieben wird, muß zuvor jedoch die Form entwickelt werden, in der sich die Widersprüche in der internationalen Zirkulation bewegen. Wir fragen daher nach den Formunterschieden zwischen nationaler und internationaler Zirkulation.

In der Zirkulation der Waren ${ }^{68}$ ) sind die Formen gesetzt, die eine Krise möglich machen und die Ausbreitung der Krise bewirken. Die Möglichkeit der Krise entsteht dadurch, daß einem Verkauf nicht unbedingt ein Kauf zu folgen braucht und damit die Zirkulationskette Ware - Geld - Ware unterbrochen warden kann ${ }^{69}$ ). Die Bewegungsiormen der Ware in der Zirkulation "schlieBen daher die Möglichkeit, aber auch nur die Möglichkeit der Krisen ein ..." (MEW, 23, S. 128). In der Tatsache, daß bei entwickelten Verhältnissen der Warenproduktion ein Kapital vom anderen kauft und ein Kapital dem anderen verkauft, ist auch immer die abstrakte Möqlichkeit eingeschlossen, daß diese Käufe und Verkäufe, die jeweils notwendig zur Aufrechterhaltung des Reproduktionsprozesses sein mögen, nicht gelinaen. Die Gründe, aus denen das Nichtgelingen resultiert, entstammen natürlich nicht der Zirkulation; aber in der Zirkulationssphäre merkt der einzelne Kapitalist die Krise, wenn er seine Ware nicht mehr oder zu sinkenden Preisen verkaufen und die Waren, die er zur Produktion benötiat, nur noch zu. steigenden Preisen einkaufen kann. Hat dies eine Einschränkung der Profitrate oder qar einen Verlust zur Folge, so wird er es sich überlegen, ob er den Produktionsprozeß von Waren fortsetzt oder einschränkt, d. h. Atbeiter entläßt und Kapazitäten stillegt.

Selbstverständlich handelt es sich bei der Warenzirkulaton um kapitalistisch produzierte Waren. Aber die allgemeine Möglichkeit der Krise ergibt sich nicht daraus, daß die Waren als Warenkapital zirkulieren, sondern daraus, daß das Warenkapital als Ware zrkuliert. Betrachten wir die Zirkulation als

B3) Wir behandeln hier die Warenzirkulation, wobei selbstverständlich ist, daß es um die Zirkulation kapitalistisch produzierter Waren geht. Wir sprechen deshalb nicht von Kapitalzirkulation, well die Momente, um die es hiep geht, der Zirkulation als Warenund nicht als Kapitalzirkulation zukommen.

69) Marx schreibt: "Keiner kann verkaufen, ohne daß ein anderer kauft. Aber keiner braucht unmittelbar zu kaufen, weil er selbst verkauft hat. Die Zirkulation sprengt die zeitlichen, örtlichen und individuellen Schranken des Produktenaustausches eben dadurch, daß sie die hier vorhandene unmittelbare Identitäł zwischen dem Austausch des eigenen und dem Eintausch des fremden Arbeitprodukts in den Gegensatz von Verkauf und Kauf spaltet. Daß die selbständig einander gegenübertretenden Prozesse eine innere Einheif bilden, heißt ebensosehr, daß thre innere Einheit sich in äußeren Gegensätzen bewegt. Geht die äußeriche Verselbständigung der innerlich unselb. ständigen, well einander ergånzenden, bis zu einem gewissen Punkt fort, so macht sich die Einheit gewaltsam geltend durch eine - Krise .. "Kapital, Bd. I, MEW, Bd. 23, S. 127 f. 
Abschnitt im Kreislauf des Kapitals, dann ist darin auch der Produkionsprozeß eingeschlossen, aus dessen Widersprüchlichkeit heraus die Krisenhaftigkeit des Kapitalismus erst begründet werden kann ${ }^{70}$ ).

Die Form der Krise ist gleichwohl in der nationalen und internationalen Zirkulation gesetzt, denn in beiden Zirkulationsbereichen werden Waren zirkuliert- Es ändert sich nichts an der Möglichkeit des Auseinanderfallens von Kaufs- und Verkaufsakten dadurch, daß zwischen Käufer und Verkäufer eine nationale Grenze liegt und die Geldtransaktionen zwischen beiden in den Zahlungsbilanzen der Nationalstaaten erscheinen. Es ist für einen kapitalistischen Verkäufer von Waren auch gleichgültig, ob dieser Zirkulationsakt Ware gegen Geld (worin der produzierte Mehrwert eingeschlossen ist) auf der anderen Seite einen kapitalistischen oder nicht-kapitalistischen Partner (z. B. Außenhandelsmonopol eines sozialistischen Landes) hat ${ }^{71}$ ). Die Hauptsache ist dabei, daß der Verkaufsakt selbst vollzogen wird, die Rückverwandlung des Warenwerts und damit des Mehrwerts in Geld gelingt.

Allerdings ergeben sich hier doch wichtige Unterschiede zwischen nationaler und internationaler Zirkulation. Wir haben bereits gesehen (Abschnitt 2.1.), daß die Verwandlung von Ware in Geld im Rahmen nationaler Zirkulation mit dem Verkauf (vom Kredit sehen wir ab) volizogen ist, während beim Verkauf über die Grenzen die Verwandlung in Geld in zwei scharf zu unterscheidende Akte gespalten ist. Für den Verkauf der Ware im Ausiand erhält der Verkäufer-Kapitalist nämlich nicht Geld seiner nationalen Zirkulation, sondern Devisen, d. h. fremde Währungen, die er in einem zweiten Akt erst in nationales Geld seiner nationalen Zirkulation zu verwandeln hat. Mit anderen Worten: Der Verkauf seiner Ware im Ausland zieht einen zweiten Verkaufsakt nach sich, nämlich den Verkauf der an die Stelle der Ware getretenen Devisen gegen nationales Geld seiner nationalen Zirkulation. Die Zirkulationsakte werden somit verdoppelt und die Warenmetamorphose komplizierter. Denn schließlich kann der abstrakten Möglichkeit nach der Fall eintreten, daß unser Verkäufer zwar erfolgreich den Akt Ware gegen Devise vollzieht, aber ihm der Verkauf der Devisen gegen Geld der nationalen Zirkulation zum durch die Wertgröße der Ware bestimmten Preis miBlingt. Dies ist kein unrealistischer Fall. Bei Kursstürzen der Devisen erhält nur einen Teil des Warenwerts in Geld ausgehändigt, was sich für ihn genauso

70) Auf die krisentheoretischen Grundlagen der hier analysierten Probleme kann an dieser Stelle nicht eingegangen werden. In einem der nächsten Hefte wird ausführlicher darauf zurückzukommen sein.

7i) Dies ist ganz vom Blickwinkel des Einzelkapitals aus betrachtet. Aus der Sicht des Gesamtkapitals sieht dies insofern anders aus, als ja den Exporten auf lange Sicht Importe entsprechen müssen. Die Konkurrenz, die gerade durch Exporte aus dem inneren Markt getrieben wurde, kommt so evtl. verstärkt wieder herein. Insbesondere gilt dies für den "Osthandel". Denn die "lukrạtiven" Exporte müssen bezahlt werden von den Käuferländern und dies kann nur geschehen, wenn sie ebenfalls verkaufen, d. h. exportieren, d. h. vom ursprünglichen Exportland aus betrachtet, wenn impor. tiert wird. 
darstellt, als ob er seine Ware im Inland unter Wert verkauft hätte ${ }^{72}$ ). Durch den Akt "Ware gegen Devisen", "Devisen gegen Geld" (nationale Währung) entsteht notwendig neben dem Warenmarkt auch ein Devisenmarkt. Auf dem Devisenmarkt werden, wie im Abschnitt über die Zahiungsbilanz gezeigt wurde, bei entwickeltem Weltmark ${ }^{t}$ außer den für die internationale Warenzirkulation notwendigen Devisen auch Leihkapital verschiedener Währungen, fiktives Kapital usw. gehandelt, so daß die Warenzirkulation auf dem Weltmarkt Bedingungen unterworfen ist, die grundsätzlich die Warenmetamorphose im Vergleich zur nationalen Zirkulation erschweren.

Die Realisierung des Warenwerts erfolgt über die Realisierung zweier Preise, nämlich des Waren- und des Devisenpreises. Folglich ist von beiden Preisen die Größe des dem Kapitalisten zurückströmenden Geldkapitals abhängig ${ }^{73}$ ). Währungskursveränderungen gewinnen auf diese Weise ihre Relevanz für die Einzelkapitalisten, die natürlich so widersprüchlich wie ihre einzelkapitalistischen Interessen sind, darauf jeweils reagieren werden: Über eine Währungsaufwertung werden die Importeure von Waren jubeln und die Exporteure zetern und umgekehrt.

Es wurde schon gezeigt, daß Warenpreise und Wechselkurs, aiso auch Warenmarkt und Devisenmarkt nicht unabhängig voneinander sind. Vielmehr ergibt sich der Kurs einer Währung (von Schwankunqen aufgrund besonderer Faktoren abgesehen) aus den relativen Wertverhältnissen der produzierten Waren in verschiedenen Ländern. Das uns hier lediglich interessierende Resultat ist, daß Kurse, die zu stark von den Wertverhältnissen der Währungen untereinander abweichen, prohibitiv sein können. Bei einer stark überbewerteten Währung kann es u. a. geschehen, daß kein im Ausland für eine im Inland produzierte Ware erzielbarer Preis hinreicht, um die Devisenmenge in eine dem Warenwert adäquate Geidmenge inländischer Zirkulation einzutauschen. Der Exporthandel würde in einem solchen Fall erliegen - was nun rückwirkend den Devisenmarkt beeinflußt, da ja der Kauf der nationalen Währung durch das Ausland zum Bezahlen dieser Ware aufhören bzw. der Eintausch von Devisen in die nationale Währung durch inländische Kapitalisten aufhören würde. Bei flexiblen Kursen wäre ein Kursverfall unvermeidlich. Bei fixierten Kursen könnte zwar die Zentralbank durch Interventionen am Devisenmarkt und die Regierung durch Exportsubventionen (die aber anderen Kapitalisten und der Arbeiterklasse weggenommen werden müßten) eine Zeitlang das unrealistische Kursgefälle halten. Auf

72) Es ist natürlich auch der umgekehrte Fall möglich. - In Japan hat beispielsweise die Zentralbank nach dem 15. August 71 Dollardevisen zum alten Kurs von privaten Devisenbesitzern aufgekauft, bevor sie zum "Floating“ des Yen überging. Ganz zwel. fellos eine Maßnahme, um die Wertrealsierung nicht durch den Devisenmarkt zu beeintrãchtigen.

73) Daraus ergibt sich bereits das Interesse des Kapitals an fixierten Wechselkursen um nämlich die Realisierung der Warenpreise in nationaler Währung ausgedrückt zu erleichtern und von "Unsicherheiten "zu befreien. 
die Dauer kann dies aber nicht gelingen, wie gerade die Währungskrisen der vergangenen Jahre beweisen ${ }^{74}$ ).

Die Darstellung ist zwar überspitzt, aber insoweit realistisch, als bei fixierten Kursen der Währungen und ungleichmäßiger Entwicklung der jeweils nationalen Produktivkraft der Arbeit die Wertrelationen als Basis der aktuellen Kursschwankungen sich notwendig verschieben müssen. Modifizierende Umstände wie kompensierende Unterschiede in den Ausbeutungsbedingungen der Arbeit vor allem (Vgl. dazu Abschnitt 1) können nur eine Zeitlang die wirklich stattgefundenen verschiebungen kaschieren, auf die Dauer müssen sich die veränderten Wertrelationen jedoch auch in den Kursrelationen der Währungen niederschlagen, vorausgesetzt, die veränderten Wertrelationen werden in den Weltmarktpreisen der nationalen Einzelkapitale durch Preissenkungen der produktiver gewordenen Kapitale, bzw. durch ungleichmäßige Preissteigerungen dargestellt.

Dies bedeutet, daB Devisen- und Warenmarkt eng mileinander verbunden und voneinander abhängig sind. Der einzelne Kapitalist alierdings finde! den Zusammenhang nur darin vor, daB er beim Verkauf seiner Ware im Ausland nicht nur einen Preis, sondern zwe? Preise von nicht nur einer Ware, sondern von zwei Waren (Ware und Devise) zu realisieren und diese Tatsache in seiner Kalkulation zu berücksichtigen hat.

Der zweite Aspekt, unter dem betrachtet sich Unterschiede zwischen nationaler und internationaler Zirkulation ergeben, bezieht sich auf das Verhältnis von innerem und äußerem Markt. Unter dem Aspekt der Wertrealisierung gibt es zwischen innerem und äußerem Markt keine anderen Unterschiede als die oben gezeigten, doch gibt es immer wieder historische Umstände, unter denen das Kapital eher auf den äußeren Markt verwiesen wird und Umstände, unter denen es vorwiegend für den inneren Marki produziert Die Ungleichmäßigkeit der Entwicklung einzehner Produktionszweige in einem Lande und die Ungleichmäßigkeit der Entwicklung auf dem Weltmarkt bewirken ein permanent sich veränderndes Verhältnis zwischen innerem und äußerem Markt. Am Beispiel der BRD läßt sich dies insofern sehr gut illustrieren, als im Verlauf der Wirtschaftszyklen der Anteil der Exporte an der Gesamtverwendung des Sozialprodukts (Antell der Exporte an der Summe von Konsumtion, Investition und Export) wechselte, also die Bedeutung des äuBeren Markts für die Realisierung des Warenwerts, und des heißt des Mehrwerts, mal größer und mal kleiner war. Die Zuwachsraten der Exporte waren immer auch AnstöBe für konjunkturelle Aufschwungsphasen, woraus hervorgeht, daß die Pralisierung der Warenwerte immer dann in besonders hohem Maße zuf dem äußeren Marki erfolgt, wenn die Realisierung auf dem inneren Markt aufgrund des Nach-

74) Darin drückt sich übrigens eindeutig die Begrenztheil des staatlchen interventionismus aus. Gegen die Wirkung des Wertgesetzes kann aul dia Dauer noch nicht einmal. der mãchtigste Staat ansteuern, Die Aufgabe der traditionellen Interventionsmaßnah. men auf den Devisenmärkien und die Zulassung dess "Floating " sind genauso Ausdruck der interventionistischen Unfähigkeit wie die protektionistischen Maßnahmen der USA gegenüber ihren Konkurrenten auf dem Welmaikt. 
lassens der Konjunktur schwieriger wird ${ }^{75}$ ). Dies bedeutet für das von uns untersuchte Problem des Unterschieds zwischen nationaler und internationaler Zirkulation folgendes: Da die Zirkulation im Inland und die Zir kulation auf dem Weltmarkt noch verschiedenen Einfüssen unterliegt, kann man auch noch nicht von einer gleichmäßigen Weltkonjunkiur sprechen $\left.{ }^{7 k}\right)$. Daher sind die Realisierungsmöglichkeiten auf innerem und äuBerem Markt nicht gleichmäßig. Die Zirkulation mag im inland bereits stocken, während sie auf dem Weltmarkt flüssig verläuit ${ }^{77}$ ). Auch die "Asynchronität" der nationalen Konjunkturverläufe auf dern Weltmarkt ist ein Ausdruck der modifizierten Wirkung des Wertgesetzes. Allerdings wurde im Abschnitt 1 gezeigt, daß die Kräfte der Durchsetzung des Werigesetzes auch auf dem Weltmarkt nicht aufgehoben sind unc daher diese "Asynchronität" der zyklischen Bewegung der nationalen Kapitale dahin tendiert, in eine "Synchronität" überzugehen. Ist dies der Fall, dann wird die Welt" marktkrise unausweichlich sein und konjunkturelle AnstöBe durch den Weltmarkt - wie in Westdeutschland nach 1967 - werden ausbleiben. Solange aber noch der Weltmarkt durch die UngleichmäBigkeit der konjunkturellen Entwicklung gekennzeichnet ist, wäre das Kapital kein Kapital, würde es nicht solche Unterschiede zwischen nationaler und internationaler Zirkulation für sich nutzbar machen und dadurch gerade für eine Ausbreitung der Stockung in der nationalen Zirkulation auf den Weltmarkt sorgen ${ }^{78}$ ). Mit dieser Feststellung wären wir bei der zweiten Funktion der Zirkulation angelangt, auch die vermittelnde Sphäre zu sein, über die sich Krisen ausbreiten.

Im Rahmen der nationalen Zirkulation wird die Krise eines führenden Handelszweiges notwendig zur Krise der gesamten Ókonomie ${ }^{72}$ ), da nur sämtliche Zirkulationsakte in Stockung geraten. Ist die Krise in einem führenden Weltmarktland ausgebrochen, so wird sie über die internationale Zirkulation vermittelt zur Krise in anderen kapitalistischen Ländern oder gar der gesamten Weltwirtschaft. Hier aber endet bereits die Analogie zwischen na-

75) Vgl. konkretes Material dazu, das hier nicht zitiert worden ist, in $E$. Altvater, Die Weltwährungskrise, a. a. O., S. $82 \mathrm{ff}$. sowie die Gutachten des Sachverständigenrats und vor allem Rüdiger Hopp.

${ }^{76)} \mathrm{Vgl}$. zu den „Ungleichzeitigkeiten" der nationalen Konjunkturen die Abbiidung in: Sozialistische Politik, Nr. 5, 1970, S. 12 sowie Teil 1,4 des Aufsatzes. Die Feststellung von Ungleichzeitigkeiten, das muß ausdrücklich betont werden, bedeutet aber nicht, daß sich Krisen nicht ausbreiten können!

77) Daraus darf natürlich nicht geschlossen werden, daß in bezug auf die Wertrealisierung an die Stelle der nationalen Zirkulation einfach die internationale treten könne. Abgesehen davon, daß sich Stockungen der nationalen Zirkulation international ausbreiten, geht es nicht um die Wertrealisierung überhaupt, sondern um die Realisierung einer für dile Akkumulationszwecke des Kapitals ausreichenden Profitrate. Ist die Profitrate dur chBedingungen des nationalen Reproduktionsprozesses des Kapitals so gedrückt, daß sich die Produktion nicht mehr "lohnt" dann rützen auch die bester Realisierungsmöglichkeiten nichts mehr.

78) Auch hierfü ist die BRO Beispiel. Die Rezession von 1967 wurde duroh stake AuBenhandeisüberschüsse beschleunigt uberwunden. Alferdings mit der Konsecuenz, daß Länder wie Frankrelch in Wähningskrisen garieten. 
lionaler und internationaler Zirkulation. Denn zwei Probleme müssen bedacht werden:

(1) Führende Weltmarktländer können infolge ihrer Größe, ihres Antells am Welthandel die okonomische Eniwicklung in anderen Ländern und das heiBt de facto tie Entwicklung des Weltmarkts bestimmen, onne selbst jedoch gieichermalen von der Weltmarktentwicklung beeinflubt zu sein. Dieser Fall triffit vor allem auf die USA $2 \mathrm{U}$, die im Jahre 1970 zwar $139 \mathrm{v}$. H. der gesamten Weltaustuhr und $12,4 \mathrm{~V} . H$. der Welteinfuhr aul sich vereinigen und somit einen entscheidenden Fakior tür die reibungslose Abwicklung der internationaten Zirkulation darstelien, aber der AuBenhandeisanteil (Exporte) am Sozialprodukt beträgt nur 4 V.H. Die USA-Konjunktur beeinfluBt also den Weltmarkt. Umgekehrt beeinfluBt der Welimarkt die US-Konjunktur in einem durchaus geringeren Umfang. Die BRD vereinigt zwar auf sich 9,3 ช. H. der Weltimporte und $11 \mathrm{v} . H$. der Weltexporte, aber diese machen auch 18 v. H. des gesamien Sozialprodukts aus. Der Anteil Belgiens an den Weltexpoten beträgt 3,5 v. H., aber der Exportantell am Sozialprodukt beläuft sich auf 46 V. H. ${ }^{89}$.

Es sind also zwei Gröben zu kombinieren, wenn die Ausbreitungseffekte einer Stocking in einem lande untersucht werden, nämlich: das Verhäinis der in der nationalen und internationalen Zirkulation zirkulierten Wertmasse erstens bezogen auf den Produktenwert des jeweiligen Landes und zweitens bezogen auf die insgesam auf dem Weltmarkt zirkulierte Wertmasse ${ }^{81}$ ).

Es ist natürlich zu berücksichigen, daß der Exportanteil des Sozialprodukts selost nur eine Durchschnittsgröße ist und die Verschiedenheit der Exportanieile nach Branchen, Unternehmensgrößen nich darin erscheint. Da aber die einzelnen Branchen und großen Einzelkapitale ungleichmäßig vom äuBeren Markt abhängig sind, muB Stockung auf dem Weltmarkt die Ungleichmäßigkeit der nationalen Entwicklung vergröBern. Oieses Problem ist in besonders großem Ausmaß für die BRD und Japan virulent ${ }^{82}$ ). Ergreift die Krise ein führendes Weltmarktland und sind einige wichtige Handelszweige relativ stark vom Weltmark abhängig, dann kann realistisch damit gerechnet werden, daß die Krise auch andere Nationalstaaten ergreift.

79) Val dazu Theorien über den Mehrwert, Bd. 2, MEW, 26.2. S. 518 fi.

Bi) Ouelle: Statistisches jahrbuch der BRD, 1971, S. $7^{*}$ und Suddeutsche Zeinung yom 28./29.8. 1979.

Bi) Daß in diesen okonomischen Verhältnissen auch politische Dominanz begründet ist, dokumentier sich in dem Verhalien der kapitalistischen Nationalstaaten in der jüngsten Währungstrise, vor alle min den Reaktionen auf die Maßnahmen der USRegierung zur Abwehp yon harenimporten. In dep "Wirtschaftswoche" (Nr. 39 vom 24. 9. 71. S. 10) wird ausdiücklch zur Kennzeichnung der jeweiligen Verhandiungsstärke auf die Verhämisse won Excort, Sozialproduki und Welmarkanteil rekurient. aq) Vgl. z. B. die Angaben in: Wirtschaftswoche, Nr. 37. 1971, 3. 65 über die Exponto

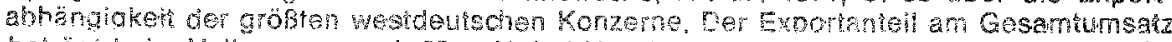

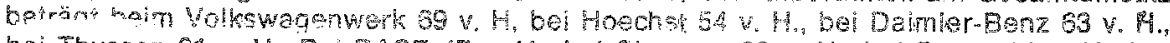

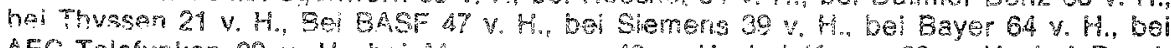

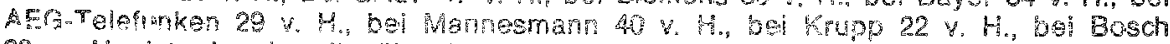

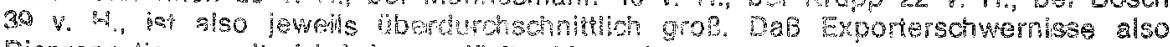

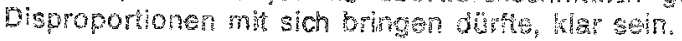


Ist also der Anteil des Exports an der Gesamtzirkulation eines Landes und der Anteil der Exporte eines Landes an der gesamten Weltmarkizirkulation relevant, um die Ausbreitungsprozesse von Stockunger einzuschätzen, so muß nun auf den zweiten Unterschied zwischen Ausbreitung der Krise in der nationalen und intemationalen Zirkulation hingewiesen werden. Und dieser Unterschied liegt in der Regulierung der Zirkulation selbst begründet Der Zirkulationsmechanismus, das Welwährungssystem, erlangi ein relatives Eigengewicht gegenüber dem, was zirkuliert wird, rëmlich den Kapital in Waren- und Geldform, und ist in der Lage, diese Zirkulation in Grenzen zu modifizieren. Um diese Grenzen festzlistellen, ist es notwendig, den Mechanismus des derzeitigen Wellwährungssystems darzustellen.

\section{2. Dollar als Papierwelsgeld}

Auf dem Weltmarkt verlieren die einzeinen nationalen Gestalten des allgemeinen Aquivalents (Geld) ihre Gültigkeit; sie gelten als Werigestalten, die in keinem Vorrangverhältnis internationaler Art zu anderen Waren und anderen nationalen Währungen stehen. Sie sind also bioke Waren, die als Devisen auch als solche gehandelt werden, wies aut den Devisermärkien geschieht. Jede Währung ist als Ware besonderes Aquivalent für eine andere Währung als Ware, solange sich nicht aut dem Weltmarkî ein allgemeines Aquivalent herausbildet. Mit dem Gold ist ein solches Weltgeld entstanden. In der historischen Eniwicklung des Weltgeldes drückt sich die Tatsache aus, daß auf allen Warenmärkten, so auch auf dem Welmarkt, die relativen Werte der gehandelten Waren in einem gemeinsamen Dritten er scheinen und darin gemessen werden. Hat das Gold die Funktion des Wertmaßes übernehmen können, weil es als Arbeitsprodukt selbst Wert hat, so ergeben sich bei der Betrachiung von Papiergeld als Weltgeld Probleme. Unter dem Aspekt des relativen Geldwerts ist es, wie wir gesehen haben, rein rechnerisch gleichgültig, ob wir - solange wir das Geld nur als Kargh mittel betrachten - die Wechselkurse der verschiedenen Währungen nur in diesen Währungen selbst ausdrücken und damit den "Geldweri" aufgrund der Kaufkraft bestimmen, oder ob wir diese Kaufkraft des Geldes, d. h. seinen relativen Wert selbst noch einmal rückbeziehen aut ein intemetional einheilliches Wertman, auf eine Geldware als Weltgeld (Gold). Und diese Rechenoperation hat ihre Berechtigung insofern, als in der Tai bei funktionierender internationaler Zirkulation das Geld bloß als Rechemgeld fungient und diese bloße Funktion vergessen Iäit, daß das Geld seine spezifischen Funktionen seiner Eigenschaft als Maß der Werte verdankt, also colbst einen bestimmien Wert haben muß, urm überhaupt Wert ausdrücken zu können. In der Krise zeigen sich die Grenzen solcher Rechenoperationen sehr schnell. Jeder amerikanische Tourist multe diese am eigenen beibe erfahren, als er in Rom vor dem Bankschalter stand und au seimen Wunsch, Traveller schecks einzulösan, die niederschmentemde Anwon emptr: "Tut uns leid, wir tauschen überhaupt koine Dollar," s?)

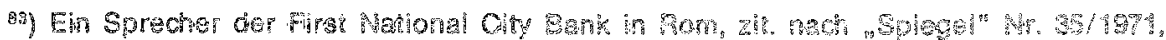
S. 21 . 
Später wird zu entwicke!n sein, aus welchen spezifischen Regelungen des internationalen Währungssystems und welchen langiristigen undd konjunkturellen Veränderungen in der Produktion und dem Warentausch zwischen den kapitalistischen Staaten die aktuelle Krise des Weitwährungssystems resultierte. Wir wollen uns hier nur auf das Problem konzentrieren, daß wie es der bürgerliche Geldtheoretiker Forstmann ausdrückt: "das Geld als innerwirtschaftliche Erscheinung durch den Primat der Fecheneinheit vor der Tauschmittlerfunktion gekennzeichnet ist, während die "Währung'vor allem durch ihre Aufgabe als Mittier des internationalen Güter- und Leistungsaustausches charakterisiert isi "und daß die Abschalfung des Goldes in der internationalen Zirkulation "den Ersatz durch ein adäquates Mittel integrierend voraussetzt" 84), weil der internationale Austausch ein "Tauschmittel mit ,international anerkanntem Eiganwert" verlangt. Diese Rolle spielt heute der Dollar. Aber erfüllt der Dollar wirklich die Bedingungen, die an das Weltgeld gestellt sind?

Das Gold war Weligeld geworden aus den gleichen Gründen, weshalb es zur einzig anerkannten Geldware werden konnte, weil es von Natur zur gesellschaftlichen Funktion eines allgemeinen Äquivalents taugte. "Adäquate Erscheinungsform von Wert oder Materiatur abstrakter und waher gleicher menschlicher Arbeit kann nur eine Materie sein, deren sämtliche Exemplare dieselbe gleichförmige Qualität besitzen. Andererseits, da der Unterschied der Wertgrößen rein guantiativ ist, muß die Geldware rein quantitativer Unterschiede fähig, also nach Willkür teilbar und aus ihren Teilen wieder zusammensetzbar sein. Gold und Silber besitzen diese Eigenschaften von Natur." (MEW, 23, S. 304). Auch das Papier besitzt diese Eigenschaften und hat darüber hinaus den Vorteil, daß, während die Abnutzung der Goldstücke in der Zirkulation wirklichen Wertyerlust bedeutet, ein abgenutztes Papiergeldstück jederzeit praktisch ohne Wertverlust ersetzbar ist. Aber Gold stellte selbst Wert dar, während Papiergeld bloß Wert repräsentiert. Die von Marx noch angenommene wirkliche Repräsentation von Gold( daher auch die Regelung der Papiergeldquantität durch die entsprechende notwendige Goldmenge die es vertritt (MEW, 23, S. 138), ist immer mehr zurückgetreten. Die Aufhebung der Konvertibilität von Papiergeld in Gold, wie sie in der nationalen Zirkulation eingeführt wurde, hob auch die sich aus der Goldrepräsentation ergebenden Quantitätsgesetze auf. Die nationale Papiergeldmenge wird heutzutage durch die Notenbanken „manipuliert", und zwar der Theorie nach entsprechend den Notwendigkeiten der Zirkulation ${ }^{85}$ ).

Der nationale Geldwert bestimmt sich in der relativen Weise, wie wir es zuvor dargestellt haben. Die internationale Zirkulation weicht hiervon jedoch in wesentlichen Momenten ab. Dies wird schon oberflächlich symbolisiert durch die Bindung des Dollar an eine bestimmte Goldparität und durch das "Chaos', weiches durch die Aufkündigung der Konvertibilität des Dollar in

84) Forstmann, a. a. 0., 5. 516/17.

85) Die verschiedenen Theorien, die sich um das Problem von Geldmenge und Preisniveau drehen, konnen ner nicht behandett werden. 
Gold ausgelöst wurde. Aber ist der Wert des Dollars durch seine Goldpariag bestimmt? Um diese Frage zu beantworten, müssen wir uns der Probleme vergewissern, die es mil sich bringt, daß in Gestalt des Dollar Papiergeld z.um Weltgeld geworden ist.

Das Papiergeld muB in jedem Fall Wertquana repräsentieren, wena es auf dem Weltmarkt getauscht werden soll. Für die einzelnen nationalen Währungen haben wir entwickelt, daß sich diese Weriquanta als relativer Wert ("Kaufkraft") der Währung im Verhältnis zum Wert anderer Währung darstellt. Für den Dollar als Weltgeld gilt ebenso wie für jedes Geld, daß im relativen Wertausdruck, zu dem es anderen Waren verhilft, sein eigener Wert richt ausgedrückt wird. Man kann zwar sämtliche Wechselkurse rückwärts lesen und erhäll damit den Wert des Dollar ausgedrückt in allen anderen Währungen, aber die 118 Dollar-Werte, die man dadurch erhält (der IMF hai 118 Mitglieder) zeigen den Wert des Dollar wiederum nur als relativen Wert, als Repräsentant des durchschnittlichen Warenwerts der seitens der USA auf dem Weltmarkt getauschten Waren, bezogen auf die Warenwerte der jeweiligen Länder. Der Dollar als aligemeines Aquivalent der anderen Währungen, der den Wert dieser Währung zu messen hat, kann dies nur aufgrund der internationalen Warenwerte, die er repräsentiert. Auch beim Gold wurde eine spezifische Arbeit (Goldproduktion) zum Repräsentanten der abstrakt allgemeinen, gleichen Arbeit. Im Dollar aber wird eine spezifische nationale Arbeit (und damit eine bestimmte nationale Produktivkraft der Arbeit) zum Repräsentanten der universellen Arbeit. Der Wert des Weitgeldes und damit seine Fähigkeit, zum Material des Wertausdrucks der auf dem Weltmarkt gehandelten Waren zu dienen, hängt somit von einer Unmenge von Faktoren ab, die die Entwicklung der Produktivkraft der Arbeit in den USA bedingen (langfristiger und konjunktureller Art, aber auch "monetärer" Art wie die Inflation). Sind die Wechselkurse anderer Währungen in Dollar fixiert, so sind in unmildelbarer Weise die verschiedenen nationalen Arbeiten miteinander verkoppelt. Verschiebungen der Wertverhältnisse zwischen den nationalen Kapitalen müssen sich in Änderungen der Währungsparitäten niederschlagen.

Was wir gegenwärtig erleben, ist der Versuch, durch eine umfassende Änderung der Wechselkurse die relativen Werte der verschiedenen nationalen Währungen neu zu bestimmen und den reąlen Verhältnissen anzupassen. Dies bringt unlösbare Schwierigkeiten mit sich. Wie soll man den relativen Wert einer Währung "berechnen", wenn dies erfordern würde, daß man die relativen Werte sämtlicher auf dem Weltmarkt getauschten Waren „berechnen" müBte, $d$. h. die entsprechende Produktivkraft der Arbeit, die verausgabte Arbeit pro Woche, die an der kapitalistischen Oberfläche gar nicht erscheint, weil dort nur die bezahite Arbeit (Lohn) als Arbeit, die unbezahite Arbeit aber als Mehrwert in seinen verschiedenen Gestaiten (Profit, Zins, Grundrente) zu Tage tritt. Letzlich bleibt nur das Mittel des "Floating“ (oder der erweiterten Bandbreiten. d. h. einer größeren Schwankungsmöglichkeit der Kurse), um im Vergleichungsprozeß $B$ auf dem Markt die verschiedenen 
nationalen Währungen au ihren Wert zu reduzieren. Auch hier seizt sich das Wertgesetz eben nur vermitzels der Zirkulation durch.

Dle einzig mögliche Bestimmung des Wertes des Dollar als relativem Wert augrund der relativen Werte der von ihm repräsentierten Waren, bringt in dem Moment eine un sich greifende Unsicherheit in die internationale Zirkulation, in dem die amerikanischen Waren und das exportierte Kapital aufgrund des realen vergleichungsprozesses auf dem Weltmark zunehmend auf die Konkurrenz anderer Länder treffen, der sie weniger als früher gewachsen sind. Der Wert des Dollar wird trotz oder gerade wegen der Fixie-

\title{
Sanierung = furr wen?
}

GEGEN SOZIALSTAATSOPPORTUNISMUS UND KONZERNPLANUNG

\author{
Eine Texisamming. \\ herausgegeben vom \\ Büro für Stadtsanierung \\ und soziale Arbeit \\ Berlin-Kreuzberg
}

2., erweiterle Auflage Juli 1971 (352 S. / IBM-Schreibmaschinen-Satz / DM 8,50)

Die Textsammlung gibi einen Überblick über die sctialen Konsequenzen kapitalistisch betriebener Wohnungs- und Sanierungspolitik.

Sie verdeutlicht den Beitrag bürgerlicher Sozialwissenschaften zur Durchführung fechnokratischer Peformen und liefert Material und Ansätze für eine Aufarbeitung der "städtischen Reiorm" im Rahmen der Klassenanalyse.

Neben historischen Beispielen wie den Wiener Arbeiter-Wohnungsbau der zwanziger Jahre und der Geschichte der Mieistreiks in Großbritannien vertieft die Textsammlung die Frage -- von Politikern z. Zt. heraufbeschworen, von technokratisch orientierten Sozialwissenschaftlem heruntergespielt - inwiefern Stadtentwicklung und stadtsanierung in der BRD in derselben Richtung verlaufen, wie seit geraumer Zeit in den USA: in Richtung auf eine Katastrophe städtischer infrastruktur.

Sei genauerer Kenntnis der Entwicklungstendenzen wird deutlich, daß stückweise Reiormen darauf nicht die adäquate Antwont sind; daB der Angriff des Kapltals auf die Lebensbedingungen der Abhängigen vielmehr eine offensive proletarische Klassenpolitik notwendig macht.

ZU BEZIEHEN über: die Buchlädien des Verbandes des linken Buchhandels oder direkt vOM BÜO FUR STADTSANIERUNG UND SOZIALE ARBEIT

1 Berlin 36 , Postfach 244 
rung der Wechsekurse "angezweifelt", das Vertrauen in das Welgeld nimm ab und die Suche nach einer anderen allgemeinen Form des gesellschathlichen Reichtums setzin.

Es ist kein Zuiali, daß in den leizten jahren das Gold immer mehr in den Vordergrund der Debatten rückt. Denn bel einem drohenden Zusammenbruch der internationalen Zipkulation ist der Umschlag aus dem System des Wellpapiergeldes in das "Monetarsystem" schier unausweichlich. Es entsteht die Notwendigkeit der Rückverwandung aller nur repräsentativen Formen des Geldes (Papiergeld, Wechsel, Bankguthaben) in mirkmohe Werquanta die

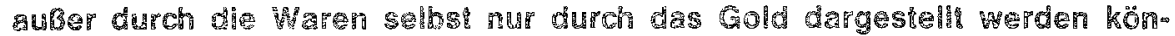
nen. Der Wert der Währungen würde in diesem Falle wieder am Goldwert gemessen und nicht mehr nur als relativer Wert zwischen den verschiedenen Währungen. Das Gold wäre wieder internationales Mals der Verte.

Trotz einer festzustellenden Tendenz zur "Remonetisierung des Goldes" ist das internationale Währungssystem noch weit vom Endpunkt einer solchen Entwicklung entrernt. In dieser Tendenz zeigt sich zwar "das interesse an bestimmten stabilisierenden Elementen im Weltwirtschaftsprozeß..., um die Dynamik der Produktivität mit dem gesellschattichen Charakter der AuBenwirtschaftsbeziehungen zeliwellig in Ubereinstimmung zu bringen" ${ }^{\text {so }}$, aber dieses Interesse drückt sich derzeit viel eher in den Versuchen aus, aur internationaler Ebene augrund von pollischen Vereinbarungen zur Neuregelung des Währungssystems zu kommen, wobei die Vorschläge etwa für eine Welbank, die eine "neutrale" Weltwährung entsprechend den internationalen Liquiditäłsbedünfnissen schöpten kann, an den Strukturen anknüpten, die bereits mit dem System von Bretton Woods in der internationalen Zirkulation ebablert wurden. Wir müssen deshalb diese Strukturen vor allem unter dem Aspekt der 2 ilgemeinen Bedingungen untersuchen, die es zuließen, daß Paplergeld (im Dollar ein nationales) zum Weltgeld wurde. Auf dem Weltmarkt können einzelne nationale allgemeine Aquivalente (nationale Währungen) zu Weltgeld mit der Funktion des Zirkulations und Zah lungsmittels werden, wenn sie als solche anerkannt werden, wenn also die Warenverkäufer der Länder A, B, C das Geld des Landes $Z$ jederzeit als Weltgeld, als Kaufmittel akzepieren. Das wérden sie aber nur, wenn (1) dieses nationale Geld des Landes 2 jederzeit in die allgemeine Wertgestalt (Gold) umtauschbar ist, wenn (2) mit diesem nationalen Geld des Landes $Z$ jederzeit wieder waren gekauit werden können, ohne dab dabei Wertverluste (durch Kursverfall der Währung oder Preisanstieg der Waren) entstehen, wenn dieses Geld also auch in der nächsten Zirkulationsrunde als Kaufmittel fungieren kann und wenn (3) dieses Geld jederzeit als Zirkulations- und Zahlungsmittel auch für Geschäfte zwischen Ländern $E$ und $F$, die dio Wäh rungen $a$ und $f$ besitzen, beschaift Merden kann. Die dritte Bodingung or fordert einen weitlaufigen Ausbau des Bankensystems des Landes $Z^{27}$ ).

8) Kühno, a. a. 0. \$. 166.

87) Vgl. Hür die USA: Harry Megdof, Das Zeitalter des Imperialismus, Frankpurt/M., $1970,5.59$ If. 
Diese Bedingungen beziehen sich wohlgemerkt nur auf das Weltgeld in Form des Papiergeldes. Daß nationales Geld zum Weltgeld werden kann, setzi bereits eine bestimmte Entwicklungsstufe in der Integration des kapitalistischen Weltmarktes voraus. Dieser hat sich erst in den letzten 100 Jahren ais kapulizalistischer Weltmarkt herausgebiidet. Vermittelt über Krisen, Kriege und Verschiebungen der Machtverhältnisse zwischen den einzelnen kapitalististischen Staaten hat sich die Internationalisierung des Kapitals vollzogen. Hierbei hatten die Formen, in denen das Kapital auf den Weltmarkt trat, zu den verschiedenen Zeiten ein unterschiedliches Gewicht. Zwar gab es schon vor 1914 internationale Trusts, aber das Kapital trat wesentlich als Warenkapital und zinstragendes Kapilal (Leihkapital) auf den Weltmarkt ${ }^{88}$ ). Seitdem hat sich schrittweise und parallel zur Akkumulation im Rahmen des Nationalstaates die Akkumulation in Form von Konzentration und Zentralisation des Kapitals im internationalen Maßstab entwickelt. Die Durchsetzung des Wertgesetzes auf dem Weltmarkt führte zu einer schrittweisen Vertiefung der Konkurrenz der Kapitale in dem Sinne, daß auch die Produktion des Kapitals internationalisier wurde. Die sogenannien "multinationalen" Konzerne, die sich vor allem nach dem Zweiten Weltkrieg in vielen Produktionszweigen (Öl, Chemie, Elektronik, Autoproduktion) gebildet haben ${ }^{89}$ ), sind die Form, in der diese Internationalisierung der kapitalistischen Produktion erscheint. Die Internationalisierung der Produktion in einigen Produktionszweigen wurde jedoch begleitet von eine weiterhin eng nationalstaatlich bestimmten Akkumulation in anderen Produktionszweigen. Das bedeutet, daß der Weltmarkt zwar einerseits zusehends nicht nur vom Austausch der Waren und dem Verkehr des Leihkapitals her ein "integrierter Markt" wurde, sondern vielmehr der Internationalisierung des Warentausches eine Internationalisierung der Warenproduktion entspricht, daß aber andererseits der internationale Markt doch durch seine nur partielle "Integration" gekernzeichnet ist. Einerseits bildeten sich vor allem nach dem Zweiten Weltkrieg integrierte Großmärkte (USA, EWG, EFTA, japanische Einflußzone) heraus, andererseits dienten diese Formen der "regionalen" Integration der Abschirmung nicht auf dem Weltmarkt konkurrenzfähiger Industriezweige und zugleich der Konkurrenz zwischen den "Wirtschaftsblöcken". Einem solchermaßen nur halb integrierten Weltmarkt muß notwendigerweise eine halb integrierte Form der Zirkulation entsprechen ${ }^{90}$ ).

88) Vgl. das Gewicht, welches Hilferding und auch Lenin dem Finanzkapital zumaBen.

89) Auch in der Zwischenkriegszeit gab es internationale Konzerne, allerdings nicht in dem Umfang und mit dem für alle wirtschaftlichen Prozesse großen Gewicht, wie es nach dem zweiten Weltkrieg der Fall ist.

${ }^{20}$ Die ansatzweisen Versuche, vor dem zweiten Weltkrieg zu integrierten Wirtschaftsblöcken zu kommen, scheiterte nicht nur an der Weltwirtschaftskrise, sondern vor allem daran, daß die wichtigsten kapitalistischen Staaten (England, USA, Frankreich) koloniale und halbkoloniale EinfluBzonen besaBen. Diese wur: 
Die Etablierung des Systems von Bretton Woods geschah zu einer Zeit, da die internationale Zirkulation durch die Weltwirtschaftskrise und den Krieg zusammengebrochen war. Der Dollar als Weltgeld wurde aufgrund der absoluten (damals sich politisch und militärisch ausdrükkenden) ökonomischen Vormachtstellung der USA inthronisiert. Zwar haben 29 Staaten das System gegründet, de facto aber war es nur ein Staat, nämlich die USA, welcher sich hier quasi ,weltstaatliche' Machtpositionen gesichert hatte und sie mit der Inthronisierung seiner nationalen Währung als internationales Geld bestätigen ließ. Denn Deutschland und Japan waren zerschlagen, der britische Kolonialimperialismus brach zusammen, das Pfund Sterling als Weltgeld hatte schon in der Weltwirtschaftskrise abgedankt, die Londoner City als Weltfinanzzentrum war zurückgedrängt, Frankreich und seine Währung waren ausgepowert. Damit war es eine sehr klare Entscheidung, welche Währung im neu errichteten Währungssystem von Bretton Woods die Rolle des Weltgeldes, d. $h$. die Rolle des Substituts und Stellvertreters des Goldes einnehmen mußte: der Dollar. Unter diesem System näherte sich die Form des Weltgeldes der einer nationalen Währung an. An die Stelle des Goldes als einziger Inkarnation des gesellschaitlichen Reichtums trat mit dem Dollar ein Papiergeld mit staatlichem Zwangskurs: mit einer festen Gold-Dollar-Parität von 35 Dollar je Unze Gold Dem Staatspapiergeld entsprach jedoch nur solange die begrifflich vorausgesetzte zentrale politische Autorität, als die USA tatsächlich ökonomisch und politisch den gesamten kapitalistischen Weltmarkt beherrschten. Sie waren auch allein verantwortlich für die Stabilität des Dollars und schienen diese "Verantwortung" vor allem kraft ihrer hohen Goldreserven tragen zu können. Zur Zeit der Gründung des IMF war die Bindung des Dollar an das Geld auch insofern noch eine reale als eben aufgrund des damaligen desolaten Zustandes des Weltmarktes die allmähliche Loslösung des Papierweltgeldes vom Gold noch nicht möglich war; denn die zirkulierten Dollars waren in der Masse nicht mehr als die USA Gold besaßen. Dies änderte sich aber durch die Wiederingangsetzung der internationalen Zirkulation und

den in der Krise nach dem Zusammenbruch des Weltmarktes zur Grundlage von autarken Wirtschaftsräumen. Die "Entkolonialisierung" nach dem zweiten Weltkrieg sowie die Abschaffung des Kapitalismus in den osteuropäischen Staaten, was mit einem Forffall von Rohstofflieferanten und Absatzmärkten von Industriewaren vor allem der mittel- und westeuropäischen Staaten verbunden war, wurden zu wichtigen Bedingungen dafür, daß die kapitalistischen Länder über eine relativ lange Zeit stabile große Märkte schaffen konnten. Im Gegensatz zu den kolonialen oder semikolonialen Einflußzonen der einzelnen imperialistischen Staaten sind die integrierten Großmärkte aber nicht autark, da nicht von einem einzigen Nationalstaat eindeutig dominiert. Verwertungs- und Realisierungsprobleme wichtiger kapitalistischer Länder werden daher innerhalb dieser Wirtschaftsblöcke zu Konkurrenzkämpfen der „feindlichen Brüder“ führen. Die Konkurrenz drückt sich auch in Konflikten um die ,Leitwährung' des jeweiligen Blocks aus, wie am Beispiel der Pläne für eine europäische Währungsunion sichtbar wird. 
durch die Authebung der "Devisenzwangswirtschaft" sowie die volle Herstellung der Konvertibiliät der Währungen, durch welche sich die Funktionen des Weitgeldes erst voll durchsetzen konnten ${ }^{91}$ ). Während jedoch im natlonalen Rahmen für sämtliche Währungen inzwischen die Konvertibilität in Gold abgeschaift wurde, und sich somit die Papiergeidbesitzer auf der Suche nach einem "neutralen Reserveinstrument" - wie es die bürgerliche Okonomie nennt - diversen absolut sicheren Anlagemöglichkeiten zuwenden müssen (Grund und Boden z. B., sogenannte Sachwerte, aber auch noch Edelmetalle, wie besonders in Frankreich), wenn sie nicht daraut hoffen - was trügerisch ist -., daß der Staat selbst für den Geidwert Sorge iragen und bei einem Bankerott der nationalen Währung zur Rechenschast gezogen werden könne. hing über den Weltmarktländern das Damoklesschwert der Konvertibilität des Dollar in Gold im internationalen Zahlungsverkehr. Die USA konnten zwar für eine bestimmte Phase den Weltmarkt absolut dominieren; das Wertgesetz als Gesetz der kapitalistischen Konkurrenz mußte ihnen eines Tages einen Strich durch die Rechnung machen. Die absolute Nowendigkeit der Pepräsentation von Wertquanten durch das Papiergeld, die im nationalstaatichen Rahmen auf Kosten der "Nichtsachwertbesitzer", $d$. h. der Lohnarbeiter, umgangen werden kann, blieb im internationalen Rahmen erhalten. Während die verschiedenen kapitalistischen Staaten ihre interne Währung immerhin in Dollar umwandeln konnten, falls die nationale Währung auf dem Weltmarkt nichts galt ${ }^{92}$ ), gab es für den Dollar als Weltgeld nur noch das Gold als MaB seines Wertes, als absolute Form des gesellschaftlichen Reichtums. Der "Wer" des Dollar hing allerdings - wie wir gesehen haben - keineswegs allein von den Goldreserven ab. Einerseits nämlich wurden die verschiedenen nationalen Währungen mittels fester Paritäten an den Dollar, andererseits der Dollar selbst in gleicher Weise an einen bestimmten "Goldpreis" gebunden. Die feste GoldDollar-Parität schien den Traum der bürgerlichen Okonomie vom "festen Geldwert" endlich zu verwirklichen (Grundrisse, S. 53). Gerade das Gegenteil ist eingetreter. Das einzige, was beim Geld wirklich fixiert ist, ist der Mafsetala Dreise ( 1 Dollar, 10 Dollar, 1000 Dollar). Dieser Maßstab bleibt, ewig' erhalten. Der Geldwert selbst jedoch ändert sich.

91) Vgl. Kühne, a. a. 0., \$. 157.

"2) Der Umtausch einer "weichen" Währung in "harte" Dollars war natüplich nicht dem Staat ohne weitere Verplfichtungen möglich. Auch der "Mann auf der StraBo" hat diese Gelegenheit nicht. Wohl aber können große Kapitalisten davon Gebrauch machen - und die nationale Währung vollends ruinieren, wis der Großkapiualist Stinnes in der deutschen inflatio 11922 - 1924 vorexerzlerte. Durch Dollarkäufo mit Relchsmark gelang es ihm, den Wert der Währung syste. matisch zu drücken, was inn einerseits entschuldete, da ja alle ausgenommenen Kredite von Tag zu Tag real weniger wert waren und nur noch "Schwerte", die er sich mit den Krediten verschaffte, zählten, und was ihm andererseits den Vor. wand lieferte, vom "deutschen Yolk", also der Arbeiterklasse, zusätzliche Mohr. arbeit, nämtich Aufhobung des nach der Revolution eingeführten a-StundenTages, zu fordern. 
Er schwankt mił den Veränderungen der gesellschafttich notwendigen Arbeiszzeit, die in der Geldware inkorporiert ist, beim Papiergeld mit der durch es repräsentierten nationalen Arbeitszeif. Jede langfristige Senkung des "Werts des Dollar" mußte deshalb zu einem Verirauensschwund, d. h. zur berühmten "Flucht aus dem Dollar" führen. Die Flucht aus dem Dollar, gekennzeichnet durch den Umtausch von Dollar gegen Gold bei der amerikanischen Notenbank (Frankreich) oder durch Ankauf von Gold auf dem Goldmarkt, war andererseits nur in dem Maße möglich, wie sich die kapitalistischen Konkurrenten der USA dies ökonomisch und politisch leisten konnten, d. h. wie stark sie selbst auf dem Weltmarkt wurden und damit ihre Abhängigkeit von den USA verminderten.

Da der Dollar als Weltpapiergeld mil Zwangstirs allgemeines Aquivalent einer nur partiell integrierten Zirkulation war, blieb die Repräsentation von wirklichen Wertquanta durch das Papier der nur nationalstaatlich bestimmten - anders ausgedrückt - der imperialistischen Politik der USA überlassen. Die internationale Zirkulation konnte so lange relativ reibungslos funktionieren und der Dollar so lange die Funktion des allgemeinen Äquivalents ausüben, wie der Wechselkurs des Dollar gegenüber den anderen Währungen im allgemeinen die Weriverhälthisse widerspiegelte (hierzu waren in den ersten Jahren nach dem Krieg gewaltige Abwertungen ${ }^{93}$ ) der politisch überbewerteten Währungen vor allem Frankreichs und Englands notwendig. Der Dollar repräsentierte insofern wirkliche Wertquanta, als mit ihm tatsächlich jederzeit Waren gekauft oder Geldkapitalquanten in Dollar sich gegen Produktionsmitzel und Arbeitskrati austauschen konnten, sich amerikanisches Kapital also überall verwerten konnte. Die Goldbindung dos Dollar war hierbei nur von zweitrangiger Bedeutung. Es wäre, solange die Weltmarktzirkulation reibungslos funktionierte, auch gleichgültig gewesen, ob der Dollarpreis des Goldes 35 pro Unze oder 70 oder 100 betragen hätte. Genau wie in der nationalen Zirkulation das Geld als Maß der Werte und als Kaufmittel fungiert, ohne daB Goldkonvertibilität existieren muB, kann in der internationalen Zirkulation diese Konvertibilität sozusagen als "VertrauensvorschuB" fungieren, d. h. aktuell keine Bedeutung haben. Sobald aber das Papierweltgeld selbsit an Wert verliert (durch Inflation z. B) oder die internationale Zirkulation ins Stocken gerät, findel auch hier eine Flucht in die "Sachwerte" statt, die sich im Gegensatz zur nationalen Zirkulation nicht als

13) Di eAbwertungssätze der wichtigsten Weltwährungen gegenüber dem Doliar in den Jahren 1945 bis 1950 betrugen zum Teil bis zu 50 v. H. Oberhaupt spiegeln sich in den Kursveränderungen der Währungen gegenüber dem Dollar die sich ändernden Weltmarktverhältnisse empirisch wider. Das Prund Sterling wurde nach dem zweiten Weltkrieg zweimal abgewertet. Es fiel vo neiner Parität von mehr als 4 Dollar auf eine solche von 2,46 Dollar. Der Franc sank von etwa 0,8 Dollar auf 0,18 Dollar. Die DM sank von 0,30 Dollar bis 1961 auf otwa 0,25 Dollar, um heute wieder 0,30 erreicht zu haben. Vgl. die instruktive Graphik der Paritätsveränderungen seit dem zweiten Weltknieg in: Der Spiegel, Nr. 35/4971. 
Erwerb von Grund und Boden, Häusern, dauerhaften Konsumgütern etc. äußern kann, sondern nur als Erwerb von Gold. Die Goldkonvertibilität des Dollar wird also gerade dann von größter Wichtigkeit für den Weltmarkt, wenn sie de facto gar nicht mehr möglich ist. Die Folge ist dann notwendigerweise eine Goldpreissteigerung, d. h. umgekehrt eine Senkung des Dollarpreises ausgedrückt in Gold. Es ist interessant, daß wir diesen Prozeß seit Anfang der 60er Jahre anhand der Goldspekulation verfolgen können, die es entgegen den Interventionen der Zentralbanken (Bildung des Goldpools) geschafft hat, für Gold einen "freien Markt" zu erzeugen, auf dem tendenziell der Dollarpreis des Goldes steigt. Dieser Prozeß wäre auch dann einGetreten, wenn der Dollarpreis des Goldes nicht bei 35, sondern bei 70 oder irgendeiner anderen Größe gelegen hätte, da es hier nur auf die Wertrelationen ankommt und die Skala des Maßstabs der Preise g'eichgültig wird. Mit der Veränderung der internationalen Konkurrenzbedingungen, der wachsenden Konkurrenzfähigkeit anderer kapitlistischer Staaten verloren die USA ihre absolute Weltmarktdominanz, dem Dollar entstand Konkurrenz durch die Währungen, die innerhalb bestimmter Wirtschaftsblöcke kraft deren Dominanz durch ein nationales Kapitel, allmählich die Rolle eines zumindest nicht aliein nationalstaatlichen allgemeinen Aquivalents zu spielen begannen (DM, Yen, und immer noch das Pfund im Sterling-Block). Gleichwohl konnten die USA allein aufgrund ihrer politisch-militärischen Macht und der Abhängigkeit einzelner nationalstaatlicher Kapitale (vor allem die wichtigsten Konkurrenten auf dem Weltmarkt, nämlich die BRD und Japan) von diesem "Schutz", auch noch die Vorherrschaft des Dollar als Weltgeld aufrechterhalten.

Wenn wir bislang nur von der Funktion des Weltgeldes als Rechengeld und Zirkulationsmittel gesprochen haben (vgl. die Erörterung des Werts der Währungen), so hatte das sein Recht in der Tatsache einer relativ - und nach der weitgehenden Abschaffung der Devisenbewirtschaftung und der vollen Konvertibilität der Währungen der wichtigsten kapitalistischen Länder (wobei Japan eine gewisse Ausnahme machte) - einige jahre sehr gut funktionierenden internationalen Waren- und Kapitalzirkulation. Als Banknote ist der Papierdollar aber, auch wenn er in der Zirkulation blOB als Kaufmittel fungiert, Kreditgeld. Jeder Dollarbesitzer hat einen Wechsel auf die Zentralbank der USA in Händen, den er in Gold umtauschen konnte. Ähnliches gilt für die anderen nationalen Währungen, allerdings nur in dem Sinne, daß sie jederzeit in das Weltgeld Dollar konvertierbar sind. Früher konnten die Banken, die Noten ausgaben, nur partiell bei drohendem Bankerott durch staatliche Intervention von der Pflicht zur Konvertibilität enthoben werden. Heute, da die Banknotenausgabe ein staatliches Privileg ist (Notenbanken), fungiert die Banknote faktisch nur noch im internationalen Rahmen als Kreditgeld. Sofern der Dollar bei den Notenbanken der anderen Staaten als Reservewährung angelegt wurde, beruhte dieses 
Reservesystem somit auf Krediten, die diese Notenbanken der amerikanischen Notenbank gewährten, indem sie nationale Währung gegen Dollar eintauschten. Solange sich die amerikanische Zahlungsbilanz im Gleichgewicht befand, gaben diese Kredite keinen Anlaß zur Beunruhigung. In dem Maße, wie aber das Defizit der amerikanischen Zahlungsbilanz, vor allem durch Kapitalexporte in Dollarform anwuchs, und die amerikanische Zahlungsbilanz ist seit 1950 (mit der Ausnahme des Jahres 1957) defizitär, wuchsen die internationalen Kredite dermaßen, daß die ganze Künstlichkeit des Systems in der Krise zu Tage treten mußte. Denn durch die Tatsache, daß die Salden in den Zahlungsbilanzen der verschiedenen Länder wiederum durch Weltpapiergeld (Dollar) ausgeglichen wurden, entwickelte sich ein verzweigtes System des internationalen Kredits, das letztlich allein auf der Fähigkeit der amerikanischen Zentra!bank beruhte, die in der Weltzirkulation umlaufenden Dollars zu garantieren. Der Goldreserve des Federal Reserve Board kam somit die Bedeutung zu, Reserve für nahezu das gesamte internationale Kreditsystem zu werden. Der illusorische Charakter des Geldes (wirklichen Geldes, also Goldes) im Kreditsystem, wie inn Marx analysiert hat ${ }^{94}$ ), kommt hierin schlagend zum Ausdruck. Die Konvertibilität des Doliar in Gold konnte deshalb nur ein schwacher Trost sein (und nur lllusionisten wie der Franzose Rueff konnten sich vorstellen, das ganze Dilemma durch eine Reinthronisierung des Goldes als Weltgeld zu lösen). Denn erstens bestand stets die Möglichkeit - die inzwischen zur Wirklichkeit geworden ist, daß die amerikanische Regierung die Konvertibilität aufhob. Zweitens aber entsprachen die Goldbestände in Fort Knox jahrelang ungefähr der kurzfristigen Verschuldung der USA im Ausland, keineswegs aber den Dollarbeständen der Notenbanken (heute 51,3 Mrd). Der Unterschied zwischen nationaler und internationaler Zirkulation, sofern er sich aus der Tatsache der nur partiellen Integration des Weltmarktes ergab, wird nun in dem Punkt entscheidend, daß einem national integrierten Markt auch eine politische Zentralgewalt entspricht, die jeden Schuldner rechtlich, notfalls polizeilich, zur Bezahlung seiner Schulden zwingen kann. Dies ist im internationalen Rahmen nicht möglich, wenn man die Möglichkeit eines Krieges, der zudem gewonnen werden muß, ausschließt. Handelte es sich bei den Gläubigern der USA um privates Kapital, so könnte dies eventuell über die amerikanische Gerichtsbarkeit seine Forderungen einklagen. Da es sich aber um nationale Notenbanken handelt, ist der Konflikt unmittelbar ein politischer, der mittels staatlicher Maßnahmen (in letzter Instanz der Enteignung von amerikanischem Kapital in jeweiligen Land) ausgetragen werden muß. Die Grenzen, die einem Weltpapiergeld durch den Unterschied zwischen nationaler und internationaler Zirkulation gesetzt sind, zeigen deutlich genug, wie sehr Marx recht hat, wenn er schreibt, daß in der Geldkrise (und in der Krise überhaupt) der Umschlag des Kreditsystems

ni) Vgl. Kapital III, 35. Kapitel "Edelmetall und Wechselkurs", MEW 25, S. 580 f. 
in das Monetarsystem notwendig ist. Der "Vertrauensschwund" wird umso stärker sein, je stärker die Krise ist. Wenn außer dem Gold schließlich keine Geldform mehr als internationales, allgemeines Aquivalent akzeptiert wird, ist der Weg nicht mehr weit zu dem Zeitpunkt, da als Werte aut dem Weltmarkt nur die Waren seibst gelten, was zwangsläufig zu einem Zusammenbruch der Weltzirkulation und zum Übergang zum Bilateralismus führen muß, wie in der Weltwirtschaftskrise von 1929. Die Angst vor einer solchen Entwicklung ist in diesen Wochen in allen Kommentaren zur Währungskrise herauszulesen. Das Vertrauen in das Weltgeld, soiern es Papiergeld ist, gilt nämlich nicht diesem Geld, sondern der funktionierenden Zirkulation, die selbst nur Resultat einer florierenden Produktion ist: "Es ist das Vertrauen in den gesellschaftlichen Charakter der Produktion, welches die Geldform der Produkte als etwas Verschwindendes und Ideales, als bloße Vorstellung erscheinen läßt" (MEW, 25, S. 588). Insofern stelit die bürgerliche Presse und die bürgerliche Okonomie das Verhältnis auf den Kopf, wenn sie meint, das System von Bretton Woods mit seinen festen Wechselkursen habe einen "ungeahnten" Aufschwung des internationalen Handels und damit der nationalen Wirtschaften hervorgeruien. Umgekehrt: durch die riesige Vernichtung von Kapital in der Weltwirtschaftskrise und während des Zweiten Weltkrieges, die damit gegebenen günstigen Verwertungsbedingungen des Kapitals, die absolute Vormachtstellung der USA sowie die Möglichkeit des US-Kapitals, sich überall hin auszubreiten, funktionierte die Weltmarktzirkulation jahrelang gut, und deshalb auch das Währungssystem.

Die Situation 1971 ist noch um einiges von der oben beschriebenen Konsequenz des Rückfalls in den Bilateralismus entfernt. Sie ist durch Versuche gekennzeichnet, der Währungskrise durch eine erneute internationale polltische Ubereinkunft $(z$. B. durch die Schaffung neuer kollektiv garantierter Reserveinstrumente, wie schon bei den Sonderziehungsrechten, die - zwar nicht konvertibel - immer noch an das Gold gebunden sind), zu begegnen. $\mathrm{Da}$ dies heute wesentlich schwieriger sein wird als 1944 zeigen die bislang statigehabten Konferenzen, auf denen nicht nur die Konkurrenz der anderen kapitalistischen Länder gegenüber den USA, sondern auch die Konkurrenz zwischen allen kapitalistischen Ländern schon lange nicht mehr bekannte politische Formen angenommen hat ${ }^{95}$ ). Die USA pochen auf ihre immer noch bestehende politische und militärische Vormacht und setzen die anderen Länder unter Druck: „Amerika weiß seinen Einfluß als stärksie Industriemacht richtig einzuschätzen. Bewußt haben die Amerikaner deshalb eine Lage geschaffen, in der sie alle anderen zu Verhandlungen zwingen können. Der Dollar mag als Leitwährung abgedankt haben, indem or sich nich mehr beliebig umeauschan läBî. Aber für den andgühon Thronverzicht kann noch eine Gegenleistung yerlangt

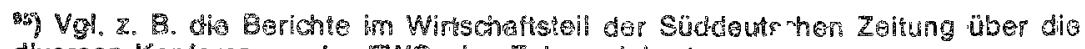

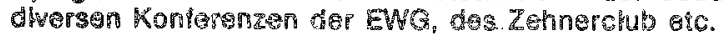


werden" $\left.{ }^{96}\right)$. Mit anderen Worten: die USA sind in der Position eines mächtigen Schuldners, welcher verlangt, daß seine Schuiden einfach reduziert werden. Angesichis dieser Situation sind wieder einmal alle Pläne, nach denen aine Weltbank gegründet werden soll oder der Dollar nur die gleiche Rolle spielen soll wie etwa die $\mathrm{DM}$, illusorisch ${ }^{97}$ ).

96) $5 Z, 14.9 .71$

"i) Die Widersprüchllchkeit der gegenwärtigen Situation schlägt sich in den sehr unterschiedlichen Lèsungsvorschlägen nieder, die von den verschiedensten Sei. ten angesichts der aktuellen Währungskrise vorgetragen werden. Sie schwanken zwischen den beiden Extremen: Umschlag ins "Monetrasystem", d. h. „Remonetisierung des Goldes", oder Verbesserung des internationalen Kreditwesens. So schreibt etwa das Deutsche Institut pür Wirtschaftsiorschung in seinem Wochenbericht Nr. 36/71: Die Gefahr könne nur gebannt werden, wenn "künftig eine inlernationale Reservewährung zur Verpügung gestellt wird, die nicht zugleich eine nationale Währung ist. Als internationales Reservemedium, das an die Stelle des Dollars treten kann, bieten sich die bereits eingeführten Sonderziehungsrechte beim Weltwährungsiond an". Hierzu müßten jedoch die ausländischen Doliarguthaben in SZR umgewandelt werden, was einer langiristigen Verschuldung der Vereinigten Staaien gegenüber dem Wellwährungsfond gleichkäme. Das Gold müsse aus der iniernationalen Zirkulation ausgeschaitet werden. Das würde jêdoch bedeuien: "Eine Neuordnung des Währungssystems, die den SonderziehungGrechten eine zentrale Rolle einräumi, setzt das Einversiändnis aller fühencen westlichen Industriestaaten voraus." Zu einer eher pessimistischen Einschätzung gelangt der Präsident der Bank of London and South America, Sir George Bolton, in einem Artikel in der NZZ (23. 9. 1971, S. 19). Bolton spricht von einer zunehmenden "Xenophobie" un ddavon, daß "kein militärischer Druck eire Eingung zwischen den verschiedenen Ländern erzwingt". Er schlägt deshaib eine Umwandlung der amerikanischen Schuld in Gestalt der Dollarbestände auBerhalb der USA in "Darlehen", d. h. in eine ordentliche Staatsschuld, vor, also eine direkte, offiziell sanktionierte Verschuldung, ohne Einschaltung des Weltwährungsionds. Denn auf die verschiedenen stattfindenden Konferenzen setzt er keine großen Hofinungen. Von daher ist auch sein Vorschlag zu interpretieren, "einen neuen Mechanismus für die Goldtransaktionen" zu finden, der in der Bildung freier Goldmärkte bestehen würde. Bolton meint: "Es wäre weit besser, in der interimsphase, in der wir uns befinden, das Gold vollständig dem Tost eines freien Marktes zu unterwerfen", was der interpretation einer Tendenz zur "Pemonetisierung des Goldes" entsprechen würde. Der "Test", d. h. de? Marit soll den realen Wert des Goldes zum Ausdruck bringen, wodurch das Gold in der Tat wieder zum Maßs der Werte werden könnte. Bolton schätzł dis Tatsache, daß rund $40 \%$ der Währungsreserven der kapitalistischen Welt aus Gold bestehen, höher ein als alle internationalen Konferenzen.

Oberhaupt drückt sich in den gegenwäritig diskutierten Plänen zur "Neuordnung" des internationalen Währungssystems die Tatsache aus, daß zwar im einzelnen sehr viele Variationen möglich sind - und diese machen die Unzaht von verschiedenen Plänen aus --, aber im Grunde nur die Alternative besteht zwischen einem synthetisch zu schaffenden internationalen Papiergeld, der inthronisierung einer nationalen Währung als Weltgeld, und einem wenn auch modifizierten Goldstandard, in dem das Gold direkt und nicht über sinen Reprä. sentanten, der stets überfordent ist, als MaB der Wert fungiert. Die erste Möglichkeit setzt allerdings eine weitgehende ökonomische und politische Ubereinstimmung der Welmarktander yoraus, was gerade in Zellen sich verschiortender Konkurrenz kaum zu enwarten ist. Die zweire Alternative hat sich mit der Dollarkrise ais unmöglich herausgestell und die dritte Möglichein bleibt ous den oben angeithrten Gründen ausgeschlossen. Es blebp folglich zur "Retung"

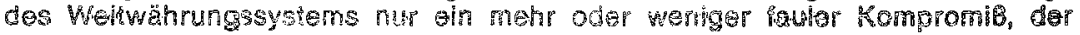


Gegenwärtig scheint es noch realistisch, davon auszugehen, daß sich am Ende der ganzen Krise im Hinblick auf die Gestalt des Weltgeldes wenig ändern wird. Sämtliche Pläne der relevanten kapitalistischen Länder in Bezug auf die Neuordnung des Weltwährungssystems deuten dies an. Man spricht von der Rückkehr zu festen Wechselkursen auf der Basis neufestgesetzter Faritäten und von mehr Elastizität der Bandbreiten, d. h. der Marge, in der die festen Wechselkurse schwanken können. Der Streit geht hauptsächlich um die Höhe der Paritätsänderungen, wobei bis zu ihrer Fixierung die Wechselkurse sich bereits durch das "Floating" auf neue Paritäten eingespielt haben werden (allerdings ist dabei zu berücksichtigen, daß das Floating z. T. durch staatliche Interventionen beeinträchtigt wird, was Schiller mit dem Terminus des "schmutzigen Floating" kennzeichnete ${ }^{98}$ ). Interes" sant ist in unserem Zusammenhang nur noch die Frage der Änderung der Gold-Dollar-Parität, weil sich hierin nicht nur eine Abwertung des Dollar ausdrücken wird, die die amerikanischen Kapitalexporte beeinträchtigen wird, sondern weil sich hierin vermutlich die "Remonetisierung des Goldes" widerspiegelt.

\section{3. Das Weltwährungssystem}

Wir haben hier in sehr allgemeiner und verkürzter Form die Leidensgeschichte des Dollar als Weltgeld beschrieben. Sie beweist, daß die Funktionen des Weltgeldes nicht einfach politisch zu manipulieren sind, sondern strengen ökonomischen Gesetzen unterliegen. Diese Tatsache wird zeitweise dadurch verhüllt, daß die Zirkulation reibungslos verläuft und die Repräsentation von Wert hinter die Funktion des Zirkulationsmittels zurücktritt. Aber gerät die Zirkulation durch Krisenerscheinungen ins Stocken, dann beginnt die Stunde der Wahrheit für das Weltpapiergeld. Versuchen wir nun, die Geschichte des Währungssystems genauer in den Griff zu bekommen, da sich nur so die theoretischen und praktischen Verzweigungen der Dollarkrise eröffnen.

Wenn wir uns die Technik des Systems von Bretton Wood genauer anschauen, so werden wir entdecken, daß vieles, was heute nur als technische Regelung erscheint (und als solche auch in den diversen Reformvorschlägen behandelt wird), seine tieferen ökonomischen Gründe hat. Die drei von uns abstrakt aufgeführten Bedingungen dafür, daß eine nationale Währung zur Weltwährung werden kann, finden wir in verkleideter Form in der Organisation des Weltwährungssystems wieder:

(1) Die Notwendigkeit der Umtauschbarkeit (Konvertibilität) der nationalen Währung in das wirkliche allgemeine Äquivalent, nämlich das

die nächste Krise schon in sich birgt, insbesondere dann, wenn die internationale Zirkulation aus Gründen, die dem Reproduktionsprozeß des Kapitals selbst geschuldet sind, ins Stocken gerät.

${ }^{08)} \mathrm{SZ}, 18 . / 19$. 9. 1971 . 
Gold, wird berücksichtigt in der Konvertibilitätsbestimmung des Dollar: jeder Dollar konnte jederzeit (jedenfalls von den Banken) präsentiert und in Gold verwandelt werden. Der Dollar war nach dem zweiten Weltkrieg in der Tat goldgedeckt, und so war die Konvertibilitätsbestimmung keine bloß technische Erfindung ohne ökonomische Basis wie etwa seit 1955, wo die Dollarguthaben im Ausland die US-amerikanischen Goldbestände zur Deckung dieser Guthaben überstiegen, oder gar ab 1965, wo klar wurde, daß jeder Dollarumtausch in Gold die USA in größte Schwierigkeiten zu bringen vermag (Beispiel Umtauschaktion Frankreichs), sondern die wesentliche Grundlage der Dollarvormacht. Aber zu dem Zeitpunkt, als die Goldbestände der USA nicht mehr die Dollarguthaben deckten, florierte bereits der Welthandel in einem AusmaB, daß auch "falsches Pfund Sterling für ein echtes" hätte zirkulieren können, ohne der Zirkulation irgendwie Abbruch zu tun $\left.{ }^{89}\right)$.

(2) Die Eintauschbarkeit des Dollar in Waren, ohne dabei Wertverluste zu erleiden, wurde realisiert durch das System fixer Wechselkurse mit nur geringfügigen Schwankungsbreiten. Wertverluste auf den Devisenmärkten wurden dadurch ausgeschaltet und die Verwandiung von Ware in Geld (nationaler Prägung) oder von Geld (nationaler Prägung) in Ware erleichtert ${ }^{100}$ ). Das System fixer Wechselkurse diente allerdings nicht nur der Handelserleichterung, sondern es ermöglichte überhaupt erst die Herausbildung eines nationalen Geldes als Weltgeld. In einem System freier Kurse, und zwar aller Währungen, kann es für das Wert$\mathrm{maß}$ der nationalen Geldwaren kein gemeinsames Drittes außer dem Gold geben. Daher war es nur konsequent, bei der Installation des Dollar-Papiergeldes als Weltwährung, alle Währungskurse auf die Dollareinheit - die wiederum auf das Gold bezogen ist - zu beziehen. Verändern sich die Währungsparitäten untereinander (etwa durch eine Spekulation, die sich bei freien Kursen allerdings leichter tut) und passiert dies eine längere Zeit, dann ist die Funktion des Weltgeldes durch eine nationale Währung nicht mehr wahrnehmbar.

sonđern auch das Geldkapital fungiert, werden die Geldströme auf dem sondern auch als Geldkapital fungiert, werden die Geldströme auf dem Weltmarkt auch dann in Dollar abgewickelt werden, wenn sis keinem

09) Karl Marx, Grundrisse der Kritik der politischen Okonomie, Berlin 1953, S. 125: „Wenn Ware a zum Preis von 1 Dollar gegen ein falsches Pfund (St.) ausgetauscht und diese falsche Pfund (St.) wieder ausgetauscht wird gegen Ware b von 1 Pfund St., so hat das falsche Pfund (St.) absolut denselben Dienst geten, als ob es ein echtes wäre. Das wirkliche Plund (St.) ist daher in diesem Prozels in der Tat nur ein Zeichen, soweit nicht das Moment betrachtet wird, wonach es die Preise realisiert, sondern das Ganze des Prozesses, worin es nup als Zirku. lationsmittel dient und worin die Realisierung der Preise nur ein Schoin, ver* schwindende Vermittlung ist. .."

100) Auch die Risiken freier Kurse können ausgeschaltet werden durch entsprechende Termingeschäfte. Zum Mechanismus vgl. Helmut bipfert, a. a. O. Allep dings sind solche Geschäfte mit Kosten verbunden und von der Spekulation ab. hängig, so daß sie nur einen schlechten Ersałz für fixierte Kurse darsiellen. 
Warentransfer entsprechen. Die Installation des Dollar als Reserveund Interventionswährung diente genau diesem Zweck. Einmal intervenierten die Zentralbanken auf den Devisenmärkten nur in Dollarwährung und wurden auf diese Weise notwendig in das weltweite Zahlungs- und Kreditsystem der USA einbezogen ${ }^{101}$ ), zum anderen ermöglichte die Tatsache, daß der Dollar Reservewährung war, die Eintauschung von Auslandswechseln, die auf Dollar lauteten, bei der Zentraibank in nationale Währung - was für andere Währungen nicht ganz so selbstverständlich war. Die Kaufleute der kapitalistischen Länder berücksichtigen dies dadurch, daß sie die Rechnungen vorwiegend in Dollar fakturierten. Dollarkonten gibt es daher bei jeder größeren Bank in den kapitalistischen Industrieländern ${ }^{102}$ ).

Daraus ergibt sich: Das allgemeine Weltmarktäquivalent, sofern es eine nationale Währung ist, muß gleichzeitig Reservewährung, interventionswährung und Leitwährung sein. Warum der Dollar diese Funktionen erfüllen konnte und derzeit nicht mehr auszuüben vermag und daher eine schwere Weltwährungskrise heraufbeschworen hat, ist nur historisch zu klären. Es ist hier nicht notwendig, auf die Feinheiten der technischen Organisation des Weltwährungssystems einzugehen, vielmehr soll kurz gezeigt werden, wie sich historisch die Entwicklung dieses System vollzog, die zu den heute aktuellen Resultaten führte. Das allgemeine Äquivalent auf dem Weltmarkt muß sich notwendig in dem Maße verschlechtern, wie es seine Funktion positiv erfüllt. Dieser in einem System, das auf einer nationalen Währung als Weltgeld beruht, eingeschlossene Widerspruch muß sich in Krisen Luft verschaffen. An dieser Stelle interessieren die Widersprüche, soweit sie aus der Besonderheit der Zirkulationssphäre auf dem Weltmarkt resultieren. Im nächsten Abschnitt wenden wir uns dann den in der Reproduktionsstruktur der einzelnen kapitalistischen Länder aufgebrochenen Widersprüchen zu. Um nach dem zweiten Weltkrieg den Welthandel wieder in Gang zu bringen, mußten die prospektiven Welthandeisländer mit Weltgeld (Zirm

102) Daraus resultiert auch der Vorwurf an die westeuropäischen Zentralbanken, nur Zweigstellen des Federal Reserve Systems der USA zu sein. ES ist amüsant, daB gerade die reaktionären US-Okonomen à la George Friedman diesen Vorwurf gerade dann erheben, wenn sich die europäischen Zentralbanken streng an die "Spielregeln" des Systems von Bretton Woods halten Vgl. Z. B. das Interview mit Friedman in: Walter Slotosch, Das Geld mit dem wir leben müssen, München, Wien, Basel 1971, S. $191 \mathrm{ff}$, insbesondere S. 192.

102) Seit dem Aufbrechen der Dollarkrise werden in zunehmendem MaBe internationale private oder staatliche Kontrakte in anderen als der Dollarwährung fakturiert. Von den Zentralbanken werden seit 1970 "DM-Anlagen als Währungsreserven ... zum ersten Mal in nennenswerten Größenordnungen " gehalten (Geschäftsbericht der Deutschen Bundesbank für das Jahr 1970, S. 36), private Kontrakte werden häufig in DM fakturiert und das österreich-tschechaslowakische Handelsabkommen vom August 1971 lautet nicht mehr wie üblich auf Dollar, sondern auf - Schilling. Seit dem Floating der DM hat allerdings die Möglichkeit, in DM abzuschließen, deutlich abgenommen, nachdem vorher etwa $90 \mathrm{v} . \mathrm{H}$. der Exportkontrakte Westdeutschlands auf DM gelautet hatten. Nach: Wirtschaftswoche, Nr. 37, 1971, S. 76. 
kulationsmittel) ausgestattet werden. Die Dollarwährung als ökonomisch einzig mögliche Weltwährung befand sich in den USA, die übrigen Länder litten unter chronischer "Dollarknappheit", zumal die meisten kriegführenden Länder hoch an die USA verschuldet waren. Durch Exporte in die USA wurden zwar Dollar in die Zirkulation auf dem Weltmarkt geworfen, da die USA die salieferten Waren in Dollar bezahlten, aber zumindest bis 1950 waren die kapitalistischen Länder außer den USA ökonomisch noch so schwach im vergleich zu den USA (die Produktivkraft der Arbeit war niedriger, die Verschuldung größer, die Kriegszerstörungen spielten eine Rolle, die Kommunikationsstruktur war unterbrochen, die Wirtschaftsstruktur $z$. T. einseitig auf den Krieg ausgerichtet usw)., daß die USA permanent weniger importierten und dadurch die gelieferten Dollars immer wieder der Weltmarktzirkulation entzogen. Die Warenexportüberschüsse der USA waren die beste Methode, um der Weltmarktzirkulation Weltgeld zu entziehen - und da als nationale Währung nur der Dollar die Rolle des Weltgeldes übernehmen konnte, die internationale Zirkulation über kurz oder lang zum Erliegen zu bringen.

In einer solchen Situation gibt es nur eine Möglichkeit, die internationale Zirkulation mit Geld zu versorgen. Die USA mußten den Weltmarktländern Kredite oder Schenkungen gewähren und ihnen auf diese Weise Dollars als Kaufmitel verschaffen. Diese Funktion erfüllte - obwohl nicht explizit zu diesem Zweck geschaffen - der "Marshallplan", in dessen Verlauf im Zeitraum 1948-1952 in die westeuropäischen Länder Dollarkredite im Umfang von etwa $13 \mathrm{Mrd}$. Dollar gepumpt wurden. War dies sozusagen die "Initialzündung" für die internationale Zirkulation, so taten die Militär- und "Entwicklungs"hilfen der USA in den folgenden Jahren das Übrige, um einzelne Nationalstaaten mit Kaufmitteln auszustatten ${ }^{103}$ ). Die Größenordnung dieser Dollarbeträge beläuft sich im Zeitraum Juli 1945 bis Dezember 1961 auf 82.9 Mrd Dollar und von 1962 bis 1969 sind jährlich zwischen 4,5 und 5 Mrd Dollar hinzugekommen ${ }^{104}$ ).

Ein weiterer Posten sind die privaten Kapitalanlagen der USA-Kapitalisten im Ausland, wird doch in diesem Fall von US-Kapitalisten mit Dollarwährung als Kaufmittel Produktivkapital („Direktinvestitionen“) oder fiktives Kapital, also Aktien, Obligationen usw. (.,Portfolioinvestitionen") im Ausland erworben. Allein die Bestände an Direktinvestitionen der USA im Ausland machten Ende 1969 70,8 Mrd Dollar aus,

103) Der Zweck der "Hilfen" war natürlich ein anderer, als internationales Zirkulationsmedium zu schaffen. Es ging darum, ein antikommunistisches Bollwerk zu setzen. Daß all die unterstützten Staaten dadurch, daß sie nun über Dollar verfügten, quasi-automatisch in die kapitalistische Weltzirkulation einbezogen wurden, war ein für den Imperialismus erfreuliches Nebenprodukt. Jalée geht zu Recht davon aus, daß den Ländern der dritten Welt so viel Kapital entzogen wird, daß diese ohne „Entwicklungshilfe" schon längst total ausgepowert wären. Pierre Jalée, Das neueste Stadium des Imperialismus, München 1971.

104) Quelle: Statistisches Jahrbuch der BRD 1971, S. 142*. 
denen noch (1965) 21.6 Mrd Dollar Portiolioinyestitionen hinzugezäht wercun müssen ${ }^{105}$. Kein Wunder also, daß die Zahlungsbllanz der USA noch dem zweiten Weltkrieg insgesamt permanent negativ war, obwoht die Handelsbilanz abenso permanent einen Uberschus auf. wies $\left.{ }^{100}\right)$. Beidas hängt unmittelbar zusammen. Denn die über dem Weltmakkidurchschnitt liegende Produktivität der Arbeit (wiedergespiogelt in der viel diskutierten "technologischen Lücke"107) in deri USA begünstigte die Waranexporte. Das relativ hohe Produktivitätsniveau war zugleich Garant dafür, daß der Dollar als internationales Kaufmittel auch "sicher" war, selbst wenn or nicht in Gold, sondern in ,ordinärer Warenpobbel" getauscht wurde. Die internationale Zirkulation konnte unter diesen Umständen (permanenter HandelsbilanzüberschuB) nur mit Dollar-Kaufmittel versorgt werden, wenn die USA eine negative zantungsbilanz "in Kauf nehmen". Auî die Dauer bedeutete dies, daß die Goldreserven der USA in die anderen kapitalistischen Staaten, vor allem nach Westeuropa unvertellt wurden. Der Goldbestand der USA verringerte sich von 1953 bis Mitte 1971 von 22,1 aut 10,6 Mrd Dollar. 将苚tend die Goldreserven Westeuropas von 5,4 auf 18,7 Mrd Dollar anstiegen ${ }^{198}$ ). Es ist daher auch keine Koninzidenz zweigr yonein. ander woitgehend unabhändig verlaufender Prozesse, wenn in der gegenwärtigen Krise der Dollar als Weltgeld entthront wird und gleichzeitig "zum ersten Mal in der amerikanischen Geschichte seit 1893 " (wie es immer mit schreckhaftem Erstaunen in allen Berichten über die Dollarkrise vom August 1971 hieß) die Handelsbilanz negativ wird. Denn beiden Prozessen liegt die gleiche Ursache zugrunde: Rückgang des roduktivitätsvorsprungs der USA gegenüber den anderen kapitalistischen Ländern mit den daraus resultierenden Konsequenzen.

in diesen empirischen Angaben zoigt sich, auf welcho Weise Geld, whllar als Weltgeld, in die internationale Zirkulation kommt. Beilebe ntott durch irgendwelche abgestimmte politische Entscheidungen der Weltmarktlinder oder internationaler Organisationen wie des IMF. sondern aufgrund der Expansion der nationalen Waren und Kapitalzirkulation der USA über die Grenzen. Das Geld entsten naturwüchsig aus der Warenzirklation; und es zeigt sich, daß dies durchaus nicht anders ist im Falle der internationalen Zirkulation. Zwar ist hier die staalliche Vermittlung von größerer Bedeutung als atwa bei der Go nesis des Metallgeldes; aber diese staatliche Vermittlung ist in den Gignzen befangen, die aus der Warenzirkulation als kapitalistischer zirkulation resultieren. Die Künstlichkoit des internationalen Zirkula-

105) Obande und Plore Jalé, a. a. O., 3.66. Dont schreibt er, daß der Anteil der US am gesamien Kaplualexport dor imperialistischen Länder otwa $80 \mathrm{~V}$. H. boträgt.

104) Vgl. Daten in Statistics of Balance of Payments, OECD, Paris 1964, 5. 19.

307) Etws ausfuhrlichere Angaben dazu in Altvator, a. . 0.5 .29$.

4. $Y$ gl. Monatsborichte der Deutschen Bundesbank und Iaufends Angaben in ei: Youen Züricher Zoitung. 
tionsmechanismus täuscht über diese elementaren Zusammenhänge hinweg und varanlaßt zu solch illusionären Konstruktionen, wie der Schaffung von synthetischem Geld, einem "Weltgeld aus der Retorte" das nicht einer nationalen Geld- und Warenzirkulation entetamms, sondern der Weltzirkulation bewuBt eingepflanzt wird.

Der Gollar als "Weltgeld" diente also der internationalen Zirkulation als Zirkulationsmittel, war dabei aber an die Reibungslosigkeit der Zirkulation, die nicht aus dem Dollar, sondern aus dem weltweiten Boom der Nachkriegszeit resultierte, gebunden. Der Dollar als Kapital diente den US-Kapitalisten dazu. Anrechte auf Teile des von der jeweiligen nationalen Arbeiterklasse produzierten Warenwertes zu erwerben. Das Weltgeld Dollar fungierte also als Vehikel des US-Imperialismus. Solange der Mehrwert nicht in die USA transferiert, sondern in denjeweiligen Ländern akkumuliert wurde, fungierte das den USKapitalisten gehörende Auslandskapital als Teil des jewoiligen nationalen Gesamtkapitals ${ }^{109}$ ). Nur in bezug auf die Eigentumstitel gab es einen Unterschied und - in der Regel - in bezug auf die Produktivität und intensität der Arbeit. Denn mit den Geldkapitalexporten (die als Direktinvestitionen verwendet wurden) exportierten die US-Kapitalisten in wichtigen Branchen auch moderne Technologie des Produktionsprozesses und immer auch "moderne, effiziente" Organisations- und Managementtechniken ${ }^{110}$ ). Damit aber bewirkten sio unfroiwillig, daß die technologische und manageriale Lücke zwischen den USA und Westeuropa verkleinert werden konnte - wodurch zugleich auch die Basis des US-Vorsprungs auf dem Weltmarkt verringert und der Dollar als Weltgelo untergraben wurde.

Während dies allerdings nur im Verhälnis von USA und anderen entwickelten kapitalistischen Ländern zutraf, hatte der Kapitalexport in schwach entwickelte Länder einen anderen Charakter. Hier verhielt sich das US-Kapital in der Regel nicht als Teil des nationaion Kapitals; os bezog den Mehrwert aus dem jeweiligen Land und transferierte ihn zum großen Teil in die USA zurück, nachdem er auf dem Weltmarki in Geld verwandelt war. Piere Jalé gibt hierzu Zahlen der Weltbank wieder. Fur 1964 werden die retransferierten Profite (alle entwickelten kapitalistischen Länder; aber die USA vereinigten den weitaus größten Teil aus sich) auf 4 Mrd Dollar geschätzt, wobei die europäischen Mittelmeeriänder (Spanien, Portugal, Türkei, Griechenland) nicht berücksichtigt sind. Da nur 970 Mio Dollar zuflossen, "läuft dieses Go-

109) Vgl. Alvater, a. a. O., S. 65 \% dalée schreibł: "In Westeuropa habon in jüngster Zei insbesondere die Länder des Gemeinsamen Marktes das amerikani. sche Privatkapital angezogen. Fast $70 \mathrm{v}$. H. der amerikanischen Investitionen innerhalb der EWG wurden nach 1970 getätigt (fïr Großbritannien 56 v. H.) ... Des Kapital betätigt sich an Ort und Stelie und ein weiter Markt steht ihm offon. Das Kapital verügt übar seine Technik, as bringt sein know-how mit und findet in Europa billigera Arbeilskraft vor als in den USA... (5. 76)

110) Vgl. Günde! wrt Nohls, a. 0 . 
schäft auf ein Defizit von jährlich 3 Mrd Dollar in der Zahlungsbilanz dieser Länder hinaus" " 111 .

Was bedeutete dies für das Weltwährungssystem? Jeder Kapitalexport der USA war gleichzeitig "Erzeugung" von internationalem Kaufmittel und die Schaffung von Stützpunkten des US-Kapitals im Ausland. Denn der erste Kaufakt, der mit dem Kaufmittel Dollar vollzogen wurde, bevor der Dollar weiterzirkulierte, war der Kauf von ausländischen Froduktionsmitteln, Arbeitskräften, Handelswaren, Kapital in fiktiver Form (Effekten usw.). Die Verkäufer dieser Waren akzeptierten die Dollarbeträge, da sie sie mit Notenbankgarantie unmittelbar in nationale Währung umtauschen konnten. Von anderen Kapitalisten wurden die Dollarbeträge von der Zentralbank oder direkt auf dem Devisenmarkt gekauft, um ihre respektiven Wareneinkäufe zu ermöglichen. Denn die Rechnungen auf dem Weltmarkt wurden ja, von Ausnahmefällen abgesehen, bis vor wenigen Jahren in Dollarwährung fakturiert. Die Zentralbanken selbst konnten bis zum 15. August 1971 die Dollardevisen pro forma - aufgrund der Konvertibilitätsbestimmung - in Gold transferieren - was sie aber füglich nicht taten, um nicht das ganze künstliche System der auf dem Dollar beruhenden internationalen Zirkulation zu zerstören. Wenn auch die Reibungslosigkeit der internationalen Zirkulation nicht dem Dollar geschuidet war, so hätte sie doch schwer getroffen werden können, wenn das Medium der Zirkulation auf seinen Goldkern befragt worden wäre. Die kapitalistischen Staaten, die aus Eigeninteresse an der Funktionsfähigkeit der internationalen Zirkulation interessiert waren, deckten daher auch den durch das Weltwährungssystem vermittelten US-Imperialismus ab ${ }^{112}$ ). Am klarsten wird dieser Zusammenhang am Beispiel der Aggression cer USA gegen das vietnamesische Volk. Für den Vietnam-Krieg haben die USA von 1966 bis 1970 nach offiziellen Angaben 104,4 Mrd Dollar ausgegeben. Rechnet man bis Mitte 1971 weitere 20 Mrd Dollar hinzu, dann ergeben sich Gesamtkosten von rund 125 Mrd Dollar. Zusammen mit den in anderen Etats ausgewiesenen indirekten Kosten und Kriegsfolgelasten belaufen sich die Ausgaben für die Aggression auf mindestens 155 Mrd Dollar. Auf den ersten Blick scheint es so, als ob diese Summen von den USA selbst aufgebracht werden. Aber „wenn man davon ausgeht, daß der heutige Papierdollar ohne effektive Golddekkung nichts anderes darstellt als eine Schuldverschreibung - dann kann man die in Europa in wachsendem Umfang auftauchenden USDollars auch als amerikanische Staatsanleihe betrachten; auch Staats-

1"1) Pierre Jalée, a. a. O., S. 68 f. Auch bezüglich der Gebrauchswertseite unterscheiden sich die Kapitalanlagen in den entwickelten von den Anlagen in den schwach entwickelten Ländern. In der dritten Welt hat sich das US-Kapital vorwiegend in der extraktiven Industrie (Rohstoffe) festgesetzt, in den entwickelten kapitalistischen Ländern in moderner Industrie.

$\left.{ }^{112}\right)$ Hier gilt das gleiche wie für die nationale Zirkulation. Aus dem Geld entsteht keine Krise. Aber entzieht man der Zirkulation das Geld, dann wird es eine Krise geben. 
anleihen sind nichts anderes als Schuldverschreibungen. Wenn man will, kann man sie dann auch gleich als Kriegsanleihen ansehen. Mit dieser hätten die Papierdollar dann auch gemeinsam, daß sie um so wertloser zu werden pflegen, je länger der Krieg dauert" 113). Jeder Krieg, aber schon die hohen Rüstungsausgaben der USA ${ }^{114}$ ), verursachen notwendig inflationäre Prozesse. Rüstungs- und Kriegsaus* gaben des Staates sind Kaufmittel, mit denen der Zirkulation Arbeitskräfte und Waren entzogen werden. Es fließt also Geld in die Zirkulation. Am Ende der Produktionsprozesse der Rüstungsindustrie jedoch sind keine Waren vorhanden, die als solche in die Zirkulation geworfen werden. Die Waren der Rüstungsindustrie dienen weder der individuellen noch der produktiven Konsmtion. Aber um den ProzeB in der Rüstungsindustrie erneut beginnen zu können, müssen die dort operierenden Kapitalisten der Zirkulation erneut Arbeitskräfte und Produktionsmittel (Arbeitsinstrumente u. Rohstoffe) entziehen. „Da beständig Elemente des produktiven Kapitals dem Markt entzogen werden und für dieselben nur ein Geldäquivalent in den Markt geworfen wird, so steigt die zahlungsfähige Nachfrage, ohne aus sich selbst irgendein Element der Zufuhr zu liefern. Daher Steigen der Preise, sowohl der Lebensmittel wie der Produktionsstoffe ..." (MEW, Bd. 24, S. 317) Rüstungsausgaben, die permanent diese beschriebene Wirkung haben, sind daher einer der wichtigsten, wenn nicht der wichtigste Faktor der permanenten Inflation. Die Inflation hat aber die Eigenschaft, sich bis zur Krise zu verstärken. Denn ist sie Ausdruck steigender zahlungsfähiger Nachfrage, so können die daraus entstehenden Impulse nur erhalten werden, wenn die Faktoren der Inflation sich verstärken. Schließlich fungieren auch die in der Rüstungsindustrie angelegten Kapitale als akkumulierende Kapitale, d. h. sie entziehen der Zirkulation in immer steigendem Maße Arbeitskräfte und Produktionsmittel und die Resultate dieser Industrie - Rüstungsgüter müssen auf erweiterter Stufenleiter abgekauft werden, was nicht anderes bedeutet, als daß immer mehr zahlungsfähige Nachfrage staatlich in den Kriegs- und Rüstungssektor umgeleitet werden muß.

Die in den USA in den letzten Jahren gestiegene Inflationsrate jedenfalls hat zusammen mit den verringerten Produktivitätsunterschieden „die Wettbewerbsfähigkeit der amerikanischen Wirtschaft gegenüber dem Ausland" ${ }^{116}$ ) stark gemindert, so daß die schleichende Dollarkrise der letzten Jahre durch die Handelskrise (negative US-Handelsbilanz) verschärft wurde.

So implizierte die Anerkennung des Dollar als Weltgeld durch die kapitalistischen Staaten notwendig die ökonomische Stützung (in der

113) Walter Slotosch, a. a. O., S. 189 f.

114) Die US-Militärausgaben sind nachzulesen in OECD, National Accounts of OECD Countries 1950 - 1968, Paris (1970), S. 50 f. Die Militärausgaben steiger. ten sich von 14,2 1950 auf 80,9 Mrd. Dollar pro Jahr (1968).

$\left.{ }^{115}\right)$ Geschäftsbericht der Deutschen Bundesbank für das Jahr 1970, S. 33. 
Regel auch die politische Stützung) des US-Imperialismus überall in der Welt. Die darin angelegte Unterminierung des Dollar als Weltgeld beweist den imperialistischen Ländern heute, daß sie nicht nur durch Unterlassungen (nämlich ihre Dollarbestände der US-Zentralbank zU präsentieren) den US-Imperialismus unterstützten, sondern nun zum Handeln, nämlich zum Bezahlen, direkt aufgefordert werden. Von Westdeutschland fordern die USA z B. eine "fühlbare" Erhöhung der "Devisenausgleichsbeträge", also Bezahlung der US-Truppen in Europa, sowie eine solche Handelspolitik, daß die USA einen Handelsbilanzüberschuß von - wie es heißt - mindestens 13 Mrd Dollar erzielen können ${ }^{116}$ ): also Verzicht auf Exportmärkte zugunsten des US-Kapitals. Dies alles soll natürlich dazu dienen, die US-Wirtschaft aus der aktuellen Krise zu befreien. Es hat aber auch den Zweck, die in den kapitalistischen Ländern befindlichen Dollar-Guthaben per Warenexporte, die in Dollar zu bezahlen wären, aufzulösen und die für die USA sehr einträgliche Funktionsweise des Dollar als Weltgeld wiederherzustelien. Der große Rüstungssektor hat in den USA die stagnativen Tendenzen nicht aufhalten können. Wie sollte dies auch möglich sein, da ja auch die dort angelegten Kapitale akkumulieren müssen. Zwar sind die Realisierungsbedingungen der produzierten Werte günstiger als in anderen Bereichen, die Produktionsbedingungen (Arbeitsproduktivität, organische Zusammensetzung des Kapitals, Löhne, Arbeitszeit und -intensität) jedoch bewegen sich genauso zyklisch und beeinflussen folglich die Profitrate wie in anderen Branchen aucn. Gerade die Tatsache, daB aus den USA Jahr für Jahr langfristiges Kapital ins Ausland abfließt, drückt die Erwartung des US-Kapitals aus, im Ausland eine höhere Profitrate $z u$ erzielen, als in den USA selbst ${ }^{17}$ ). Die oben beschriebenen Zusammenhänge zwischen Zirkulationsmechanismus auf dem Weltmarkt und US-Kapitalexport sind natürlich dem einzelnen USKapitalexporteur nicht bewußt und wenn sie ihm bewußt sind, dann

119) in der Süddeutschen Zeitung vom 16. 9. 71 heißt es dazu: "Wie wahrhaft giganisch aber die Aufgabe ist, Amerikas Zahlungsbilanz auf die Beine zu helfen, zeigen schon einmal die Vorstellungen der USA selbst. Volcker meinte jüngst in Paris, die jetzt ersimais in diesem Jahrhundert defizitäre amerikanische Handelsbilanz müßte einen Überschuß von nicht weniger als dreizehn Milliarden DN ausweisen, damit die Gesamtzahlungsbilanz ausgeglichen schlieBe. Hierbel kalkulierte er - zur Verstimmung seiner Gesprächspartner - allerdings, notwendige private Kapitalexporte' von 2 bis 3 Milliarden Dollar ein." Die US-Vertreter fordern damit schlichtweg einen Handelsbilanzüberschuß, wie sie ihn nach dem zweiten Weltkrieg noch niemals erreicht haben. Vgl. OECD, National Accounts, a. a. O., S. 58 f und OECD, Economic Surveys: United States, 1970, S. 28 f. Daß auf solchen Kapitulationsforderungen chauvinistische Gefühle wachsen, ist allerdings nicht verwunderlich. Man bedenke, daß die USHandelsbilanz in den $60 \mathrm{er}$ Jahren den höchsten Über,schuß mit 6,8 Mrd. im Jahre 1964 erzielt. Mit Forderungen der genannten Größenordnung schaufelt sich der imperialismus als einheitliches ökonomisches und politisches System das eigene Grab.

117) Die oben angeführte Forderung der USA, jährlich $2-3$ Mrd. Dollar an Geldkapital zu exportieren, drückt in der Tat die mangelnden "Investitionsgo. legenheiten" aus, d. h. die niedrige Profitrate in den USA. 
werden sie sicherlich nicht zur Grundlage seiner Entscheidungen, Kapital nicht in den USA sondern z. B. in Westeuropa anzulegen. Die Basis seiner Entscheidungen ist die jeweils erzielbare Profitrate auf das exportierte Kapital. Er würde nicht Kapital exportieren, auch wenn die Exporte die beschriebenen vorteilhaften Konsequenzen für das Gesamtkapital der USA hätten, könnte er im Inland eine höhere Profitrate erzielen als im Ausland. Als notwendige Bedingung für den USKapitalexport muß also hinzukommen, daß sozusagen ein "Gefälle" an Profitraten der einzelnen Länder besteht. Allerdings kann dies nicht heißen, als ob eine Art Hierarchie der Profitraten bestünde, die den Kapitalexport veranlaßt und daß dieser Kapitalexport aufhören würde, wenn diese Hierarchie eingeebnet ist. Vielmehr findet der Kapitalexport deshalb statt, weil der US-Kapitalist aufgrund des höheren Produktivitätsniveaus, der billigeren Kredite, der besseren Rohstoffquellen und dergleichen mehr einen zumindest zeitweisen Extraprofit erwartet. Die Jagd nach Extraproften veranlaßt folglich den Kapitalexporteur zu AnAnlagen im Ausland und die durchschnittlich höhere Produktivkraft der Arbeit in den USA bringt ihm den zeitweisen Erfolg in Form einer hohen Profitrate, der man natürlich nicht ansieht, welcher Teil auf Extraprofiten beruht. Es ist klar, daß diese lukrativen Geschäfte dann ein Ende haben, wenn die Produktivitätsbedingungen in den wichtigsten Weltmarktländern verallgemeinert sind oder die Lohnbewegungen einen Teil des Extraprofits aufzehren oder die Realisierungschancen auf dem Woltmarkt zu gering sind, um die steigende Warenmasse abzusetzen. So ist ersichtlich, daß die für die Einzelkapitalisten günstigen Bedingungen für Kapitalexporte, vor allem Direktinvestitionen, nicht ewig dauern können. Die Krise der amerikanischen Währung und der Krise des US-Handels wird die Krise der US-Kapitalexporte dann folgen, wenn die Anlagesphären des US-Kapitals vor allem in Westeuropa selbst in eine Krise geraten.

Während sich der langfristige US-Kapitalexport grundsätzlich an der industriellen Profitrate ausrichten muB (mit den geschilderten modifizierten Bedingungen), richtet sich das kurzfristige Kapital nach den Zinssätzen. Das aus verschiedenen Gründen, die hier nicht untersucht werden können ${ }^{18}$ ), kurzfristig (für drei Monate bis zu zwei Jahren) verfügbare Kapital strömt sehr schnell auf die Märkte, wo die Zinsen vergleichsweise hoch sind. Insbesondere ist es infolge der entwickelten Kommunikationsstrukturen auf dem Weltmarkt in der Lage, sehr

${ }^{118)}$ Das kurzfristig verỉübare Kapital stammt zum größten Teil aus Zirkulationsprozessen von Einzelkapitalen. Einnahmen können nicht sogleich zu Einkäufen verwendet werden, Amortisationsfonds sammein sich an usw. All diese Gelder werden kurzfristig bei Banken deponiert, um in den Zinsgenuß zu kommen und werden von den Banken ebenso kurzfristig verschoben. Gefährlich wird dieses System dann, wenn auf diesen kurzfristigen Krediten in der Hoffnung, daß es schon gelingt, Kredite auizutreiben, langfristige Anlagen aufgebaut werden. Dies ist zum Teit in den letzten Jahren in der westdeutschen Wirtschaft geschehen. 
schnell Zinsniveauverschiebungen auf den nationalen Märkten zu berücksichtigen oder als Spekulationskapital im Falle erwarteter Wechselkursänderungen zu fungieren. Um das kurzfristige Geldkapital im Lande zu halten - denn würde es abströmen, dann würde die Auslandsverschuldung noch mehr zunehmen -, sorgten US-Regierung und Zentralbank jahrelang dafür, daß das Zinsniveau in den USA im Durchschnitt höher als in Westeuropa war. Dadurch konnte das massenhafte, und das heißt krisenhafte Ausströmen von kurzfristigem Kapital aus den USA eingedämmt werden. Eine solche. Hochzinspolitik wurde aber immer unmöglicher, als deutlich wurde, daß sich hierdurch die Wirtschaftskrise verschärfte: die Zinsen drückten die industrielle Profitrate zum Teil bis in die Verlustzone. Die Nixon-Regierung war gezwungen, das Zinsniveau zu senken. Daraufhin aber sah das kurzfristige Kapital keine Veranlassung mehr, in den USA zu verbleiben. Es strömte seit 1970 en masse nach Westeuropa, vor allem in die BRD. Hier zeigt sich, wie sich in den langfristigen Kapitalexporten strukturelle und in den kurzfristigen konjunkturelie Faktoren ergänzen. Die Problematik der Währungskrise ist daher auch nur unter Berücksichtigung beide Aspekte zu lösen. Wenden wir uns nach der Behandlung der strukturellen Probleme den empirischen Erscheinungsformen der konjunkturellen Faktoren zu.

Als die USA noch 1969 ihre Hochzinspolitik betrieben, betrug z. B. der Satz für Dreimonats-Eurodollar ${ }^{119}$ ) bis zu 12 v. $H_{\text {. }}$, während in der BRD der gleiche Satz nur 5,5 v. H. betrug. Ende März 1971 dagegen war der entsprechende Eurodollar-Satz auf $5,25 \mathrm{v}$. H. gesunken, während er in der BRD 7,5 v. H. betrug. Amerikanische Dreimonats-Schatzwechsel lagen noch im Januar 1970 bei 9 v. H., im März 1971 dagegen nur noch bei $3,3 \vee \mathrm{H}$. Entsprechend der Umkehrung der Zinsverhältnisse drehten sich die kurzfristigen Kapitalströme. Noch 1969 zogen die USBanken etwa $9 \mathrm{Mrd}$. Dollar kurzfristiger Gelder aus dem Ausland an. Im Jahre 1970 dagegen gaben sie etwa $6 \mathrm{Mrd}$. Dollars ans Ausland ab, was auf eine Verschlechterung der US-Zahlungsbilanz von einem Jahr auf das andere um $13 \mathrm{Mrd}$. Dollar hinauslief ${ }^{120}$ ). Und dieser Trend setzte sich bis zur Panik verstärkt im Jahre 1971 fort. In den ersten drei Monaten 1971 wurden etwa 4 Mrd. Dollar aus den USA exportiert. Von Januar bis Juli waren es 8,6 Mrd. Dollar. Insgesamt stiegen dadurch die kurzfristigen Auslandsverbindlichkeiten der USA auf 51,9

119) Auf den Euro-Dollar-Markt gehen wir hier nicht ein. Es handelt sich dabei um einen Markt von in Europa angelegten und nicht wieder in die USA repatrierten US-Dollar, die von westeuropäischen Banken bei Rückflüssen erneut wieder in Europa angelegt werden. Dieser Geldmarkt ist direktes Produkt der Verselbständigung der Dollarzirkulation, die daduch entstehen konnte, daß das Weltgeld Dollar zwar als Geldkapital profitabel exportiert aber nicht mehr profitabel importiert werden konnte

120) Geschäftsbericht der Deutschen Bundesbank für das Jahr 1970, S. 33 f. 
Mrd. Doilar im August $1971^{121}$ ) (davon: 32,1 Mrd. Verbindlichkeiten gegenüber Regierungen und öffentlichen Institutionen und 17,9 Mrd. Dollar-Guthaben privater Devisenaus(änder), denen Währungsreserven der USA in einer Höhe von nur 12,2 Mrd. Dollar gegenüberstanden. Darunter befanden sich Goldbestände im Werte von nur 9,7 Mrd. Dollar. Die Situation war so kritisch wie die eines Unternehmens, das sich total überschuldet hat und dessen Gläubiger bisher darauf vertrauten, daß es eigentlich noch ganz gut funktioniere, nun aber (infolge der Krise in den USA) den endgültigen Zusammenbruch befürchten mußten Sie standen mit ihren Forderungen abwartend vor den Toren Schlange und stellten Überlegungen etwa darüber an, ob nicht ihre Forderungen in eine "ordentliche" Staatsschuld verwandelt werden könnten. Als dann einer der Gläubiger, nämlich Frankreich, hervortrat und sich eine Dollarforderung in Höhe von $191 \mathrm{Mio}$. in Gold konvertieren ließ, war es soweit: Die USA bekannten ihre Zahlungsunfähigkeit, indem sie die Konvertibilität des Dollar aufhoben und mit der Importsteuer den anderen kapitalistischen Ländern zeigten, daß sie zwar pleite aber noch längst nicht am Ende seien ${ }^{122}$ ).

Die Krise in den USA machte Maßnahmen erforderlich, die den Papierdollar als Weltgeld außer Funktion setzten:

(1) Als Re serve währung hat der Dollar ausgespielt, da die USA offiziell mit der Aufhebung der Dollarkonvertibilität in Gold eingestehen mußten, daß die Dollarguthaben in Gold ausgedrückt nichts mehr wert sind, d. h. nicht mehr im Falle einer Zirkulationsstockung in die allgemeine, überall akzeptierte und reale Wertgestalt des Goldes verwandelt werden können. Die "Dollargestalt der Werte“ ist nun keine "flüchtige" mehr, sondern eine sehr unangenehm dauerhafte. Konnte man bei Existenz der Konvertibilität noch von einem Repräsentationsverhältnis zwischen Dollar und Gold sprechen, so jetzt nur noch davon, daß der Dollar nichts außer seinem und des US-Imperialismus Desastre repräsentiert. Die Dollarguthaben können nur noch gegen US-Waren getauscht werden. Aber wie soll dies geschehen, wenn erstens unter der Bedingung fester Wechselkurse die Modifikation des Wertgesetzes auf dem Weltmarkt dahingehend wirken kann, daß andere Länder trotz evtl. geringerer Produktivkraft der Arbeit ihre Waren dennoch billiger als die USA verkaufen können, wenn zweitens infolge der US-Inflation das Preisniveau der US-Waren stärker gestiegen ist als dasjenige anderer Länder, wenn drittens infolge eines Abflauens

$\left.{ }^{121}\right)$ Das Verhältnis von Goldreserven der USA zu ausländischen Dollarguthaben betrug Ende 1955: 21,8 Mrd. zu 11,7 Mrd.; Ende 1960: 17,8 Mrd. zu 18,7 Mrd.; Mai 1968: 10,7 zu 31,5 Mrd. Dollar. Nach Pierre Jalée, a. a. O., S. 165.

$\left.{ }^{122}\right)$ Die Zahlen sind entnommen der Neuen Zürcher Zeitung vom 28. 8. 71. Ein weiterer Grund für die Maßnahmen war natürlich die negative Handelsbilanz der USA. Von Januar bis Juli 1971 bertrug das Defizit bereits 676,4 Mio. Dollar, nachdem die Handelsbilanz 1970 noch einen Überschuß von 2,7 Mrd. Dollar erbracht hatte. 
der Wirtschaftstätigkeit in vielen kapitalistischen Ländern gar nicht mehr der unmittelbare Bedari nach US-Importen besteht? Wir sehen ganz davon ab, daß auch noch die Gebrauchswertseite der Waren relevant ist, wenn nach ihnen Nachírage bestehen soll und wir haben noch gar nicht berücksichtigt, daß sich die Dollarguthaben zum größten Teli im Besitz von Regierungsstellen und Banken befinden und kein Einzelkapitalist nur deshalb in den USA kauien wird, um die Dollarbestände der Zentral- und Geschäftsbanken aufzulösen - es sei denn, der Dollar wird abgewerter und gerade das wollen die USA verhindern. Weiter ist es gar nicht sicher, daß die US-Warenexporteure die Rechnungen in Dollar fakturieren.

Es zeigt sich hier doch ganz deutlich, daß selbst die materielle Warenproduktion, die "größte Wirtschaftsmacht der Welt" hinter dem papierenen Dollar dann zu einem blassen Schemen wird, wenn die Krise offenbar wird. Dann bieten auch "harte" Sachen für das Dollarpapier keine Sicherheit mehr. Ohne funktionierende internationale Zirkulation, die er vermitteln soll, ist der Dollar wirklich nichts als ein Fetzen. Und das Gold herrscht sich nun als Maß aller Werte auf.

Das auf dem Dollar als Weltgeld beruhende Währungssystem wird also durch eine Krise in der US-Wirtschaft in gänzlich anderer Weise betroffen als durch nationale Krisen in anderen kapilalistischen Ländern. Selbstverständlich breiten sich Krisen vermittelt über die internationale Zirkulation aus: Exporte fallen aus, Importe werden teurer, die Konkurrenz wird schärfer, Zahlungen werden eingestellt usw ${ }^{123}$ ).

Aber eine Krise der US-Wirtschaft hat hier nicht nur infolge der GröBo und Bedeutung des Landes besondere Wirkungen, sondern infolge des Dollar als Weltgeld. Der Dollar repräsentiert nicht mehr die Geldgestalt der Warenwerte, er wird als Zahlungsmittel nicht mehr akzeptiert und wird als Goldkapital nur noch mit Abschlägen gehandelt. Dann kann es passieren, daß Länder in die Krise mit hineingezogen werden, obwohl die Widersprüche der Kapitalreproduktion noch gar nicht bis zur krisenhaften Zuspitzung herangereift sind und obwohl der Handelsverkehr mit den USA minimal sein mag, nur weil das internationale Zirkulationsmedium die Zirkulation verunmöglicht.

(2) Der Dollar hat aber auch als Leitwä h rung bei schwankenden Kursen der wichtigsten Währungen keine Funktion mehr. Wenn der Kurs des Dollar nicht seinam Wert entspricht, wie soll ar dann der

\footnotetext{
189) Einen Vorgeschmack bietet das Verhalłan des japanischen Kapitals nach der Währungskrise, das so weit ging, noch nicht einmal Kontrakte oinzuhalten. Woraut bekenntlich die Frankfurter Devisenbörse die Notierung des Yen cussetzte. Dies ist nur oin kleines Indiz pür sich verschärfende, und daher auch rupplo werdende Konkurrenz.
} 
"Fixstern" sein, um den die Kurse der anderen Währungen kreisen? ${ }^{24}$ ) Solange wie es keine fixen Kurse gibt, wird es außer dem Gold auch kein anderes allgemein gültiges internationales Zirkulationsmittel geben, außer so Krücken eines Krüppels wie den "Sonderziehungsrechten", die aber nur für den Verkehr der Zentralbanken untereinander geringe Relevanz haben. Die internationale Warenkapital- und Geldkapitaizirkulation können sie nicht vermitteln: ein Kapitalist würde lachen, wenn man eine Bezahiung in SZR anbieten würde.

(3) Auch als I nterventionswährung ist der Dollar am Ende. Heute ist es so, daß die Zentralbanken den Dollar zu stützen haben und nicht mehr mit dem Dollar, die sie in ihren Valutareserven haben, die eigene Währung stützen können. Allerdings muß hier berücksichtigt werden, daß die Absetzung des Dollar als Interventionswährung schon vor Jahren erfolgt ist mit all den Vereinbarungen zur Rettung des Währungssystems, wie der Gründung des "Zehnerclubs", dem "General Agreement to Borrow", dem "Goldpool", den internationalen Swap-Abkommen und natürlich der Erfindung der "Sonderziehungsrechte" 125 ).

Die Widersprüche, die in einem Währungssystem angelegt sind, das auf einer nationalen Währung als Weltgeld beruht, haben sich zur Krise entwickelt und in der Krise haben sich die Bedingungen, durch die die nationale Währung zum Weltgeld werden konnte, verflüchtigt. Es ist wohl noch nicht allen klar geworden, aber mit der Einstellung der Interventionen am Devisenmarkt hat die Deutsche Bundesbank zum Erkennen gageben, daß sich staatlicher Voluntarismus nicht gegen das eherne Werigesetz und dessen Wirken zu behaupten vermag ${ }^{126}$ ). Der Staatinverventionismus ist in diesem Bereich an eine Grenze geraten, die in Perioden der Prosperität und des expandierenden Weltmarkts niemand so recht wahrzunehmen vermochte.

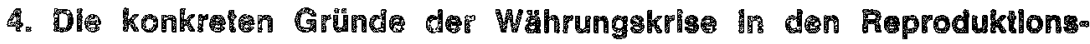 bodingungen der wichilgsten Woltmarktituder}

Wir sind von Anfang an davon ausgegangen, daß die gegenwärtige Weltwährungskrise nur als Ausdruck des Heranreifens von Widersprüchen in der Kapitalproduktion auf Weltmarktebene begriffen werden

183) Die Autwertungssätze der wichtigsten Währungen gegenübar dem US-Dollar betrugen am 2. Septembor 1971: DM: 8,0 v. H.; Pfund Sterling: 2,4 v. H.; Kan. Doliar: 6,5 v. H.; Holl. Gulden: 5,2 v. H.; Franc officiel: 0,7 v. H. und Finanzfranc: 4,1 v. H.; Yen: 6,4 v. H.; Lira: 1,6 v. H. Nach Berechnungen der Deutschen Bundesbank, in: Doutsche Bundesbank - Auszüge aus Presseartikeln. Nr. 70 vom 8. September 197\%. Wichtig dabei ist, daß diose Aư⿱w口ortungssátze von Tag zu Tag so lange schwanken, wie nicht zu fixierten Kursen zurückgefunden wordon ist.

125) Vgl. dazu Altvater, a. a. O., S. 50 if.

120) "Gegen alle Devisenbestimmungen und Elnfuhrbeschränkungen setzt sich die Tendenz des Weltmarhtes durch, selbst Im stärkst abgeschlossenen Staat." Folix Somary, Krisenwende?, Berlin 1932, S. 48 (Grobbankier und klarsichtiger Reaktionär). 
kann ${ }^{127}$ ). Die Formen der internationalen Zirkulation, den Charakter einer nationalen Währung als Weltgeld und des Goldes als Wertmaß haben wir untersucht, um die darin angelegten Möglichkeiten und Erscheinungsformen von Weltmarktkrisen aufzudecken. Wir sind dabei zu dem Ergebnis gekommen, daß der mit Notwendigkeit krisenhafte Charakter der Durchsetzung des Wertgesetzes auf dem Weltmarkt seine erste Erscheinungsform in Weltgeldkrisen, d. h. in Weltwährungskrisen hat. Diese können nicht einfach nur notwendigen Anpassungsprozessen unterschiedlich sich entwickelnder nationaler Produktivkraft der Arbeit und nationaler Inflationsratén entspringen, sondern als Krisen, welche das Vertrauen der Kapitalistenklasse in die ewige Fortdauer flotter Akkumulation auf dem Weltmarkt erschüttern, sind sie Ausdruck davon, daß die sich auf dem Weltmarkt durchsetzenden Gesetze der Kapitalakkumulation gleichzeitig Gesetze des tendenziellen Falls der Profitrate sind. Im Prozeß der Angleichung der Produktionsbedingungen der zurückgebliebenen an den Entwicklungsstand der fortgeschrittenen nationalen Kapitale muß sich die organische Zusammensetzung des auf dem Weltmarkt agierenden Kapitals erhöhen und in der Form des Falls der Profitrate auf die nationalen Kapitale zurückwirken. Wachsende Verwertungsschwierigkeiten der nationalen Kapitale und tendenzielles Zusammenfallen der nationalen Zyklen kennzeichnen den krisenhaften Prozeß der Durchsetzung des Wertgesetzes auf dem Weltmarkt. Bei einer Untersuchung der gegenwärtigen Verwertungssituation der auf dem Weltmarkt agierenden Kapitale ist also von der Betrachtung des Verlaufs der nationalen Zyklen auszugehen; nur so läßt sich die Tendenz zu einer Weltmarktkrise belegen, die durch die gegenwärtige Weltgeldkrise angekündigt wird. Dabei können wir in unserem Zusammenhang natürlich nicht eine gründliche marxistische „Konjunkturanalyse“ der einzelnen Länder vornehmen, sondern müssen uns an die Ergebnisse halten, die uns die bürgerliche Konjunkturforschung liefert.

Bevor wir nun einen kurzen Überblick über die Situation in den wichtigsten kapitalistischen Ländern geben, ist es notwendig, sich die Entwicklung des Weltmarkts in den letzten Jahrzehnten zu vergegenwärtigen. Denn diese Entwicklung deutet auf die Notwendigkeit der Zusammenfassung der nationalen Zyklen und Krisen zu einer Weltmarktkrise hin: Am Ende der Weltwirtschaftskrise existierte ein weitgehend desintegrierter Weltmarkt. Was die Weltwirtschaftskrise nicht vollbrachte, wurde vom Krieg vollendet. Die nationalen Märkte waren gegeneinander durch Zölle, Kontingente und Embargos isoliert, die Geldzirkulation auf dem Weltmarkt verlief stockend (Devisenbewirtschaftung

127) Davon gehen auch Patrick Florian, Jaques Valier, Essai d'explication de la crise du systeme monétaire international, in: Critiques de l'economie politique, No. 2, Januar/Mär 1971. Allerdings bedienen sie sich dabei einer recht formalen Unterscheidung zwischen "processus productiv mondial" und "systeme monétaire international", ohne die Vermittlung beider $k$ egorien, so wie wir es hier versucht haben, herzuleiten. 
u. dgl.). Die Wirtschaftspolitik war nationalstaatlich orientiert, indem sie vor allem die Kapitalakumulation auf nationaler Ebene voranzutreiben versuchte. Die Weltwirtschaftskrise hatte zur Folge gehabt, daß die Nationalstaaten die ökonomischen Gesetze der Durchsetzung des Wertgesetzes auf dem Weltmarkt politisch auizuhalten suchten, mit der Folge der Desintegration des Weltmarktes. Erst nach dem zweiten Weltkrieg begann ein neuer Aufschwung des Weltmarktes, der seine Grundlage im mehr oder minder ungestörten Verlauf des Akkumulationsprozesses der nationalen Kapitale hatte ${ }^{128}$ ). Die starken Hemmnisse, welche dem Wirken der ökonomischen Gesetze auf dem Weltmarkt durch nationalstaatliches Eingreifen in die Warenkapital- und Geldkapitalzirkulation entgegengestellt worden waren, wurden unter dem Sichwort "Herstellung des freien Welthandels" in den 50er Jahren Schrity für Schritt abgebaut (wenn auch nie ganz beseitigt). Die kapitalistischen Nationalstaaten folgten der Logik des Kapitals, als sie daran gingen, die nationalen Märkte zum Weltmarkt zu integrieren, sei es durch Errichtung des "Weltwährungssystems" 1944, durch Schaffung integrierter Wirtschaftsblöcke (EWG,EFTA), durch Abbau der Zollschranken (GATT und Kennedy-Runde), als Durchdringung der nationalen Kapitale mit internationalen oder multinationalen Konzernen, durch international in Einzelpunkten abgestimmte nationale Wirtschaftspolitik (OECD, EWG), durch Duldung und indirekte Unterstützung von internationalen Geldkapitalmärkten (Eurodollarmarkt), usw. Die Befreiung des Kapitals von seinen nationalen Fesseln war aber gleichbedeutend mit der Freisetzung der Tendenzen des Kapitals, den nationalen Gesamtreproduktionsprozeß zum Gesamtreproduktionsprozeß des Kapitals auf Weltebene zu machen, mit allen darin eingeschlossenen Konsequenzen: tendenzielle Herausbildung einer weltweiten Durchschnittprofitrate und Vereinheitlichung der Ausbeutungsbedingungen ${ }^{129}$ ). Wir betonen, daß es sich hierbei nur um eine, wenn auch sehr reale Tendenz handelt, der allerdings viele Faktoren entgegenwirken, so daß sie niemals, wie wir meinen, voll verwirklicht werden kann. Darunter ist die Tatsache, daß es keinen "ideellen Ge-

128) Dieser Prozeß der Schaffung des Weltmarkts wird nach jeder Weltmarktkrise (einschließlich den Weltkriegen) in jeweils verschiedener historischer Verlaufsform wiederholt. Er ist jeweils Ausdruck der allgemeinen "propagandistio schen Tendenz" des Kapitals, die Marx in den "Grundrissen", S. 311 ff. und im 14. Kapitel des zweiten Bandes des „Kapital“ behandelt.

129) Wir möchten hier noch einmal deutlich hervorheben, daß es uns in diesem Aufsatz vorrangig um die Probleme bei der Herausbildung der Durchschnittsbedingungen auf dem Weltmarkt geht. Daß Erzeugung und Authebung von Ungleichmäßigkeiten bestimmte Resultate haben, indem sie die allgemeinen Tendenzen der Kapitalentwicklung exekutieren, wurde von uns nur unzureichend analysiert. Es war also nicht Gegenstand der Untersuchung, welche Auswirkungen die Modifikationen des Wertgesetzes auf dem Weltmarkt für die Bewegung der Profitrate der Kapitale hat. Dies bedeutet aber: Aussagen über lang. fristige Trends sind auf Grundlage dieses Aufsatzes allein nur in beschrănktem Umfang möglich. Mit dieser Einschränkung geben wir aber die Aspekte an, an denen weitergearboinet werden muß. 
samtkapitalisten auf Weltebene", also keinen übernationalen Staat als Zusammenfassung der bürgerlichen Weltgesellschaft gibt und auch nicht geben kann, die bedeutendste. Denn imperialistische Konkurrenz, die das Dazwischentreten der Staaten impliziert, zwischen den hochentwickelten kapitalistischen Ländern, ungleiche Austauschbedingungen. zwischen hochindustrialisierten und schwach entwickelten kapitalistischen Ländern und schließlich auch die Existenz sozalistischer Staaten, die die Austauschverhältnisse auf dem kapitalistischen Weltmarkt doch beeinflußt, bedingt die nationale Form des Staates, die allenfalls dadurch erweitert werden kann, daß einige Nationalstaaten manche staatliche Funktionen an supranationale Institutionen übertragen. Auch die Entstehung internationaler oder multinationaler Kapitale hebt die so gesetzten Schranken nicht auf. In Zeiten hoher Akkumulationsraten auf dem Weltmarkt sind zwar multinationale Konzerne relevante Protagonisten der weliwirtschaftlichen Vereinheitlichungstendenzen (Herstellung einer Durchschnittsprofitrate, worin die Angleichung der Ausbeutungsbedingungen eingeschlossen ist), sofern man nur den Block hochentwickelter kapitalistischer Länder im Auge hat; in Bezug auf die gesamte Welt verschärfen sie den Widerspruch zwischen "Metropole" und "Peripherie", wie Stephen Hymer gezeigt hat $\left.{ }^{130}\right)$. Gehen aber die Akkumulationsraten der imperialistischen Länder zurück, dann werden sich die in den einzelnen Ländern fungierenden Teile multinationaler Konzerne als Teile des jeweils nationalen Kapitals verhalten, weil sie gar nicht anders können. Setzen die Nationalstaaten Schranken für die Angleichungstendenzen, um bestimmte Nachteile für das nationale Kapital zu verhindern (Nixons Importabgabe als Beispiel), dann wird auch der multinationale Konzern Philips fraktioniert werden in Philips USA, Philips Holland, Philips BRD usw., wobei dann im Extremfall nur noch der Name Philips multinational bleibt. Aktuallsiert wird also die Form des nationalen Staates als Gegengewicht gegen die Vereinheitlichung der nationalen Kapitale zum Weltkapital genau in dem Augenblick, wo es relevanten Teilen nationaler Kapitale an den Kragen geht. (Ihre Relevanz zeigt sich gerade in ihrer Macht, gegen andere Teile des Kapitals den Staat zu effektiven Maßnahmen zu veranlassen).

Zwar werden auf dem Weltmarkt in flotten Expansionsphasen des Kapitals wie nach dem zweiten Weltkrieg Tendenzen zum Ausgleich der Produktions- und Verwertungsbedingungen des Kapitals (zusammengefaßt in der Herstellung einer weltweiten Durchschnittsprofitrate als Tendenz) wirksam, aber die nicht nur historisch konstatierbaren Verhältnisse, sondern begrifflich aus dem Kapitalverhältnis herleitbaren Konsequenzen stellen sich real als der geschilderten Tendenz ebenso

180) Stephen Hymer, The multinational Copporation and the Law of Uneven Development, in: Baghwati (ed.), Economics and World, New York 1970. In die. sem oinigormaßen interessanten Aufsatz geh Hymer von der Sicht des Einzolkapitalisten aus und ist dahor auch nicht in der Lago, die Gosetze des Weltmarktes zu begreifen. 
wirksam entgegenwirkende Ursachen dar. Mal überwiegen die Kräfte des Wertgesetzes auf dem Weltmarkt, mal die entgegenwirkenden Faktoren, so daß als Resultat sich nur eine modifizierte Wirkungsweise auf dem Weltmarkt ergeben kann. In dieser Widersprüchlichkeit der Durchsetzung des Werigesetzes aber ist auch die Form der Bewegung, die nur zyklisch sein kanr, impliziert.

Die Staaten sind immer Nationalstaaten, die als solche in den Widersprüchen der Durchsetzung des Wertgesetzes auf Weltebene befangen sind: Einerseits haben sie, wie die Geschichte der vergangenen 25 Jahre zeigt, den propagandistischen Tendenzen des Kapitals, sich zum Weltkapital zu entwickeln, Rechnung getragen, andererseits nehmen sie doch immer dann, wenn das Wertgesetz etwa zur Eliminierung bestimmter nationaler Kapitale treibt, "Partei“ für das nationale Kapital, dessen Zusammenf́assung sie darstellen. Auf diese Weise verhalten sich die Nationalstaaten nicht als Exekutoren, sondern als Modifikatoren des Wertgesetzes auf dem Weltmarkt, mit der Konsequenz, daß auch auf dem Hintergrund der Angleichungstendenzen auf dem Weltmarkt die Produktionsbedingungen der nationalen Kapitale (Produktionsstruktur, Produktivität, organische Zusamensetzung, Ausbeutungsrate und damit auch die Profitrate) verschieden sind und bleiben. Auch die Arbeiterklasse tritt dem Kapital immer noch als nationale gegenüber, wie die der Form und häufig auch dem Inhalt nach nationalen Klassenkämpfe in Frankreich, Italien, Großbritannien usw. zeigen. Das Kapital hat daher gleichzeitig Weltmarkttendenz und eine durchaus nationale Existenzweise.

Die beiden gegenläufigen Tendenzen, nämlich der Durchsetzung einheitlicher Bedingungen des kapitalistischen Gesamtreproduktionsprozesses auf dem Weltmarkt und der permanenten Differenzierung nach nationalen Kapitalen, bewirken, daß es einen Weltmarktzyklus nur in sehr modifizierter Weise geben kann. Er ist nicht zeitlich in die Funktonsdauer des fixen Kapitals gebannt, und die Formen der internationalen Zirkulation modifizieren seine Erscheinungsweise, wie wir im Abschntt 3 zu zeigen versuchten. Die Weltmarktkrise muß folglich nicht unbedingt aus jeder nationalen Krise, auch wenn wichtige Weltmarktländer davon betroffen sind, resultieren ${ }^{131}$ ). Erst die Störung der Weltmarktzirkulation zus a $m$ me $n$ mit Krisen wichtiger nationaler Kapitale wird sich zur Weltwirtschaftskrise ausweiten.

Wenn es stimmt, daß aus der Wirkungsweise des Wertgesetzes auf dem Weltmarkt die Zuspitzung der Widersprüche resultiert, dann ergibt sich aus der Logik des Kapitals auch die historische Möglichkeit der kapitalistischen Weltkrise heute. Mit dem Nachweis dieser Möglchkeit haben wir selbstverständlich nicht die Absicht, eine historisch konkrete Prognose aufzustellen. Und dies aus mehreren Gründen nicht: (1) Es ist unmöglich, die historisch konkrete Bewegung des Weltkapitals umfassend zu untersuchen und nur,

\footnotetext{
181) Dies belegt übrigens die Krise des westdeutschen Kapitais von 1966/67. Zwar wurden davon in der Konsequenz auch andere nationale Kapitale berroffen. Aber ihren Ausdruck als für den Welimarkt bedeutsame Kilse fand die westdeutsche Rezession nur in nationalen Geldkripen: der Pfundkrise von 1967 und der Franckrise von 1968, die jeweils mit Währungsabwertungen endeten.
} 
wenn dies gelngen konnte, wären wir auch in der Lage, Konkrete Prognosen zu erstellen. (2) Zwar ist die Krise des Kapials unvermeidich, jedoch hat der Staat bei der Steuerung der Ausdrucksformen der Krise und auch des zeillichen Einitits gewisse Fegulienungsmöglichkeiten, die es verunmöglichen, eine genaue Prognose zu stellen. Uns genügt es daher, die Möglichkeiten und Grenzen der Regulierung duroh den bürgerlichen Staat aui zuweisen. (3) Die Entwicklung des Kapitals ist nicht unabhängig von den Klassenkämpien des Proletariats in den einzenen Kapitalistischen Ländem. Ohne Berücksichtigung der Kampibereitscheft des Proletariats mus jede Prognose zur leeren Hofnung oder Befurchtung werden.

Wenn wir im jolgenden die netonale Konjunkiurege in wichigen Weltnarkländern untersuchen, dann nicht unter dem Aspeki der exakten Koniunkiurbeobachung, sondem vorangig unter dem Aspekt, inwiewatt die nationalen Zyklen eine selbständige Verlaufstorn habon und inwieweit sich die Vereinigungsiendenzen des Welmarkles auch in dieser Beziehung durchsetzen ${ }^{132}$ ).

Bevor wir uns nun der Konjunkuriage einzener Länder zwwenden, werfen wir einen Blick aut eine verglelchende Darsteling der Konjunkturbewe. gungen in den wiohtigsten Malmanktländem.

Perioden überdurchschnitlichen Nachfragedrucks, in cenen das reale Bruttosozialprodukt über dem Trend von 1955 bis 1969 lag:

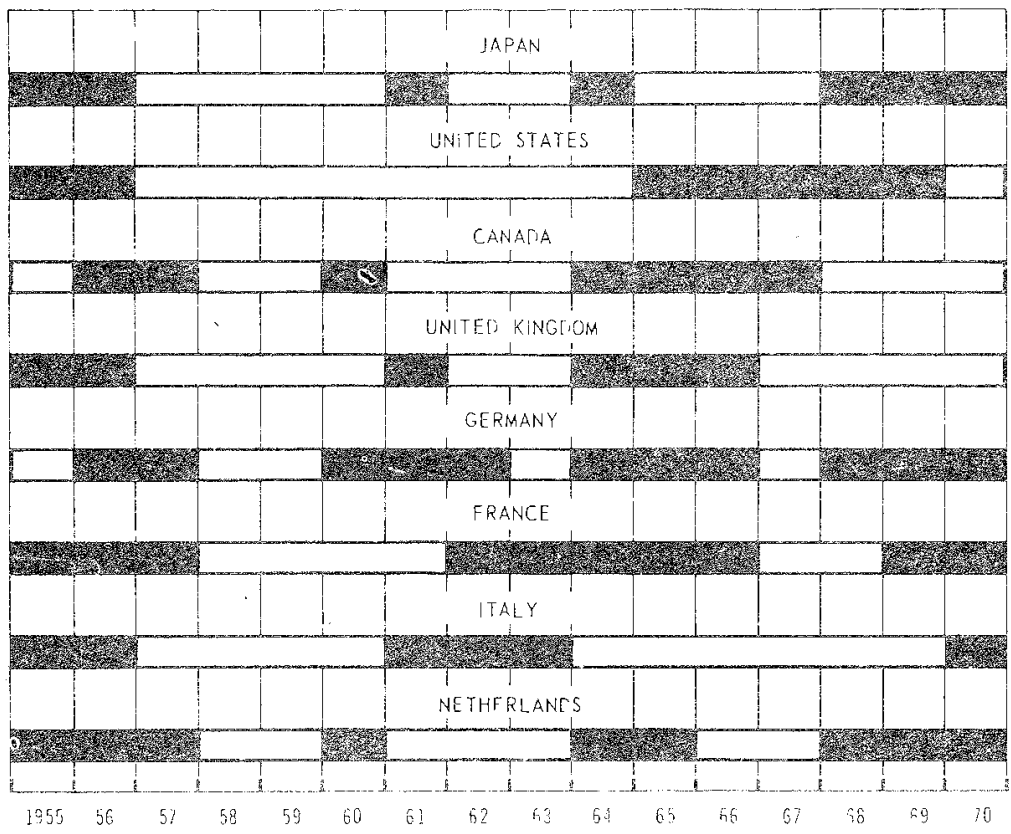

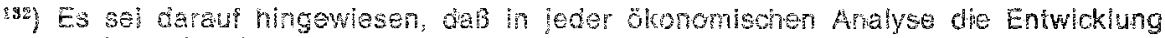
unter enem beshmien Aspek unersuh who benn das Vorhaben, dio Gesamt.

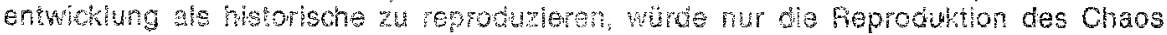


Abweichungen des realen Bruttosozialprodukts vom Trend:

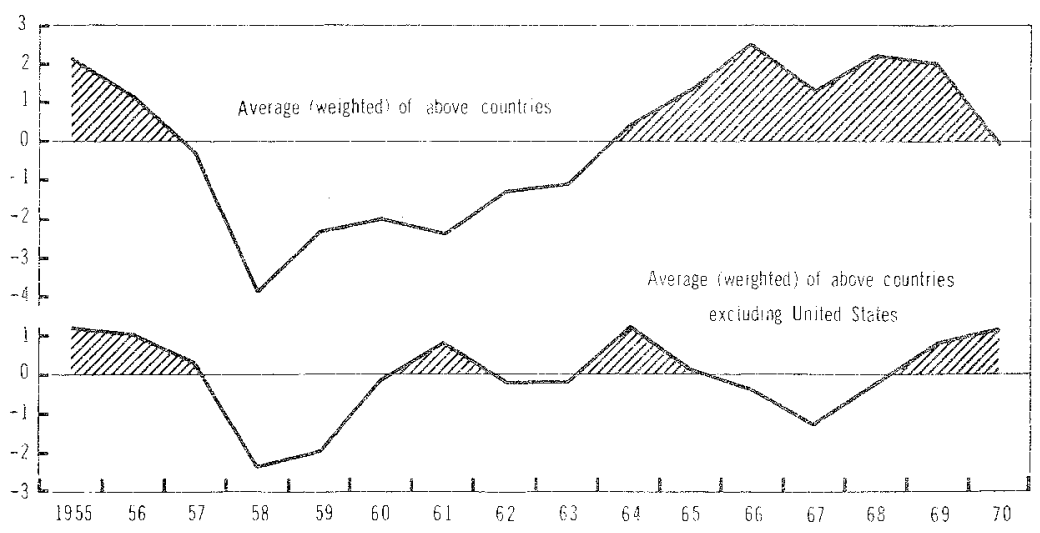

Quelle: Inflation... 3. 18.

Aus der Abbildung geht hervor, daß die zyklen eine eindeutig nationale Verlaufsiorm haben. Diese ist, wie oben hervorgehoben, der nationalen Existenzweise des Kapitals geschuldet. Jedoch ist es micht so, als ob sich in den nationalen Zyklen nicht doch ein über den Weltmarkt hergestellter Zusammenhang zeigen würde. Was auffällt, ist die "Periode unterdurchschnittlichen Nachfragedrucks" in den Jahren 1958 und 1959.

Wenn wir die Abbildung in allen hier aufgeführten Ländern bis zum Jahre 1971 verlängern, so kann man für dieses Jahr ebenfalls den Beginn einer solchen Periode allgemeiner konjunktureller Abschwächung feststellen: In Großbritannien, in Kanada, Italien, Westdeutschland und Japan schwächt sich generell die Konjunktur ab. Und auch in den USA bleibt der noch im Juli erwartete Aufschwung aus. Es ist vorauszusehen, daß 1972 wieder ein allgemeines Weltmarkttief bringen wird. Wie "tief" es sein wird, können wir nicht prognostizieren, denn die Schärfe der Krise hängt von vielen Faktoren $a b$.

Die auf eine Rezession hirdeutenden Faktoren in den wichtigsten kapitalistischen Ländern konzentrieren sich also derzeit. Die nächsten Monate werden zeigen, ob sie über die Weltgeldkrise hinaus eine Weltwirtschaftskrise bewirken.

Gehen wir nun aber auf die nationalen Konjunkturbewegungen der. wichtigsten Weltmarktländer ein, um die Krisengründe konkreter zu fassen. Wir beginnen mit einer Kur:analyse der US-Wirtschaft.

bedeuten. Es kommt allerdings wesentlich daraul an, unter welchen Aspekt die Gesellschaft analysiert wird. Wenn Lenin die Entwicklung des Kapitalismus in RuBiand (Lenin Werke Bd. 3) unter dem Aspekt der Realsienung untersucht, dann vor allem, um der volkstumlerischen These wisserschatich und polthsch entoegenzutreten, in FuBland sei kapitalistische Enwicking und daher avch eine protetariatische Pevolution unmöglich. 


\section{Vereinigte Staaten}

Der längsten Stagnationsphase seit der Weltwirtschaítskrise ging in den USA eine außergewöhnlich lange Phase der Hochkonjunktur (1963 - 1968) voraus. 1969 sank die Wachstumsrate des realen BSP zum erstenmal wieder ab und zwar auf $2,8 \mathrm{v}$. H., 1970 sank sie auf unter $0,4 \mathrm{y} \cdot \mathrm{H}^{133}$ ). Ein leichter Anstieg des Wachstums des BSP im ersten Quarlil 1971 führte dann zu positiven Prognosen über den weiteren Konjunkturverlauf, die aber mittlerweile wieder pessimistischer geworden sind. Dann im zweiten Quartal folgle aber wiederum ein Rückgang. In Preisen von 1958 betrug die Zunahme im ersten Quartal 197132 Milliarden Dollar, im zweiten nur noch 6 Milliarden Dollar. Zudem wai das Wachstum im 2. Quartal zu drei Viertel durch Konsumausgaben getragen ${ }^{134}$ ).

Die besonderen historischen Bedingungen der Krise in den USA können wir hier nicht untersuchen. Doch ihre besonderen Formen geben womöglich einigen Aufschluß darüber, inwieweit die Maßnahmen Nixons zur Erzielung "einer neuen Prosperität ohne Krieg" von Eriolg sein können. Die besondere Form der Krise zeichnet sich im Gegensatz zur westdeuischen Krise 1967 durch folgende Momente aus:

Die Zuwachsrate der Produktivität stagniert, sie liegt 1971 bel nur noch 2,8 v. H. ${ }^{135}$ ). Zwar stiegen im ersten Quartal die $\mathrm{Gew}$ in ne um 10 Milliarden, doch wirkte sich dies nicht auf die "Investitionslust" des Kapitals aus. ${ }^{136}$ )

Bei einer Kapazitätsauslastung von durchschnittlich nur 73 v. H. sah das Kapital keinen Grund für Neuanlagen. Trotz der leichten "Belebung" stieg die Zahl der Arbeitslosen im Jahre 1971 weiter an. Lag sie 1970 nach of $f i$ $z$ iellen Zahlen noch bei durchschnittlich $4,9 \mathrm{v}$. H., so wuchs die industrielle Reservearmee 1971 auf über 6 v. $H$. an. ${ }^{137}$ ) Nichtoffizielle, aber dafür exaktere Berechnungen kommen auf eine Arbeitslosigkeit von über 9 v. $H{ }^{138}$ ) Dieser Prozeß selbst war begleitet von einer anhaltenden Preisinflation. Dazu schreibt die NZZ am 22. 8. 71: „Die ursprünglich vorteilhafte Position der USA (in Bezug auf Inflationsraten im vergleich $z u$ anderen kapitalistischen Ländern - NBA) ist vor allem durch die Entwicklung in den Jahren 1969 und

133) OECD, Economic Outlook, Nr. 9, Juli 1971, S. 10.

134) Neue Zürcher Zeitung (NZZ), 19. 7. 1979.

s.85) Wirtschaftswoche (WW), 20.8. 1971.

130) WW, 4. 6. 1971, S. 26.

137) OECD, Economic Outlook, Juki 1971, S. 10.

138) Die offiziellen Arbeitslosenziffern in den USA kommen dadurch zustande, daß jeder Arbeitslose, der nicht aktiv nach einem Arbeitsplałz Umschau hält - zumeist, weil er dies als sinnlos erkannt hat - weder zu den Arbeitslosen noch zu den Beschäftigten gerechnet wird. So kann das absurde Ergebnis entstehen, daß in den USA sowohl die Zahl der Arbeitslosen wie die Zahl der Beschäftigten a b n $1 \mathrm{~mm} \mathrm{t}$ : die erste Zahl, weil Arbeitslose es aufgegeben haben, nach einem Job zu suchen; die letztere Zahl, weil Beschärtigte arbeitslos geworden sind. Aufgrund einer Berechnung: in der dieser Taschenspielertrick der US-Statistik, um sich über die Probleme des Kapitalismus hinwegzulugen, nicht gemacht wird, kommt "Monthly Review" zu einer Arbeitslosenzahl yon absolut 8,4 Millionen, das sind $9,4 \%$ H. Gegenüber offiziellen 6.2 v. H.) im Dezember 1970. Siehe: Monthy Rewew, vol. 22, No. 11, April 197:. 
1970 verlorengegangen!" Entscheidend iür das Verhältnis zu den anderen kapitalistischen Ländern seien nicht so sehr der absolute indexstand, welcher $(1963=100)$ immer noch nicht das Niveau anderer Länder erreicht hat, sondern die Zuwachsraten.

Die hohen Preisinflationen betreffen sowohl den Lebenshaltungsindex als auch die Preise der Industriewaren und Exportgüter. Der Lebensstandard der Arbeiterklasse in den USA stagniert zwar nun schon seit nahezu zehn Jahren, doch ist es dem Kapital in der Depression noch nicht gelungen, einen entscheidenden Einbruch in die Lebensbedingungen der be s $\mathrm{ch}$ äfig ten Arbeiter zu erreichen. Die Lohnsteigerungsraten von 7,8 v. H. 1970 und ca. 7 v. H. 1971 werden zwar weitgehend durch die Inflation wieder zunichte macht, doch die riesige industrielle Reservearmee hat sich noch nicht als Mittel zur Senkung des Preises der Ware Arbeitskraft in der Krise ausgewirkt. Das kapitalistische Gesetz der Lohnsenkung in der Krise über den Druck der industriellen Reservearmee scheint durch das Prinzip des „closed shop" der Gewerkschaften, durch die völlige Ausgliederung der Arbeitslosen aus der interessenvertretung der Arbeiterklasse, welche noch bestärkt wird durch die Tatsache, daß die industrielle Reservearmee zu einem großen Teil aus der schwarzen Bevölkerung besteht und in sogenannten deseased areas konzentriert ist, nicht voll zur Wirkung gelangen. Dies zusammengenommen mit der geringen Steigerungsrate der Produktivität deutet darauf hin, daß es bis jetzt in den USA nicht gelungen ist, den relativen und absoluten Mehrwert zu erhöhen. Ein Aufschwung wird aber erst dann möglich sein, wenn es dem US-Kapital gelingt, entscheidende Senkungen des Reallohns und eine Erhöhung der Arbeitsintensität durchzusetzen. Da diese in den USA jedoch schon außerordentlich hoch ist, wären solche Formen der Erhöhung der Aus* beutungsrate wahrscheinlich nur im Zusammenhang mit einer Änderung der technischen Struktur, also einer Neuanlage von Fixkapital möglich.

Der gegenwärtige Lohnstop ist von den Gewerkschaften nicht einfach hingenommen worden. Der große Haienarbeiterstreik hat trotz Androhungen von Sanktionen nach dem 14. August fortgedauert, ja sogar sich ausgebreitet. Sind auch die Gewerkschaften in den USA nur auf den Lohnkampl orientiert, so zeigt sich doch, daß Krise und industrielle Reservearmee sie bis jetzt nicht zu einer Politik der konzertierten Aktion disziplinieren konnten, daß also eine voll integrationistische Politik doch an den objektiven interessengegensätzen von Lohnarbeit und Kapital sich bricht. So bleibt zu fragen, ob nicht, ähnlich wie in England die Arbeiterklasse sich weigert, die Krise und die Folgen der imperialistischen Politik auf inrem Rücken austragen zu lassen und damit einer neuerlichen flotten Akkumulation des US-Kapitals Grenzen setzt.

Verdankte die BRD den hohen Aushhrzuwachs 1967 der partiellen Senkung der Exportpreise und die relativ geringe Steigerung der Importe der Stagnation der Inlandspreise, so hat in den USA die Preisinflation genau die gegenläufige Bewegung erzeugt. Wenn heute Nixon durch die Importsteuer diesen Trend umkehren will (verbunden mit den Aufwertungen in anderen kapitalistischen Ländern), so kann diese Maßnahme so lange nicht erfolgreich sein, wie sich die Verwertungssituation des US-Kapitals nicht ver- 
bessert. Während das westdeutsche Kapital in der Rezession 1967 einen weiteren Produktionsrückgang durch verstärkte Außenhandelsexpansion aufhalten konnte, gilt dies nicht für die USA. ${ }^{139}$ ) Zwar erfuhren 1970 auch die US-Warenexporte einen leichten Anstieg, so daß die Handelsbilanz immer noch positiv war, doch änderte sich dies 1971 grundlegend: die Handelsbilanz weist ein grobes Defizit aur.

Obwohl also der Welthandel noch florierie, konnte das US-Kapital nicht davon wie das westdeutsche Kapital 1967 profitieren. Dies zeigt einmal mehr, daß der Außenhandel für das jeweilige nationale Kapital nur in Bezug aut die Realisierung der Werte relevant ist, jedoch keinesfalls als Konjunkturstimulans eintreten kann, so lange nicht in den zu realisierenden Werten (Preisen) ein entsprechender Mehrwert bzw. Profit enthaiten ist. Und die Produktion des Profits hängt nicht von den Realisierungsbedingungen, sondern von den Ausbeutungsbedingungen dort ab, wo das Kapital produziert. So lange demnach in den USA selbst die "Investitionsgelegenheiten" mangelhaft weil unprofitabel sind, wird die US-Krise sich hinziehen mit all ihren schon geschilderten Konsequenzen für den gesamten Weltmarkt. Die Preisinflation in den USA wird sich vermittelt über die Formen der Weltzirkulation ausbreiten, ohne daß die einzelnen Länder dagegen wirksame Abwehrmechanismen haberi. Und die US-Wirtschaftspolitik besinnt sich auf die Tatsache, daB der Nationalstaat vor allem das eigene nationale Kapital zu schützen hat. Die Maßnahmen vom August 1971 sind daher auch als Versuch zu werten, die Akkumulationsbedingungen des US-Kapitals wieder zu verbessern, onne die Verbesserung der Weltmarktsituation des US-Kapitals mit einer bereinigenden Krise (weitere Steigerung der Arbeitslosigkeit), Kapitaivemichtung größeren Ausmaßes) zu erkaufen. Die Maßnahmen der USRegierung zur Begünstigung des eigenen Waren- und Kapitalexports und zur Behinderung der Warenimporte sowie zur Reduzierung der externen US-Schulden finden alierdings in einer Situation niedergehender Konjunktur in wichtigen kapitalistischen Ländern statt und sind daher in ihren Erfolgsaussichten äußerst fragwürdig.

\section{Engiand}

Die Phase stagnierenden Wachstums in Großbritannien geht 1971 in eine Rezescion über. Das ESP wuchs 1969 nur um 2,3 v. H.; aber selbst diese niedrige Wachstumsrate verringerte sich noch 1970 auf 2 v. H. und 1971 auf $0,5 \vee \cdots$ Die Arbeitslosenziffern stiegen gleichzeitig an von $1969=2,1$ v. $H ., 1970=2,3$ v $H$. auf 3 v. H. im Jahre 1971. Die Preissteigerungen übertreffen sogar diejenigen der USA: Der Preisindex des BSP erhöhte sich von 4,25 v. H. im Jahre 1969 über 7,25 v. H. im Jahre 1970 auf 8,25 v. H. in diesem Jahr. ${ }^{140}$ ) Doch hat GroBbritannien keine negative Zahlungsbilanz. Nach Schätzyngen der OECD verzeichnet die Zahlungsbilanz in den letzten Jahren Werschüsse. Auch die Handelsbilanz GroBbritanniens ist im ersten Halbjahr 1971 ausgeglichen. Defizite waren im ersten Quartal zu verzeichnen,

i39) Economic Eulletin of Europe, Vol. 22, No. 11971 (UNO), S. 1.

14) OECD, Economic Outlook a. a. O., S. 10 un dS. 14. 
welche in Zusammenhang mit den Sireiks gesehen werden müssen, Die Uberschüsse des zweiten Quartals gleichen bisher die Defizite des ersten aus. "Die Tatsache, daß die britische Handels- und Ertragsbilanz bei steigenden Exporten eine gute Position aurweist, steht jedoch nach wie yor in krassem Gegensazz zur internen Wirtschaftslage, die seit Monaten durch Stagnation, Inflation und hohe Arbeitslosigkelt gekennzeichnet ist." 1AY Dis "Wirtschaftswoche" stellt dazu Volgende These auf: "Wegen der Kosteninflation bubsen die Briten alle durch die Abwertung im November 1967 ge wonnenen Konkurrerzvortelle wieder ein. So stiegen beispielsweise die $1 \mathrm{~m}$ portpreise in den letzten zwöl Monaten nur um zwei, die Exportpreise aber um neun Prozent - beinahe so stark wie der Index der Lebenshaltungskosten. Die Zunahme des Ausfuhrwertes un $9,4 \%$, verglichen mit dem ersten Halbjahr 1970 ist also "ediglich den Preissteigerungen zu verdanken." ${ }^{42}$ ) Dort wird auch die These des einstigen wissenschaftlichen Beraters Wilsons, Nicholas Kaldor, wiedergegeben, der gegenwärige Exporiüberschuß erkläre sich überhaupt nur aus der Stagnation in England und der stark zurückgegangenen Nachfrage des englischen Kapitals nach Rohstofien und Konsumgütern. „Die Zahlungsbilanz ist nur deshalb positiv, weil 892000 Briten ohne Job und die Industriekapazitäten nur zu knapp zwel Drittel ausgelastet sind." 143) Die derzeil positive Handelsbilanz sagt daher nichts über die Konkurrenzfähigkeit des englischen Kapitals auf dem Weltmarkt aus. Die positive Zahlungsbilanz erklät sich aus Kapitalimporien, welche aut das hohe Zinsniveau, das Großbritannien seit Jahren aurechterhält um die Position des Pfundes auf dem Weltmarkt nicht völlig niedergehen zu lassen, zurückzuführen sind. Während das auf dem Weltmarkt sich bewegende Geldkapital, dessen Bewegungsrichtung sich nach dem jewelligen Zinsniveau der verschiedenen Länder richtet (vgl. Teil 3), im Jahr 1970 aufgrund der Niedrigzinspolitik zur Behebung der Krise aus den USA abflob, hatte Großbritannien weiterhin hohe Geldkapitalimporte zu verzeichnen. ${ }^{144}$ ) In diesem Zusammenhang läBt sich auch ungefähr die Verwertungssituation des fungierenden Kapitals in England andeuten. Einmal drückt die hohe Zinsrate des Bankkapitals auf die Profitrate Wesentlicher aber ist zum anderen, das die Zuwachsraten der Arbeitskosten pro Produkteinheit und der Produktivität in England im Vergleich zu Frankreich, der BRD, ltaline, den USA, Japan äuBerst ungünstig sind. So hat England eine mit Abstand unterdurchschnittliche Produktivitattszuwachsrate und eine mit ebentalls steigendem Abstand überdurchschnittliche Steigerung der Arbeitskosten. Diese Faktoren zusammengenommen geben Auschluß darüber, daf in der Tat, wie die OECD schreibt, die Ge-

141) NZZ, 15.7. 1971

14) WW, 13.8.71, S. 16.

14) ebenda, S. 15.

144) Daß es sich hier kaum um fungierendes Kapital handelt, das auch in Großbritannien Arbeitskräfte kauft, wind am Beispiel Ford deutlich. Aufgrund der Klassenkämpie in England, insbesondere der Streiks bei Ford, verlegt Ford ein geplantse Zweigwerk zur Erweiterung der Produktion auf den Kontinent. Es zeigt sich übrigens die schädliche Auswirkung, daß das Kapital intenationa! beweglich über beinahe alle Grenzen ist, aber die Kämpfe der Arbeiterklasse imrner noch der Form und zumeist auch dem inhalt nach nationalen charakter haben. 
winnmargen bzw. Profitraten des englischen Kapitals "gedrückt" sein müssen. ${ }^{145}$ )

Was die Lage der Arbeitklasse angeht, so ergibt sich ein ähnliches Bild wie in den USA: Geringe Verbesserungen der Löhne, die angesichts der nun schon jahrelangen Stagnation der englischen Industrie durch harte und permanente Klassenkämpfe erzwunden wurden. Dem englischen Kapital gelingt es zur Zeit noch nicht, entscheidende Senkungen des Preises der Ware Arbeitskraft zur Verbesserung seiner Verwertungssituation durchzusetzen.

Anzeichen eines neuen Aufschwungs lassen sich aus dem Material, welches uns bruchsłückhaft Aufschluß über die Lage des englischen Kapitals und der englischen Arbeiterklasse gibt, nicht ersehen.

Da $12 \%$ der britischen Exporte in die USA gehen, die Importe GroBbritanniens aus den USA auf der anderen Seite seine Exporte in die USA übersteigen, trifft die gegenwärtige Importbesteuerung in den USA das englische Kapital zwar hart, doch ist das Interesse des englischen Kapitals an einer allgemeinen Paritätsänderung kapitalistischer Länder (Frankreichs, der BRD und Japans) insofern klar, da eine Auffwertung des Pfund kaum oder nur in sehr geringem Maßstab erfolgen wird, eine demgegenüber hohe Aufwertungsrate der Konkurrenzländer die Exportposition des englischen gegenüber dem Kapita! der EWG-Länder und Japans verbessern würde.

Aber auch für Großbritannien gilt das, was schon in bezug auf die USA ausgesagt worden ist: Auch wenn der äußere Markt weiter expandieren sollte, so wird dies nicht unmitteibar zu einem britischen Wirtschaftsaufschwung führen. Denn Vorbedingung dafür ist eine grundlegende Verbesserung der Verwertungssituation des britischer Kapitals im doppelten Sinne: der Verbesserung der Ausbeutungsrate der Arbeiterklasse und der Verbesserung der Konkurrenzsituation durch Steigerung der Produktivkraft der Arbeit.

\section{Frankreich}

Da die uns im Moment zugänglichen Daten über die Entwicklung in Frankreich kein klares Bild über die konjunkturelle Entwicklung geben, wollen wir uns auf die kurze Darstellung der Interessen des französischen Kapitals im Zusammenhang mit der gegenwärtigen Währungskrise beschränken. Nur soviel zuvor: Die OECD Schätzungen ${ }^{146}$ ) geben zwar eine Minderung des Wachstums des BSP für 1971 an $(1969: 7,7 \% ; 1970: 5,9 \% ; 1971: 5,5 \%)$, doch von einer krisenhaften Entwicklung kann im Moment nicht gesprochen werden. Die Weigerung Frankreichs, den Wechselkurs des Franc frei floaten zu lassen, und die Einführung eines gespaltenen Devisenmarkts lassen sich allerdings deutlich aus der Entwicklung der letzten Jahre begründen. Die Mairevolte 1968 und das darauffolgende sprunghafte Ansteigen von Löhnen, dann aber auch von Preisen hatte zu einem hohen Importüberschuß und zu

145) Vgl. OECD, Economic Surveys, United Kingdom, November 1970, S. 22.

146) OECD, Economic Outiook, a. a. O., S. 4. 
einer negativen Zahlungsbilanz geführt. Nur durch eine qualitative Ängerung des Lohnniveaus war es dem französischen Kapital 1968 gelungen, die Klassenkämpfe des Proletariats zurückzudrängen. Die beträchtliche Einschränkung der Ausbeutungsrate machte es im Innern wett durch umso größere Preissteigerungen, welche im Gegensatz zur BRD und Japan nicht nur die "lokalen Märkte", sondern auch die Exportpreise betraf. Die hohen Produktivitätszuwachsraten in Frankreich, welche ihre Kehrseite in einer wachsenden Arbeitslosigkeit trotz hoher Wachstumsraten hat, zusammengenommen mit den Preissteigerungen führten zwar dazu, daß die alte Ausbeutungsrate wiederhergestellt wurde, ${ }^{147}$ ) aber die Aufblähung des Geldausdrucks der Warenwerte führte zu einem schweren Rückschlag in der internationalen Konkurrenzfähigkeit des französischen Kapitals. Erst die Abwertung des Franc im August 1969 führte zu einem Gleichgewicht der Zahlungsbilanz. Die gleichzeitige Aufwertung der DM führte zu einer entscheidenden Erhöhung der Exportpreise der westdeutschen Konkurrenten, so daß die Importe Frankreichs deutlich geringere Zuwachsraten hatten als die Exporte. Die westdeutsche Aufwertung und die französische Abwertung im Rahmen der allgemeinen Preissteigerung auf dem Weltmarkt seit 1969 ermöglichte es den französischen Exporteuren, ihre Preise in Dollar zu halten, so daß Extraprofite aufgrund der Paritätsänderungen in der französischen Exportindustrie entstanden ${ }^{148}$ ). Im Augenblick kann es dem franzöischen Kapital demnach nur darum gehen, die gerade zurückgewonnene Konkurrenzfähigkeit auf dem Weltmarkt zu halten oder gar zu verbessern.

Der für Finanz- und Handelsfranc gespaltene Devisenkurs (Freigabe der Wechselkurse für Kapital-, Beibehaltung des Kurses für Warenbewegungen) soll gleichzeitig den Zustrom von ausländischem Kapital nach Frankreich einschränken.

Da Frankreichs Außenhandel mit den USA vergleichsweise gering ist, ${ }^{149}$ ) geht es dem französischen Kapital primär um seine Stärkung gegenüber den deutschen Konkurrenten, woraus sich auch die scharfen Ausseinandersetzungen zwischen Frankreich und der BRD in Brüssel um die Währungsfrage erklären.

\section{Japan}

Japan befindet sich zur Zeit im fünften Jahre des Konjunkturaufschwungs. Die realen Zuwachsraten des BSP lagen in dieser Zeit niemals unter $10 \mathrm{v}$. $\mathrm{H}$. Die Globalzahlen verweisen auf eine einźigartige Periode in der Geschichte der Kapitalakkumulation. Jedoch geht auch dieser Boom zu Ende. Seit Mitte 1970 tendieren die Zuwachsraten nach unten. Die Industrieproduktion ging -

147) Seit der Mairevolte 1968 stagnieren in Frankreich die Reallöhne. Vgl. OECD, Economic Surveys, France, März 1970, S. 27, S. 11.

148) Das Economic Bulletin für Europe, a. a. O., S. 1, schreibt: „Die französischen Exporteure waren bei der Anhebung ihrer Preise nach der Abwertung erfolgreich, so daß ihre Dollarpreilse nicht gefallen sind."

149) Die Gesamtausfuhr Frankreichs 1969 betrug in Mio. DM: 58655. Davon gingen nur 3769 in die USA. Statistisches Jahrbuch für die BRD, 1971, S. 77. 
gegenüber den entsprechenden Vorjahresquartalen - im zweiten Vierieljahr 1970 auf 18,3 v. H., im dritten Vierteljahr auf 16,3 v. H. und im vierten Vierteljahr auf $10,5 \mathrm{v} . \mathrm{H}$. zurück. Die Auftragseingänge verringerten sich ebenfalls; in einigen Branchen (Maschinenbau und Elektrotechnik) lagen sie 1970 um 5 v. H. unter dem Wert von 1969. Die "Gewinnmargen" der Unternehmen gingen unter diesen Bedingungen zurück- so daB auch die Zuwachsraten der Investitionen fielen. Bezügilch der gegenwärtigen Gesamtsituation in Japan ergab ,eine kürzlich veröffentlichte Erhebung der Entwicklungsbank Japans, daß im laufenden Fiskaljahr (April 71 - März 72) Anlageinvestitionen der industrie geplant sind, die nur um 7,2\% höher als diejenigen des Vorjahres sein werden. 1970/71, ebenfalls ein Jahr schlechter Konjunktur, übertrafen die Anlageinvestitionen die des Vorjahres noch um 12,6\%. Die Erhebung ergab aber auch, daß im Falle einer Yen-Aufwertung von $6 \%$ und des Inkraftbleibens der Importabgabe in den Vereinigten Staaten die Zunahme der Anlageinvestitionen nur $3,2 \%$ erreichen wird. Für das nächste Fiskaljahr sahen die befragten Unternehmer eine Abnahme der Investitionen von 6 $7 \%$ voraus. Viele japanische Unternehmen haben innert der letzten drei Wochen bekanntgegeben, daß sie ihr Investitionsvolumen zurückschrauben, weniger oder gar kein neues Personal einstellen und ihre Produktion droseln werden. Im Textilzentrum der Präfektur Fukui haben die Unternehmen beschlossen, ihre Ausbringung um durchschnittlich zwanzig v. $H_{\text {. einzuschrän- }}$ ken. In Tsubame, dem Mittelpunkt der Metallbesteckindustrie, erklärten Sprecher der Branche, daß seit der Ankündigung Nixons keine Neuauttrăge mehr eingegangen seien. Der Verband der japanischen Werften gab bekannt, daB seit der Erklärung des amerikanischen Präsidenten die Industrie nur einen Auftrag ... erhalten habe." ${ }^{150}$ ) Muß man auch die japanischen Salbstdarstel. lungen mit Vorsicht einschätzen - im Jahr 70/71, nach jap. Angaben ein Jahr schiechter Konjunktur, betrug das reale Wachstum des BSP immerhin noch ca. 10 v. H.: der Rückgang der Investitionen schon vor der Erklärung Nixons ist eine Tatsache. 1965 stand einem Rückgang der Investitionen um $8,3 \%$ ein Wachstum des Exports um 21,4\% (Import 7,4\%) gegenüber. Ähnlich wie in der BRD wurde die damalige Krise gemildert durch Exportexpansion. Die Verschärfung der weltweiten Konkurrenz der Kapitale, die in der Währungskrise ihren Ausdruck findet, trifft demnach auch das japanische Kapital in enner Situation rückläufiger Konjunktur. Als Ankurbelungsmaßnahmen siekt die Staatsgewalt, ebenso wie in den USA und GroBbritannien, Steuererleichterungen für Investitionen vor. Deren Wirksamkeit läßt sich nicht genau einschatzen. Für Japan aber ist wichtig, daß eine solche Ankurbelungsmaßnahrne auf eine Zurückstellung der längst notwendig gewordenen Verbesserung der Infrastruktur hinauslaufen muB, was eine Verschärfung der Widersprüche des Akkumulationsprozesses und eine weitree Verschlechterung der Lage der Arbeiterklasse zur Folge haben wird, jedenfalls soweit diese durch die Infrastruktur - Verkehr, Gesundheitswesen, Schulen eic. -

150) NZZ, 16. 9. 1971. 
bestimmt ist. ${ }^{151}$ ) Die extreme Konzentration des gesellschaftlichen Reichtums bel den großen Kapitalen, die Vernachlässigung der Entwicklung der infrastruktur hat in Japan einen Zusiand zugespitzter geselischaftlicher Widersprüche geschaffen, welcher nur aufgrund der besonderen Traditionalismen der japanischen Arbeiterklasse noch nicht zu umfassenden Klassenkämpfen geführt hat. Das japanische Kapital ist aber in der nun eingetretenen Weltmarktsituation nicht dazu in der Lage, die Versäumnisse nachzuholen. Wie allen anderen Kapitalen bleibt ihm jetzt nur eine Verschärfung der Ausbeutung, der Konzentrationsprozesse, $d . h$ der progressiven Zerștörung der noch vorhandenen zurückgebliebenen Kapitale und damit der Zuspitzung der gesellschaftlichen Widersprüche in Japan, welche in ganz anderer Weise, als etwa in Westeuropa, politisch relevant werder.

Der Schock, welchen die Währungskrise in Japan auslöste, hängt mit der starken Außenhandelsverflechtung zwischen Japan und den USA zusammen. Das japanische Kapital konkurriert zudem mit dem US-Kapital nicht nur innerhalb der USA, sondern auch auf den ostasiatischen Märkten und in Australien. Die Außenhandelsstruktur Japans ist in ganz anderer Weise als die aller anderen entwickelten kapitalistischen Länder durch das klassische Muster geprägt: Nämlich Ausfuhr von Industriewaren und Einfuhr von Rohstofen. ${ }^{152}$ ) Daraus folgt, daß Japan auf den ostasiatischen Märkten und in Australien mit den US-Kapitalisten in Konkurrenz auf den Industriewarenmärkten steht. Eine Aufwertung des Yen würde zu einer Verschärfung dieser Konkurrenz zuungunsten Japans sowohl in den USA selbst auch in Südostasien führen. Die Verbilligung der Importe durch eine Aufwertung würde demgegenüber nicht zu einer Konkurrenizverschäriung innerhalib des japanischen Marktes führen, da die nach Japan importierten Rohstoffe dort gar nicht produziert werden. Sie würde im Gegenteil bessere Verwertungsbedingungen für das industrielle Kapital schaffen, indem der Preis des konstanten Kapitals durch Bezug billigerer Rohstoffe gesenkt würde. ${ }^{153}$ ) So entspricht es nur kapitalistischer Logik, wenn die USA jetzt von Japan eine „stärkere Beteiligung an der Entwicklungshilfe" ${ }^{154}$ ) - sprich an den militärischen Kosten der imperialistischen Ausbeutung und der Herrschaftssicherung über die südostasiatischen Völker - fordert. Denn während die USA durch den Vietnamkrieg ihre eigene Wirtschaft mit zugrunderichteten, profitierten die japani-

151) Bisher hatte Japan im Vergleich zu den übrigen imperialistischen Ländern den geringsten Anteil an Staatsausgaben a.m BSP, nämlich nur 20,8 v. H. Zum Vergleich: Frankreich hatte $39 \mathrm{v}$. H., die BRD $36,4 \mathrm{v}$. H. Italien $32,4 \mathrm{v}$. H., die USA $27,3 \mathrm{v}$. H. Quelle: OECD, Economic Surveys, Japan, 1970, S. 58 . In diesen Zahlen ist zu berücksichtigen, daß in Japan der vom Staat umverteilte Lohnanteil (,Sozlalausgaben') relativ gering ist, während die Subventionen für verschiedene kapitalistische Produktionszweige eine sehr wichtige Rolle spielt.

152) 1969 betrug die japanische Gesamtausfuhr 15990 Mio. US-Dollar. Davon entfielen auf Induistriewaren 15072 Mio. Dollar. Die Gesamtimporte betrugen 15023 Mio. Dollar, davon entfielen auf Rohstoffe 10586 Mio. Dollar. Nach OECD, Japan, a. a. O., S. 85. 13:3) Dies bedeutet für die Rohstoffe produzierenden schwach entwickelten Läncier eine weitere Verschlechterung ihrer terms of trade.

1544) NZZ, 11. 9. 1971. 
schen Kapitalisten von dieser politischen Absicherung Südostasiens. Vergleichweise gering mit Rüstungskosten belastet, konnte das japanische Kapital den ausgepreßten Mehrwert in die Entwicklung der Produktivkraft der Arbeit stecken, und zwar vor allem in den Industriezweigen, welche in Konkurrenz mit dem US-Kapital auf dem Weltmarkt stehen. Dadurch wurde aber gerade die besondere Struktur des japanischen Kapitals, nämlich hochentwickelte monopolistische Großkapitale, die in hohem Maße für den äußeren Markt produzieren, auf der einen Seite, und auf der anderen Seite äuBerst zurückgebliebene Produktionsbedingungen in den Zuliefererindustrien, welche sich überhaupt nur durch für das Kapital günstige Bedingungen der Ausbeutung halten können, verfestigt. Eine länger andauernde Krise des Weltmarkts, eine relevante Veränderung der Währungsparitäten im Sinne einer Yen-Aufwertung, nationalstaatliche Handelshemmnisse würden diesen Gegensatz innerhalb des japanischen Kapitals als Strukturkrise hervorbrechen lassen.

Es zeigt sich also auch bei der Betrachtung der japanischen Wirtschaftsentwicklung, daß die konjunkturelle Abschwächung aus den nationalen Bedingungen der Kapitalakkumulation resultiert. Die Vermittlung zum Weltmarkt ist wie folgt stichwortartig zu umreißen: Eine Voraussetzung für die flotte Akkumulation des japanischen Kapitals waren die günstigen Realisierungsbedingungen der produzierten Werte auf dem Weltmarkt. Die scharfe Konkurrenz des japanischen Kapitals, zusammen mit den sich verschlechternden Konjunkturbedingungen in den USA selbst brachte das US-Kapital in Schwierigkeiten. Der US-amerikanische Nationalstaat reagierte darauf protektionistisch mit der vielfach erwähnten Importsteuer. Dadurch geriet aber das japanische Kapital selbst in Schwierigkeiten, deren weitere Auswirkungen sowohl für die japanische Ókonomie als auch für den Weltmarkt insgesamt noch nicht abzuschätzen sind.

\section{BRD}

Ebenso wie in Japan war der Konjunkturrückgang in der BRD schon vor dem Ausbruch der Währungskrise sichtbar geworden. Nach einer Steigerung der Industrieproduktion von $13 \mathrm{v} . \mathrm{H}$. im Jahre 1969 und $6,1 \mathrm{v} . \mathrm{H}$. im Jahre 1970 verminderte sich die Zuwachsrate im ersten Halbjahr 1971 auf 2,4 v. H. gegenüber dem ersten Halbjahr 1970. Nach dem Rückgang der Aufträge in der Investitionsgüterindustrie seit dem 3. Quartal 1970 klingt nun auch die sogenannte "Verbraucherkonjunkiur" ab. Preisbereinigt hatten die Gesamtaufträge der Industrie im Juli sogar einen absoluten Rückgang zu verzeichnen: „Im Inland stieg die Nachfrage im Juli um nominal $2 \%$, real gesehen bedeutet dies bereits Nachfragerückgang. Die Auslandsnachfrage ging sogar nominal zurück." ${ }^{156}$ ) Betrafen die Rückgänge in der Industrieproduktion im

155) So stieg, um nur ein oberflächliches Indiz zu benennen, der Reallohnindex von $1965(=100)$ bis 1970 auf 146,1 ; der Index der Arbeitsproduktivität aber im gleichen Zeitraum auf 196,5 .

150) WW, 10. 9. 1971. 
3. Quartal 1970 vor allem einzelne Branchen (Elektroindustrie, Maschinenbau), so ergibt sich im Moment das Bild eines allgemeinen Konjunkturrückgangs. Die letzten Entwicklungen seit der Währungskrise lassen die bürgerlichen Konjunkturprognostiker von einer beginnenden Rezession sprechen. Auch die Entwicklung der Beschäftigung, der Kapazitäisauslastung, der In vestitionen und der Konkurse deutet auf eine Rezession der westdeutschen Wirtschaft nach einem vier Jahre dauernden Boom hin. Die Zahl der ArbeitsIosen steigt zum ersten Mal seit Anfang 1988 wieder an und betrug im Juli über 200000 . Die Zahl der offenen Stellen liegt zwar noch bei mehr als 600000 , aber sie hat seit Mitte 1970 eine eindeutig rückläufige Tendenz. Einzelne Betriebe sind zu Kurzarbeit und Einsteliungsstop bereits übergegangen. Die Kapazitätsauslastung, die im Boom über $90 \mathrm{v}$. H. betrug und in manchen Fällen bis an die absolute Auslastungsgrenze gestoßen ist, hat eine rückläufige Tendenz. Die investitionen stiegen zwar 1971 nominal um 3-4 v. H. real ist aber mit einem absoluten Rückgang zu rechnen. Die Profite des Kapitals sind angesichts dieser Indikatoren ebenfalls im Abnehmen. Die Arbeitseinkommen haben nach einer langen Stagnationsphase infolge der Krise von 1967 seit 1969 sehr stark zugenommen und auf die Profite gedrückt. Zwar haben die Einzelkapitalisten versucht, durch Preiserhöhungen dennoch „auf ihre Kosten“ und Profite zu kommen, aber der gesamten Kapitalistenklasse ist dies nicht möglich. So ist die relative Prosperität der westdeutschen Arbeiterklasse wieder einmal als Sturmvogel der Krise zu werten. Und die "Verbraucherkonjunktur", aus der von manchen OKonomen starke Hoffnungen auf eine neue Belebung geschöpft werden, ist nichts anderes als Reflex der gestiegenen Reallöhne, von denen die eine Kapitalistenfraktion noch profitiert, während die anderen, die keine Waren für die Arbeiterkonsumtion erzeugen, darunter jetzt schon "leiden". Zusätzlich wird die industrielle Profitrate aber durch das Bankkapital und dessen Zinsen eingeengt. Im Umbruch zwischen Hochkonjunktur und Krise ergibt sich eine Verknappung des Geldkapitals aufgrund der sich vergrößernden Umschlagszeit des Kapitals. Die mit der Verknappung einhergehende Erhöhung des Preises der Geldware, also des Kredits, aufgrund der zunächst noch steigenden Nachfrage drückt die Profitrate des fungierenden industriellen Kapitals. An diesem Punkt setzt auch die staatliche Geldpolitik ein, wenn sie durch Erhöhung von Mindestreserven und Diskontsätzen zusätzlich die „Knappheit des Geldes" erhöhen will, um auf diese Weise eine "Überhitzung der Konjunktur" zu verhindern. Wäre der Geldmarkt national geschlossen, so könnten solche staatlichen Maßnahmen in der Tat die "Schwindelblüte der Konjunktur" und damit auch die Schärfe des nachfolgenden Zusammenbruchs abschwächen. Für das Erscheinungsbild der westdeutschen Konjunktur ergibt sich nun folgendes Bild: Der Versuch, ein "Überschäumen der Konjunktur" durch Verknappung des Geldes zu verhindern, ist mißlungen. Bei einem Zuwachs der Industrieproduktion von 13\% hat sich im Jahre 1969 das Geldvolumen, (November 1959 gegenüber November 1968) nur um 5,3 Milliarden DM erhöht, bei einem Wachstum der Industrieproduktion 1970 um 6,1\% erhöhte es sich demgegenüber um 9 Milliarden DM (November 1970 gegenüber November 1969). "Das Hochzinsniveau hat dazu geführt, daß sich große Unternehmen, 
speziell in der Industrie,das Geld zu günstigeren Bedingungen im Ausland geholt haben. Diese Tendenz hält unvermindert an. Durch die währungspolitische Unsicherheit nach der Freigabe des DM-Wechselkurses hat sich diese Tendenz noch verstärkt... Insgesamt ist die (kurzfristige) Verschuldung der deutschen Industrie im Ausland mit 30 Milliarden DM zu beziffern, wovon vielleicht 20 Milliarden DM auf Kreditaufnahmen und 10 Milliarden auf Vorauszahlungen auf deutsche Lieferungen entfallen. . Die Kreditaufnahme sehen wir im deutschen Bankgewerbe... mit großer Sorge, weil bei möglichen Störungen im Eurodollarmarkt Beträge auf uns zukommen, die lawinenartig unsere Liquiditätsmöglichkeiten überrollen. ${ }^{\text {(5 }}{ }^{157}$ ) Der Überfluß an Geldkapital, welcher sich in den USA im Zusammenhang der nun schon zweijährigen Krise gebildet hat, bildet seit der Niedrigzinspolitik in den USA 1970 einen Fonds, auf den das deutsche Kapital in der Phase des Umbruchs zwischen Hochkonjunktur und Krise zurückgreifen kann. Würde nun die Stagnation in den USA in eine Phase wirklicher Kapitalvernichtung umschlagen, welche mit einer Geldkrise verbunden wäre, so würde das westdeutsche Kapital im Falle des Abrufs der kurzfristigen US-Gelder notwendig in eine Krise hineingerissen. Dann würde sich in ähnilcher Weise das wiederholen, was in der Weltwirtschaftskrise passierie. Das deutsche Kapital wurde aus seiner Boomeuphorie gerissen, als die USA ihre kurzfristigen Auslandsgelder zurückriefen und das ganze künstliche, darauf basierende Kreditgebäude Deutschlands in den Strudel der Geldkrise rissen.

Der Vorsprung, welchen das deutsche Kapital vor seinen Konkurrenten durch die der Krise von 1967 folgenden Produktivitätsfortschritte und Preissenkungen auf dem Weltmarkt erreichen konnte, ${ }^{158}$ ) scheint inzwischen reduziert worden zu sein. Während des Jahres 1969 sitiegen die Exportpreise kontinuierlich an, sowohl vor wie nach der Aufwertung. ${ }^{159}$ ) Trotzdem lag der Preisindex für Großhandelspreise, am ehesten vergleichbar mit Exportpreisen, im Jahre 1969 mit einer Zuwachsrate von 2,2\% noch unter der der wichtigsten Konkurrenten, welche im Durchschnitt eine 4,2prozentige Steigerung zu verzeichnen hatten. Erst 1970 lag die Preissteigerungsrate der BRD von 5,9 v. H. über dem Durchschnitt der Konkurrenten von 5,3 v. H. ${ }^{160}$ ) Dazu

157) F.H. Ulrich, WW, 11.6. 1971, S. 32. Zum Geldumlauf schreibt die Deutsche Bundesbank: "Die erwähnten Schwankungen der Umlaufgeschwindigkeit, die gleichbedeutend sind mit den Diskrepanzen in den Veränderungen des Gelovolumens und des Bruttosozialprodukts, folgen aber einem bemerkenswert regelmäßigen Rhythmus: Im Abstand von etwa fünf Jahren erreicht die Umlaufgeschwindigkeit jeweils einen Höhepunkt, und zwar 1951, 1956, 1961, 1966 und 1970; dazwischen geht sie mehr oder weniger stark zurück; Tiefpunkte waren die Jahre 1954, 1959, 1963 und 1967, Die Schwankungen haben eine deutliche Ahnlichkeit mit dem Konjunkturzyklus, so daß schlußfolgern könnte, die Umlaufgeschwindigkeit kulminiere jeweils in der Spätphase des Booms; das ist zugleich die Zeit, in der die Kreditrestriktion sich am stärksten bemerkbar macht und die Zinsen am höchsten sind." Monatsberichte der Deutschen Bundesbank, Juli 197\%, S. 14.

158) Vil. E. Altuater, Dis Weltwährungskrise, Frankiurt 1969, S. 87 if.

${ }^{159}$ ) Sachvreständigenrat zur Begutachtung der gesamiwirtschatulichen Entwicklung, Jahresgutachten $1970 / 71$, S. 183.

$\left.{ }^{160}\right)$ Geschäfisbericht der Deutschen Eundesbark ü das jahr 1970, 5.12. 
heibt es im Economic Buletin der UNO: „Der neueste Preisboom im internationalen Handel, welcher das durchschnittliche Preisniveau, ausgedrückt in Dollar für Grundstoffe und Industriewaren, um $7 \%$ zwischen dem 3. Quartal 1968 und dem zweiten Quartal 1970 anhob, war der erste seit dem Koreaboom." ${ }^{161}$ ) Dieser Preisboom sel der Aufwertung der DM geschuldet, denn die mit der Aufwertung verbundene Erhöhung der deutschen Exportpreise hätte die anderen Länder dazu veranlaßt, im Preisniveau nachzuziehen. Sie seien andererseits durch Lohnsteigerungen zu diesen Preissteigerungen gezwungen gewesen. Ohne diese fragwürdige Kausalkonstruktion weiter zu untersuchen, läßt sich doch für die gegenwärtige Situation testzustellen, daß die neueriche Aufweriung der DM nicht so einfach wie 1969 durch Preissteigerungen der Exportwaren kompensiert werden kann. So schreibt z. B. die Süddeutsche Zeitung über den VW-Export: "Sorge bereitet nicht so sehr die Importabgabe, die durch den Wegiall der Verkaufssteuer ja mehr als aufgehoben wird. Vielmehr bereitet die Erlösschmälerung durch die de facto Aufwertung der DM Kopfschmerzen. Jedoch tröstet man sich mit dem Gedanken, daß ja nach dem 9otägigen Preisstop der Regierung viele US-Áutomobile teurer werden düriten, was dem Käfer einen größeren Preisspielraum bringt." $\left.{ }^{162}\right)$ Und eine Woche nach der Nixon-Erklärung charakterisiert die Süddeutsche Zeitung die Situation folgendermaßen: "Entweder wir strengen uns an, wir bescheiden frühzeitig und freiwillig - oder wir verlieren den Weltmarkt. Dann allerdings würden wir den Gürtel wirklich eng schnallen müssen und der Traum von der permanenten Vollbeschäftigung wäre aus. Wir und andere, vor allem die Japaner, müssen Ersatzmärkte suchen; einer der verlockendsten ist der deutsche Markt." Und der Schreiber Franz Thoma, gibt die Losung aus: "Erhöhung der Produktivität durch gesteigerte Leistung und Bescheidenheit in der Lohnpolitik." 163

\section{SchluBbemerkung}

Die wenn auch kurze und nicht sehr genaue Untersuchung der Konjunkturbewegungen in wichtigen kapitalistischen Ländern zeigt, daß sich alle diese Länder - mit eventueller Ausnahme Frankreichs - gleichmäßig am Ende eines in der Regel lange andauernden Booms, bzw. wie in England und die USA bereits seit Monaten an einer Stagnation befinden. Die zyklischen Bewegungen der nationalen Kapitale laufen in einer Phase, in der die Reprodukionsbedingungen des Kapitals auf eine Krise hindeuten, weitgehend parallel. Wir haben die Konjunkiurbewegungen zwar einzeln untersucht, aber die jeweiligen nationalen Zyklen sind immer über den Weltmarkt vermittelt, so wie wir es in den Abschnitten 1 bis 3 aufzuzeigen versuchten. Daher kann auch nicht von einem: zufälligen Zusammeníallen der Konjunkturniedergänge gesprochen werden; die über den Weltmarkt vermittelte gegenseitige Abhängigkeit wird spätestens dann offensichtlich, wenn über das Brüchigwerden des Systems der Weltzirkulation die krise in den USA als Verschärfung

\footnotetext{
161) UNO, Economic Bulletin for Europe, a. a. O., S.

15\%) Suddeutsch eZeitung $21 . / 22.8 .1971$.

1 (13) ebenda.
} 
der sowieso schon bestehenden Krisentendenz in den anderen kapitalistischen Ländern zurückschlägt. Denn die Dramatik der Krise vom August ist nicht zu verstehen als bloße Konsequenz der geschilderten Ungleichmäßigkeit der Entwicklung, der langfristigen Wirkungsweise des Wertgesetzes auf dem Weltmarkt mit den daraus resultierenden Veränderungen für das Gefüge der Wechselkurse und die Rolle des Weltgeldes, sondern als Ausfluß der fortdauernden konjunkturellen Krise des US-Kapitals. Wenn auch die Ursachen dafür, daß die US-Wirtschaftskrise sich als internationale Währungskrise manifestiert, in den grundlegenden Veränderungen der kapitalistischen Reproduktionsbedingungen liegen, so war der Anlaß für die die Währungskrise auf die Spitze treibenden Maßnahmen Nixons die konjunkturelle Krise in den USA. Dadurch, daß nun aber die Konkurrenz der nationalen Kapitale auf dem Weltmarkt verschärft worden ist, und zwar in einer Richtung, die den Wertrelationen nicht mehr entspricht - das US-Kapital ist durch die partielle Abriegelung des US-amerikanischen Marktes künstlich begünstigt woren -, erhält auch die Währungskrise eine Bedeutung, die die Währungskrisen und die nationalen konjunkturellen Einbrüche der vergangenen Jahre nicht gehabt haben: Wir betonen, daß die Form der internationalen Zirkulation basierend auf fixierten Wechselkursen dafür verantwortlich ist, daß sich Wertveränderungen in den Produktionsbedingungen zunächst nicht als Welthandelskrisen, sondern als Weltwährungskrisen ausdrücken. Es zeigt sich nun aber, daß die Währungskrise zur Handelskrise durchzuschlagen beginnt. Man muß infolgedessen auch mit der Möglichkeit rechnen, daß dieses Mal die Krise ihr Werk der "Bereinigung" gründlicher vollführen muß als in den bisherigen Währungskrisen - wo Paritätsveränderungen (Aufwertungen und Abwertungen), Zinsniveauverschiebungen und internationale Kredite noch ausreichten -, bevor ein neuer über den Weltmarkt vermittelnder Aufschwung der Konjunktur des Kapitals gelingen kann.

Wir sprachen hier von „Krise“, ohne bisher allerdings sämtliche Dimensionen der Krise voll ins Bewußtsein gerückt zu haben. Wir haben versucht, in diesem Aufsatz auf einer allgemeinen Ebene den Nachweis (begrifflich und historisch) der Möglichkeit der Krise zu führen. Ein solcher Nachweis ist jedoch nur der erste Schritt, dem eine Analyse nicht nur der konkreten Reproduktionsbedingungen des Kapitals sondern vor allem der Möglichkeiten und Grenzen staatlicher Regulierung im weitesten Sinn sowie des Standes der Klassenkämpfe in den einzelnen kapitalistischen Länder folgen müßte. Wir wollen hier nur noch ein paar allgemeine Überlegungen zum „Staatsinterventionismus" anschließen, wobei klar ist, daß die reelle Entwicklung auch von den politischen Kräfteverhältnissen in der gesamten Weltpolitik abhängen wird. Die Notwendigkeit der Überschreitung der Untersuchung jener Prozesse, die sich in der Realität als "rein ökonomische" darstellen, ergibt sich schon daraus, daß die ökonomischen Formen immer schon gesellschaftliche Verhältnisse beinhalten. Das „Kapital“ ist ein bestimmtes Verhältnis zwischen vergegenständlichter und lebendiger Arbeit, zwischen den Besitzern der in den Produktionsmitteln vergegenständlichten Arbeit, den Kapitalisten, und der Lohnarbeit. Die Bewegung des Kapitals ist also die Bewegung dieses 
Klassenverhältnisses. Aber auch in einem eingeschränkteren Sinn ist die Überschreitung notwendig. Die Durchsetzung der ökonomischen Gesetze im Kapialismus, d.h. des Wertgesetzes auf dem Weltmarkt, wie wir sie hier zur Erklärung der Währungskrise dargestellt haben, setzt immer schon die poifi= tische Sanktionierung der Bedingungen dieser Durchsetzung voraus. Die Kapitalproduktion kann ohne die staatliche Garantie bestimmter Minimalbedingungen nicht funktionieren; auf nationaler Ebene nicht ohne die Einhaltung von Verirägen, die Eintreibung von Schulden etc.; auf internationaler Ebene nicht ohne die einfachen Formen der Sicherheit des Welthandels wie Schutz vor Seeraub und Beschlagnahme bis zu umfangreichen Regelungen des Warenkapital- und Geldkapitalverkehrs. Wenn aber diese Garantie auf nationaler Ebene durch den nationalen Staat mit größter Verläßlichkeit gegeben wird, so hängt die Sanktionierung der Austauschbedingungen auf internationaler Ebene davon $a b$, daß entweder ein übermächtiger Nationalstaat den übrigen kapitalistischen Staaten diese Normalbedingungen aufzwingt (England im 19. Jahrhundert - nicht ohne Mitwirkung der Flotte Ihrer Majestät, die USA nach dem 2. Weltkrieg ebenfalls nicht ohne militärische Machtausübung), oder davon, daß einigermaßen gleichstarke Nationalstaaten zu einer "welipolitischen" Einigung über die Bedingungen des Austausches kommen. Eine solche Einigung ist jedoch von der internationalen Konjunktur abhängig. In der Phase eines allgemeinen Niederganges der Weltkonjunktur verwandeln sich die ehemals kooperierenden kapitalistischen Staaten in "feindliche Brüder". Wenn sie in der Phase der aufsteigenden Weltkonjunktur sehr viel tun,, um die Schranken des Welthandels, $d \cdot h$. die Hindernisse für die Durchsetzung des Wertgesetzes zu beseitigen, so werden sie gerade bei einem zyklisch bedingten weltweiten Fall der Profite bzw. bei der Verteilung der Verluste gezwungen, den Schaden für das nationale Kapital so gering wie möglich zu halten, gleichgültig welche Schäden oder Katastrophen das in den übrigen kapitalistischen Ländern hervorruft. An die Stelle staatlicher Sanktionierung der Durchsetzung der ökonomischen Gesetze auf dem Weltmarkt, tritt dann der Versuch, deren Wirkung auf das nationale Kapital auszuschalten. Am deutlichsten kann man dies an der Weltwirtschaftskrise und dem aus ihr entstandenen "Interventionismus" erkennen. Der Versuch, mittels nationalstaatlicher Politik das jeweilige Land aus dem Bannkreis der ökonomischen Gesetze des Weltmarktes fernzuhalten (Autarkie), führt notwendigerweise zu einer Verselbständigung der diese $\mathrm{Ab}$ sperrung garantierenden Gewalt, der Staatsgewalt ${ }^{164}$ ). Die nationalstaatliche

104) Die vor allem im Rahmen der Faschismus-Diskussion entstandene Kontroverse um die „Verselbständigung des Staates“ oder den „Primat der Politik“ müßte deshalb vor dem Hintergnund der Weltmarktexistenz des Kapitals (Imperialismustheorie) und der historischen Entwicklung des Weltmarktes neu durchdacht werden. Der Aufsatz von T. W. Mason „Der Primat der Politik" (Das Argument, Nr. 41, Dezember 1966) und die sich daran anschließende Kontroverse mit DDR-Autoren (Das Argument, Nr. 47, Juli 1968) zeligen deutlich, wie dieses Problem der Abschließeng eines kapitalistischen Landes vom Weltmarkt - von der Autarkiepolitik bis zur Rüstungspraduktion - als reale Ursache für eine Verselbsiändigung des Staates nich einmal in Ansätzen reflektiert wurde. Mason scheint uns immernin auf dem richtigen Weg, wenn er das Problem der Verselbstăndigung des Staates wieder in die Debatte geworfen hat. 
Politik verselbständigt sich von den Gesetzen der Imternationalen Kapitalakkumulation - aber auf dem Boden dieser Akkumulation und angesichts ihres krisenhaften Zusammenbruchs ergibt sich ein starker Druck auf den Staat, ais Vertreter der Interessen des gesamten nationalen Kapitals und seiner Akkumulationsbedingungen in den Reproduktionsprozeb einzugreifen. Daß diese Staatseigriffe sowrohl abhängig sind von den Interessen des nationalen Kapitals ais auch notwendigerweise gegen eimzelne Kapitalfraktionen gerichtet sein können, ergibi sich schon aus der Tatsache der ungleichmäBigen Entwicklung des Kapitals im nationalen Rahmen. Der staatliche Interventionismus, sei es in der Gestalt der faschistischen Disziplinierung und Kriegspolitik, sei es in Gestalt der keynesianischen Wirtschaftspolitik und Kriegswirtschaft (USA), war historisch (und ist auch heute) weit davon entfern, seine Basis, die Akkumulation des Kapitals bzw. die Ausbeutung der. Lohnarbeit, grundsätzlich anzutasten. Die aus einer AbschlieBung von den ökonomischen Gesetzen des Weltmarktes resultierende Stärkung der Staatsgewalt und ihre Verselbständigung gegenüber dem unmittelbaren, mittels politischer Konkurrenz durchgesetzten, EinfluB des Kapitals, füht jedoch zu veränderten Bedingungen für die Austragung der Klassenkämpfe. Die Krise kann nur "bereinigt" werden, wenn durch eine allgemeine Vernichiung von Kapital und eine Senkung des Feallohns die Bedingungen für profitable Neuanlagen ais Ausgangspunkt für einen neuen Aufschwung geschaffen werden. Diese "Bereinigung" schließt somit die Auffüllung der industriellen Reservearmee, d. h. Arbeltslosigkeit, ebenso ein wie den Untergang einzelner Kapitale. Eine solche Bereinigung verlangt einen Staat, der nicht mehr nur die allgemeinen Bedingungen der kapitalistischen Reproduktion sichert, sondern der sich gegen einzeine Kapitale durchsetzen muß, der vor allem den Widerstand der Arbeiterklasse zu brechen in der Lage ist. Denn die Funktionsweise der industriellen Reservearmee im Akkunulationsprozeß des Kapitals ist durch die gewerkschaftliche Organisation der Arbeiterklasse und die Durchsetzung von vertraglichen Absicherungen (Tarifvertragssystem) in den vergangenen Jahrzehnten stark modifiziert worden. Wie gerade das Beispiel der USA und auch Englands zeigen, ist es dem Kapital nicht gelungen, trotz hoher Arbeitslosenzahlen, den Reailohn der beschäftigtest Arbeiter zu senken. Anders sieht es in der Bundesrepublik aus, wo sich die Konzertierte Aktion als ein Instrument erweist, die Funktionsweise der industriellen Reservearmee (Lohnsenkung bei Arbeitslosigkeit) mittels staaticher Interventionen aufrechtzuerhalten. Es zeigt sich schon hierbel, daß die konkreten Auswirkungen der Krise und die Formen ihrer Lösung in den verschiedenen kapitalistischen Staaten unterschiedlich sein werden. Der Rückgriff auf politische Macht, um den ökonomischen Gesetzen des Weltmarktes einen Strich durch die Rechnung zu machen, kann andererseits ebenso zu einer Verschärung der Krisenbedingung führen. Denn es ist oftenbar, dab z. 8. de Maßnamen der US-Regierung dazu führen kömen, daß die Krise umso schwerer zu "bereinigen" isĭ, je weniger den Notwendigkaiten, mämlion Dollarabwertung, Rückzug des Dollar von den internationalen Finanzmärken und Emöhung der allomemen Profitrate in den USA seibst (Kapitaivernichtung. Druck auh de Löhe), Rechnung ge- 
tragen wird. Je größer der ökonomische Druck zur Krise wird, desto stärker wird auch der politische Gegendruck sich entwickeln - eine Entwicklung, die vorderhand nur als Stärkung von faschistischen Tendenzen zu interkretieren ist, selbst wenn sie sich vorläufig no chim demokratischen Gewande etwa der "Einkomrnenspolitik" zeigt. in welcher konkreten Form sich diese Tendenz zum autoritären Staate in den jeweiligen Ländern formiert, hängt von zahireichen Bedingungen $a b$, die wir hier nicht untersuchen können. Erst aufgrund solcher Untersuchungen können Aussagen über den möglichen Gang der Krise und inre Auswirkungen auf die Arbeiterklasse gemacht werden.

(Der Aufsatz wurde Ende September abgeschlossen. An der Diskussion waren neben den Autoren Klaus Busch, Karl Hold, Wolfgang Müller, Wolfgang Schöller und Frank Seelow beteiligit)

\section{Nachbemerkung}

Im vorliegenden Aufsatz wurde versucht, anhand der jüngsten Wellwährungskrise die Durchsetzung des Wertgesetzes auf dem Weltmarkt zu diskutieren. in diesem Beitrag wurde nicht der Anspruch erhoben, alle Aspekte der Modifikation des Wertgesetzes auf dem Weltmarkt zu entwickeln. Offen geblieben sind insbesondere folgende Fragen:

1. Setzt sich, bzw. wie setzt sich auf dem Weltmarkt eine allgemeine Profitrate, und wie setzt sich und mit welchen Konsequenzen der tendenzielle Fall der Protitrate durch?

2. Welche Bedeutung haben die Kategorien Weltmarktwert und Weltmarktpreis und wie müssen sie entwickelt werden?

3. Wie stellt sich die „Durchschnittseinheit der universellen Arbeit" als Maßeinheit der internationalen Werte im realen Prozeß her?

4. Wie stellt sich das Verhälinis von Monopol und Konkurrenz auf dem Weltmarkt dar?

5. Gibt es angesichts der disproportionalen Entwicklung zwischen dein nationaien Anlagesphären des Kapitals Abstufungen der intensität der Arbeit innerhalb der Nationen? Welche Bedeutung hätte diese Stufenleiter für die Durchsetzung des Wertgestezes im nationalen Rahmen?

6. Wie wirkt sich die Modifikation des Wertgesetzes auf dem Welmank au die Akkumulation in den Entwickiungsländern aus? 
7. Uber welche Mechanismen verlagern sich nationale Reproduktionskrisen auf dem Weltmarkt? Unter welchen Bedingungen produzieren diese Verlagerungen "Weltmarkisungewitter"s?

In den PROBLEMEN DES KLASSENKAMPFES werden in unregelmäßigen Abständen Papiere vorgelegt, die in Projektgruppen am Otto-Suhr-hintitut der Freien Universität Berlin erarbeitet werden, in diesen Beirägen sollen die offengelassenen Fragen weiterdiskutlers und die Auseinandersetzung etwa mit den Arbeiten yon Amin, Emmanuel, Palloix und Bettelheim sowie mit der bürgerlichen. Theorie (Theorie der komparativen Kosten, Theorien zum Zahingsbilanzausgleich usw.) vertieft werden.

Bel der Bremer Gruppe Arbeiterpolitik wird im Oklobe:/November eine von Busch/Schöller/Seelow verfaßte Broschüe "Weltmark und Weltwährungskrise" erscheinen, in der die im vorliegenden Artikel behandelte Problemaḱk breiter, weil an Schulungszwecken orienuert, dargestellt wird. 